\title{
HOME, BUT NOT 'AT HOME' \\ THE REINTEGRATION OF UNSKILLED ETHIOPIAN FEMALE RETURN MIGRANTS FROM ARABIAN GULF COUNTRIES
}

Beza Libeyesus Nisrane 


\title{
HOME, BUT NOT 'AT HOME' \\ THE REINTEGRATION OF UNSKILLED ETHIOPIAN FEMALE RETURN MIGRANTS FROM ARABIAN GULF COUNTRIES
}

\author{
DISSERTATION \\ to obtain \\ the degree of doctor at the Universiteit Twente, \\ on the authority of the rector magnificus, \\ Prof.dr. T.T.M. Palstra, \\ on account of the decision of the graduation committee \\ to be publicly defended \\ on Thursday 30 January 2020 at 12.45
}

by

\section{Beza Libeyesus Nisrane \\ Born July 18, 1980 \\ Dire Dawa, Ethiopia}


This dissertation has been approved by:

Supervisor

Prof. dr. A. Need

Co-supervisors

Prof. dr. R. Torenvlied

Dr. M.R.R. Ossewaarde

Cover design: Google

Printed by: Gildeprint, Enschede

Lay-out: Beza L. Nisrane

ISBN: 978-90-365-4956-1

DOI: https://doi.org/10.3990.1.9789036549561

(C) 2020 Beza Libeyesus Nisrane, The Netherlands. All rights reserved. No parts of this thesis may be reproduced, stored in a retrieval system or transmitted in any form or by any means without permission of the author. Alle rechten voorbehouden. Niets uit deze uitgave mag worden vermenigvuldigd, in enige vorm of op enige wijze, zonder voorafgaande schriftelijke toestemming van de auteur. 


\section{Graduation Committee:}

Chairman / secretary

Supervisor:

Co-supervisors:

\section{Committee Members}

Prof. dr. G.J.Westerhof

Prof. dr. T. Bondarouk

Prof. dr. S. Saharso

Prof. dr. J.P.J.M. Smits

Dr. A. Guveli
Prof. .dr. T.A.J. Toonen

Prof. dr. A. Need

Prof. dr. R. Torenvlied

Dr. M.R.R. Ossewaarde
University of Twente

University of Twente

University of Humanistic Studies

Radboud University

University of Essex 


\section{DEDICATION}

This thesis is dedicated to my beloved mother, Lidet Francis, and my father, Libeyesus Nisrane, who sacrificed a lot for my success in academia as well as in other parts of my life. Unfortunately they are unable to see this day. Lidetiye, words fail me to express my gratitude for your love, encouragement and the sacrifice you made to help me achieve this and all I have done in my life. This is especially for you. You will always be in my heart. 


\section{AKNOWLEDGMENT}

First and foremost, I thank Almighty God for providing me with the opportunity, courage, and blessings to finish this research. I would also like to extend my gratitude to all who guided and helped me throughout the writing of this thesis and my $\mathrm{PhD}$ journey. My heartfelt gratitude goes to Prof. Ariana Need, my promotor, for her academic guidance, unfailing patience and the love she showed me. Prof. Ariana, I am also grateful for the lovely dinners you organized at your home with your beautiful family and your efforts to help me integrate into life in the Netherlands. I am grateful to my supervisor, Dr. Ringo Osswerede, for his guidance and insightful comments on the various drafts of the chapters in this thesis. Dr. Ringo, I appreciate your generous help and encouragement and the long chats in your office on academic and others matters. I would also like to thank my co-promotor, Prof. Rene Torenvlied, for his critical comments and insights into my work. All of you were prompt to answer my questions and comment on my work; you pushed me beyond my comfort zone, and encouraged me to look deeper into my research and critically question my findings. I would also like to thank Dr. Ann Morissens for her academic guidance, supervision and encouragement at the beginning of my PhD. I am really blessed to have you all.

Next, I would like to thank the NUFFIC project for awarding me a scholarship to undertake this study. Special thanks goes to Dr. Bertha Vallejo, project coordinator at NUFFIC; thank you for supporting me throughout this journey. Dr. Bertha, you encouraged me to continue when life threw me a curveball. Your encouragement and love kept me going even when I was tempted to give up. This $\mathrm{PhD}$ would not exist without all of the women who shared their experiences with me. I am grateful for the opportunity to meet them and share their experiences. My gratitude goes to Ato Alemayhu from Live Addis, Ato Nigusse from Agar Ethiopia, W/ro Alemsthay from Women in Self Employment (WISE), and Ato Daniel from the Ministry of Labor and Social Affairs - thank you for your cooperation, for inviting me to your organizations and workshops, for participating in the interviews, and for helping me contact returnees through your organizations. I would also like to thank my research assistants for data transcription and translation.

I would especially like to thank all the members of Siddartha organization, who work relentlessly to change the lives of those who are disadvantaged; special gratitude goes to Father August - thank you for your love, visits, prayers and support. Denise and Frederik, I really do not have words to 
thank you enough. Thank you for considering me as one of your children (it really felt like that), for spoiling me and taking care of me while I was in the Netherlands and Belgium. You and your family made my stay enjoyable. Willem and Annelies, thank you for your support and visits.

I would like to extend my gratitude to my family members, my brothers and only sister, my beloved mother-in law Worknesh, and my brothers and sister in-law for taking care of my kids while I was away. Thanks are also due to my colleagues in Addis Ababa University, School of Commerce, especially to the members of the Marketing Department, for shouldering my teaching load while I was away for my research. My gratitude goes to my dear friends Selam, Samuel, Nina, Meron, Dr. Konjit, Dr. Belaynesh, Dr. Abeba, Dr. Asede, Rahel, Nesanet, Dr. Baynesagn and Dr. Lemmesea for their help and encouragement. I am also grateful and thankful to all members of the Public Administration Department at University of Twente, Enschede for their support and for making my stay in Netherlands wonderful.

Finally, this research project would not be possible without the support and love of my darling husband, Firehun G/Yohannes, and my daughters, Steyana and Sarot. Thank you for letting me do this. Firehun, you took on the role of both mother and father while I was away and never complained, despite the burden you shouldered; you were there to listen to my frustrations and you encouraged me to continue when it was difficult to do so. Thank you my dear. 


\section{TABLE OF CONTENTS}

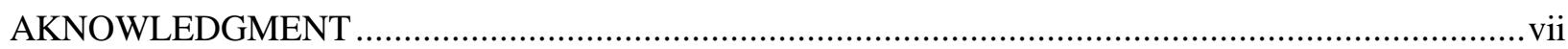

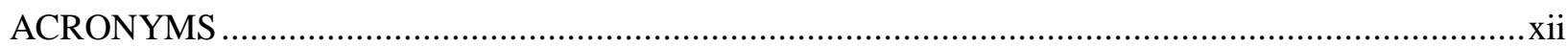

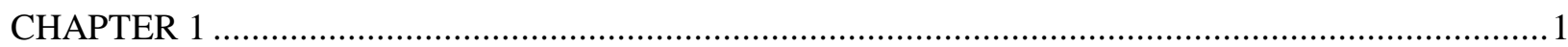

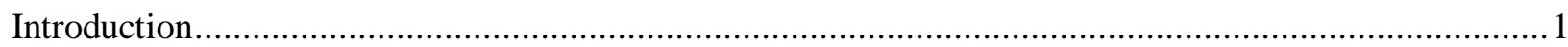

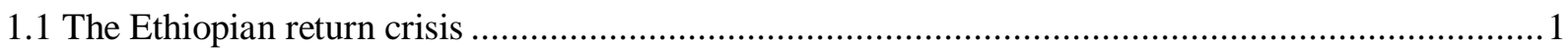

1.2 Ethiopian women migrants to the Arabian Gulf and the kafala labor system ................................. 3

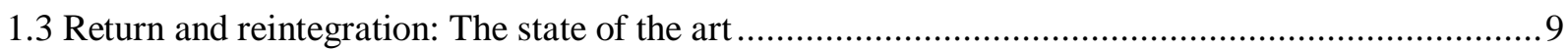

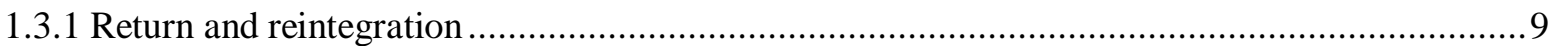

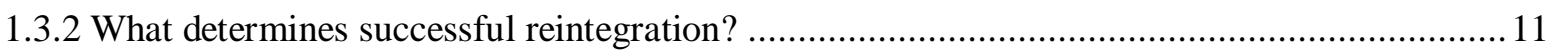

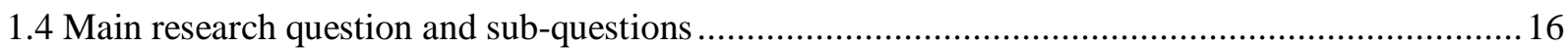

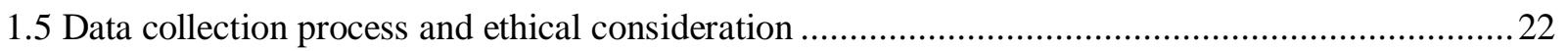

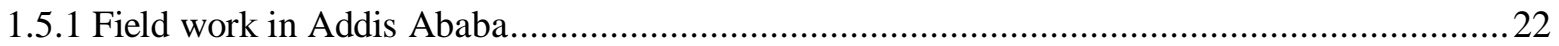

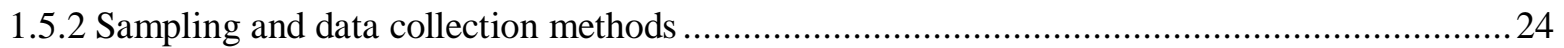

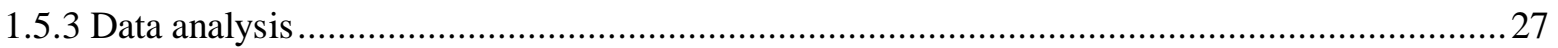

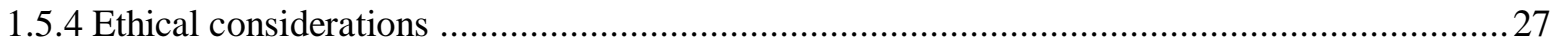

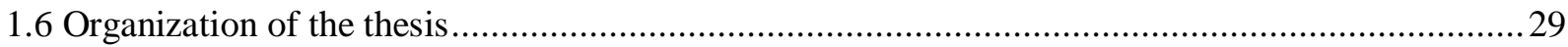

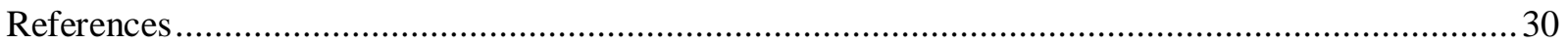

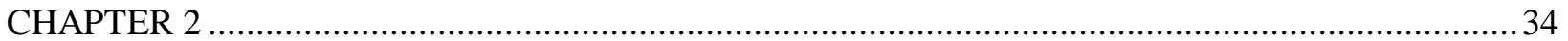

The Exploitation Narratives and Coping Strategies of Ethiopian Female Return Migrants from the

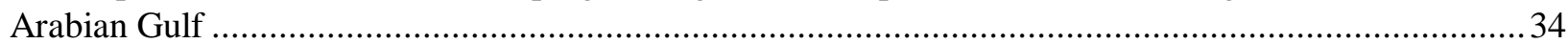

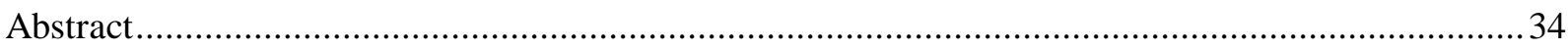

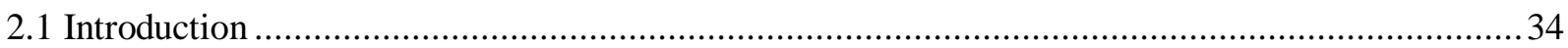

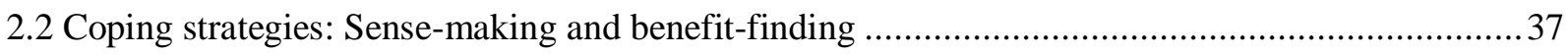

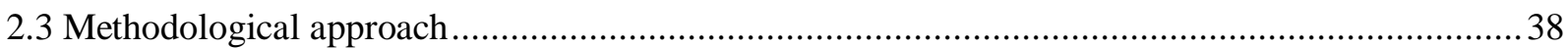

2.4 Exploitation narratives and coping strategies while in the Arabian Gulf...................................... 41

2.5 Coping strategies upon returning to Addis Ababa ....................................................................... 43

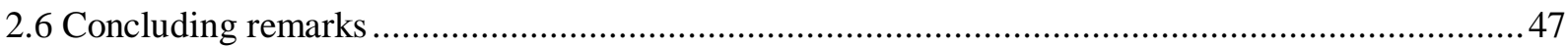

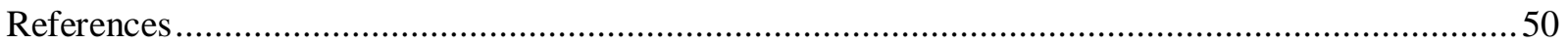

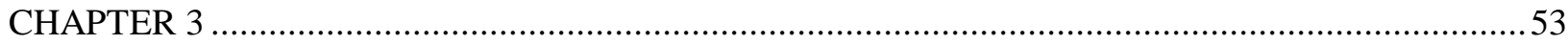

Economic Reintegration of Ethiopian Women Returned From the Middle East .................................53

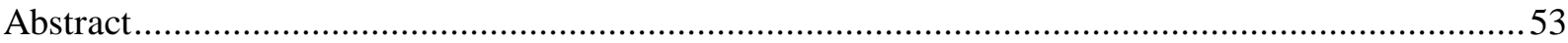

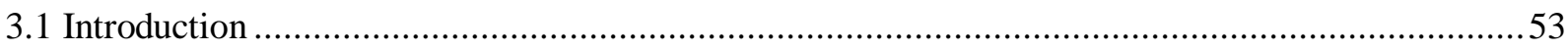

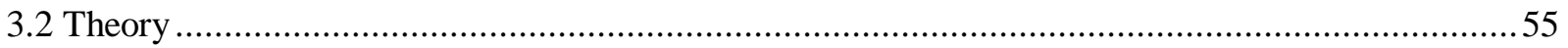




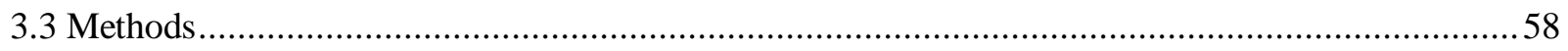

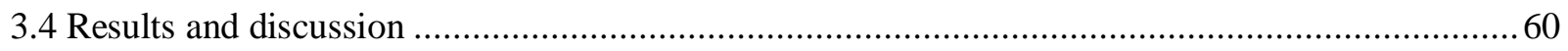

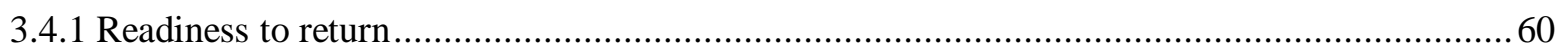

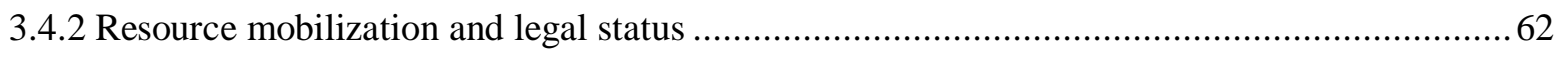

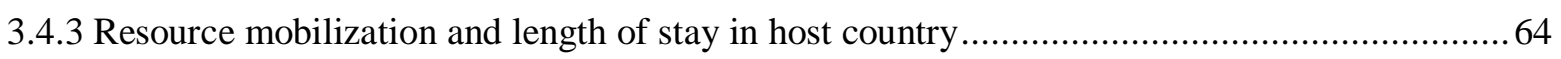

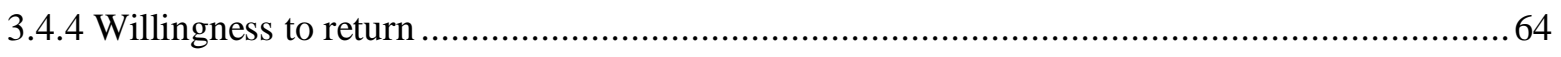

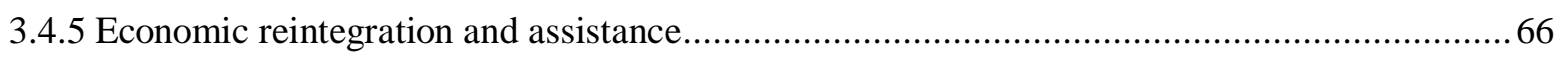

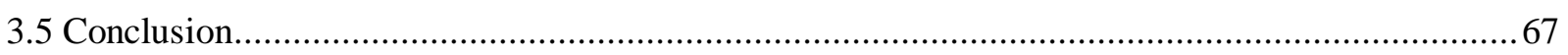

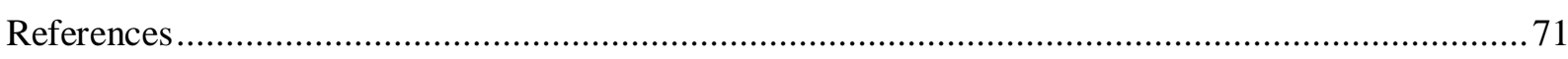

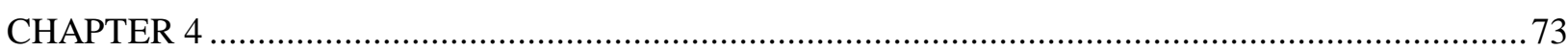

"I Should Get Married as Soon as Possible, but the Relationships I Start Do Not Work": Marital Prospects of Female Return Migrants from the Arabian Gulf ......................................................................... 73

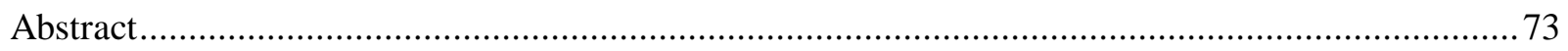

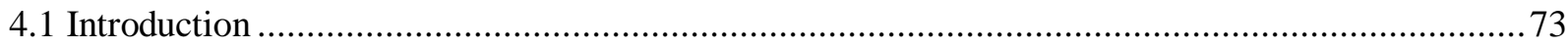

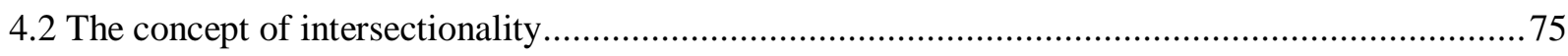

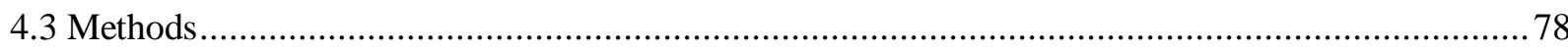

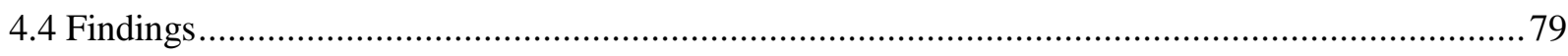

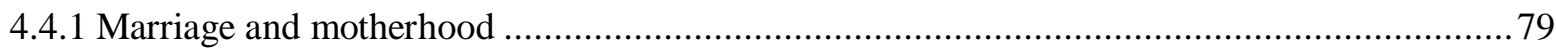

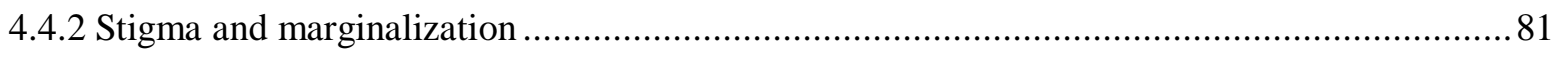

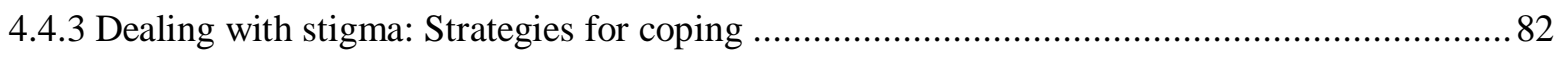

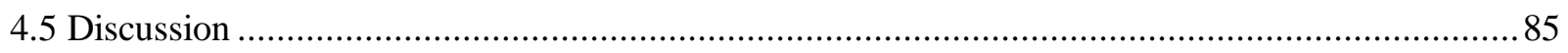

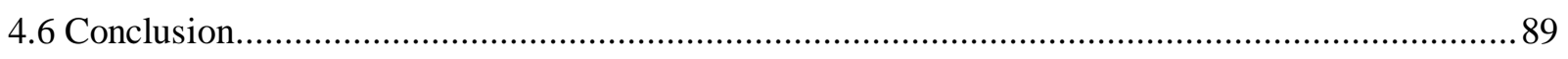

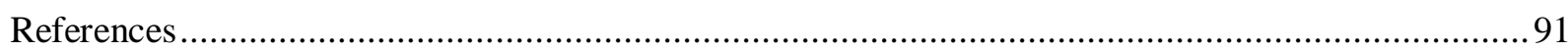

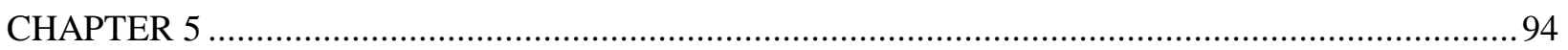

Home, but Not at Home: Sense of Belonging, Reintegration and Remigration Intention of Female

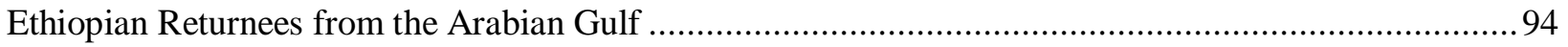

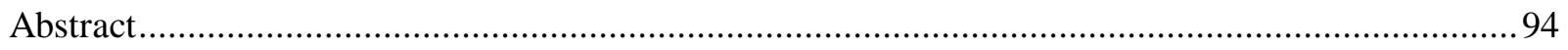

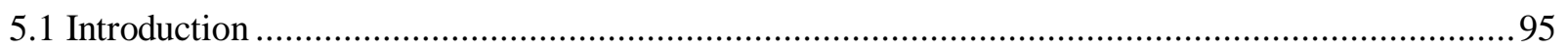

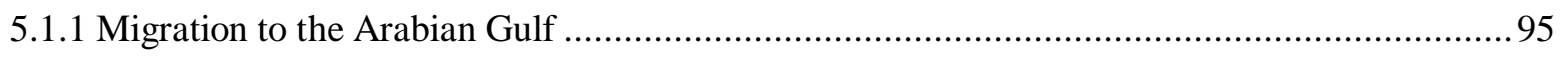

5.1.2 Coming home: The difficult task of reintegrating .......................................................... 96

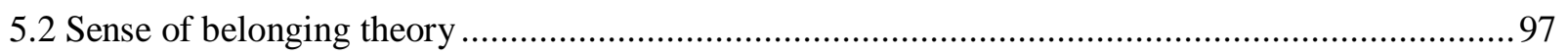

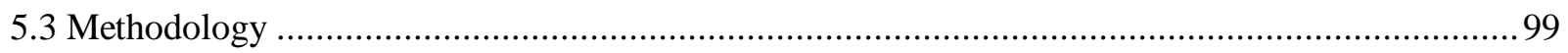

5.4 Findings: Interpersonal relationships, belonging and reintegration ........................................ 101

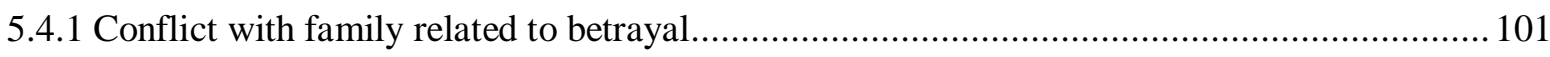

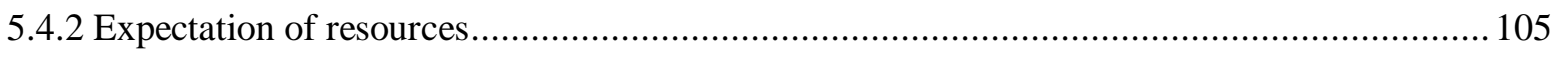




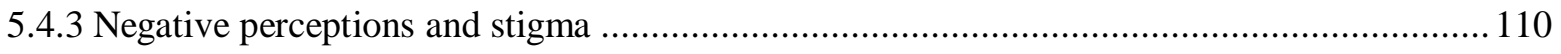

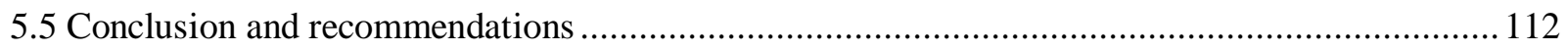

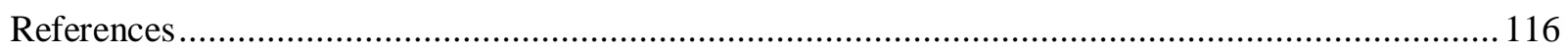

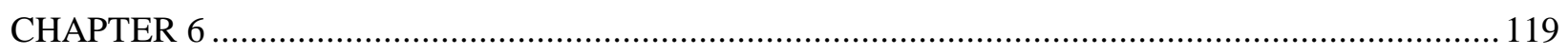

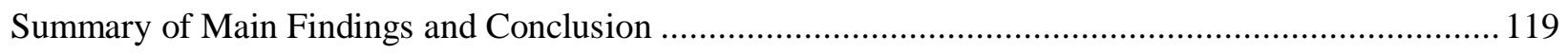

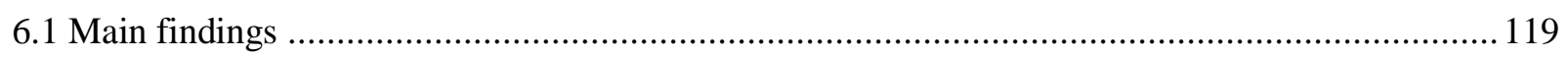

6.1.1 Exploitation narratives and coping strategies of Ethiopian female return migrants from the

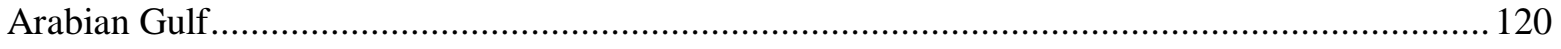

6.1.2 Economic reintegration of Ethiopian women returnees from the Arabian Gulf ................... 121

6.1.3 Marital prospects of women return migrants from the Arabian Gulf .................................. 122

6.1.4 Role of interpersonal relationships and a sense of belonging in the home country ............... 124

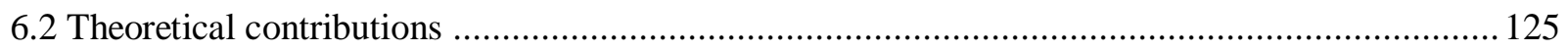

6.3 Limitations of the study and suggestion for future research............................................... 127

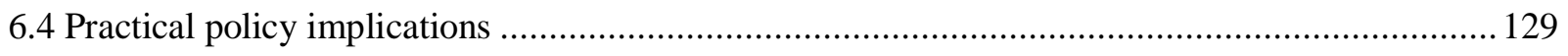

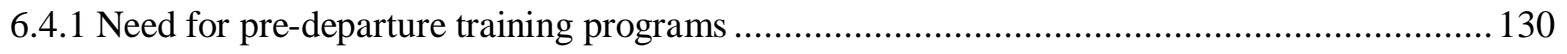

6.4.2 Improving the working conditions of migrants in destination countries ............................. 130

6.4.3 Holistic reintegration assistance in the home country ............................................... 131

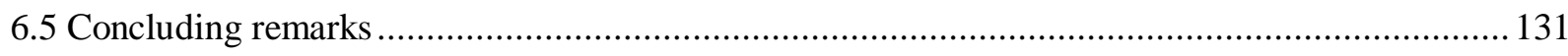

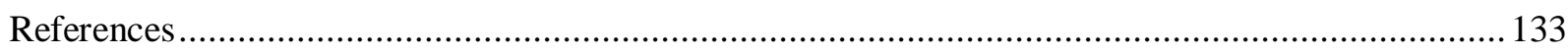

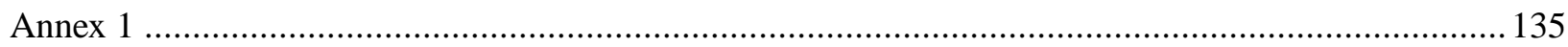

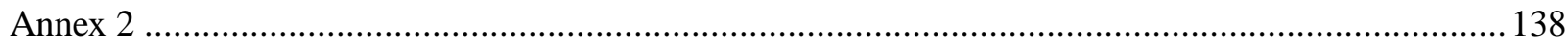

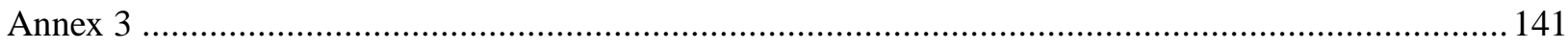

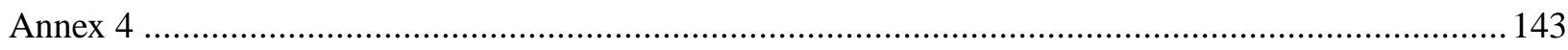

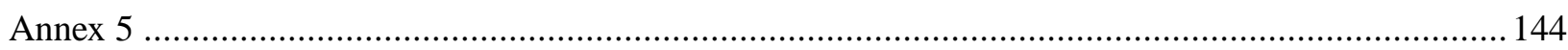

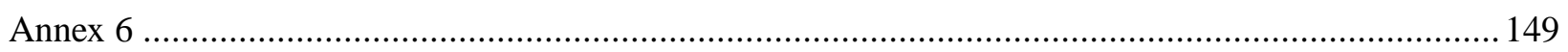




\section{ACRONYMS}

GCC

NGO

ILO

IOM

WISE
Gulf Cooperation Council

non-governmental organizations

International Labour Organization

International Organization for Migration

Women in Self Employment 


\section{CHAPTER 1}

\section{Introduction}

\subsection{The Ethiopian return crisis}

From November 2013 to March 2014 about 163,018 illegal Ethiopian migrants residing in Saudi Arabia were returned to their home country through an integrated effort by the Ethiopian government, International Organization for Migration (IOM), United Nations Children's Fund (UNICEF), and the Red Cross (De Regt \& Tafesse, 2016; Lecadet \& Tafesse, 2016). Following this mass deportation, Ethiopia was overwhelmed with returnees who needed reintegration assistance. This event was called the 'Ethiopian return crisis' (Kuschminder, Andersson, \& Seigel, 2018, p. 325). Both national and international media, such as Al Jazeera, as well as social media reported extensively on the 'return crises'. Cases of voluntary and involuntary return, the traumatic experiences of the returnees, xenophobic actions and protests, and the reintegration efforts of the government and non-governmental organizations (NGOs) were among the headlines.

Of the returnees, about 53,732 were women who had travelled to Saudi Arabia using different means, including legally licensed agents, unlicensed brokers, and social networks (siblings, neighbors, friends and relatives). Some used Muslim pilgrimage as a pretext and overstayed their visa (Mulugeta \& Makonnen, 2017). Migration to Arabian Gulf countries by women is the largest migration flow from Ethiopia, followed by migration to South Africa, North America and Europe (Fransen \& Kuschminder, 2009; Kuschminder et al., 2018). This massive migration of women poses a huge reintegration challenge in cases of mass deportation, such as that executed by Saudi Arabia in 2013/14.

Reintegration into the socio-economic context of the home country was difficult for most of the returnees, especially given their hasty and sometimes traumatic expulsion (De Regt \& Tafesse, 2016). This was more so for women returnees given their generally poor economic condition, as well as their low social position pre-migration due to Ethiopia's patriarchal social structure, which provides few opportunities in education and property ownership for women. In addition to these factors, high unemployment and poverty also contribute to women's poor social and economic status in most developing countries (Anteneh, 2011; Fernandez, 2010; Kebede, 2002; Kifleyesus, 2012). The majority of Ethiopian women who migrate to the Arabian Gulf are aged 20-46 years, 
have a low level of education, and are single or divorced with children (Demissie, 2018; Kebede, 2002; Tayah \& Atnafu, 2016), which makes reintegrating into the socio-economic situation in the home country upon return relatively more difficult for female than male returnees.

To address the massive societal challenge posed by the return crisis, the Ethiopian government and local and international NGOs developed reintegration support services and programs for the returnees. Such support services included providing temporary shelter, offering medical assistance, and reuniting the returnees with their families by covering transportation costs to their respective villages for those from outside of Addis Ababa. Gradually, returnees were also provided with vocational and business skills training, small workplaces, and access to credit to enable them to generate income and sustain their livelihood in the home country (De Regt \& Tafesse, 2016). Despite the efforts of the government and international organizations, there were still challenges with successfully re-integrating the returnees into the socio-economic context of their home country, which created frustration among the returnees (Kuschminder \& Richard-Guay, 2018). This situation, together with the ban on legal migration to the Arabian Gulf, contributed to irregular migration and the re-migration of returnees to other countries. Tayah and Atnafu (2016) show how Ethiopian female migrants are exposed to exploitation in neighboring countries that serve as transit points and how they are sometimes forced to stay in these transit countries for prolonged periods of time.

The Ethiopian government enacted the ban on migration to the Arabian Gulf in October 2013, in an attempt to protect its citizens abroad (Demissie, 2018; Jones et al., 2014; Mulugeta \& Makonnen, 2017). However, Ethiopian women continue to migrate. They use illegal means to travel to the Arabian Gulf, including traffickers and smugglers, which exposes them to much more severe exploitation conditions than traveling legally (Jones et al., 2014). The ban was lifted in May 2017 with new legislation governing labor migration, private employment agencies, and migrant skills requirements and training. Agreements between Ethiopia and destination countries in the Arabian Gulf and Middle East to improve working conditions, pay, and legal protection are ongoing. So far Djibouti, Jordan, Kuwait, Qatar, and Saudi Araba have signed memoranda of understanding to protect and improve the working conditions of Ethiopian migrants (Mulugeta \& Makonnen, 2017). The Ethiopian government is making great efforts to improve the working conditions of migrants in destination countries, which indirectly improves the reintegration of the 
returnees upon their return to Ethiopia. However, there is no direct policy or strategy in place to improve the reintegration of returnees (Kuschminder \& Richard-Guay, 2018). A lot more remains to be done to manage return crises, such the crisis that occurred in 2013/14, and to promote the successful reintegration of return migrants. This dissertation hopes to contribute to these aims and shed light on both the academic and practical aspects of the reintegration of women return migrants from the Arabian Gulf.

\subsection{Ethiopian women migrants to the Arabian Gulf and the kafala labor system}

Ethiopia is among one of the largest female labor sending countries to the Arabian Gulf and Middle East (Belay, 2014; De Regt, 2010). Ethiopian women migrate to the Arabian Gulf mainly for economic reasons, however, the poor economic and social position of women due to the gendered environment in Ethiopia also have an impact on their decision to migrate (Eresso, 2018). Many of the migrants are single women with no education other than high school (Fernandez, 2011; Kebede, 2002). Hence, they are employed in jobs that require minimal skill, mainly domestic work. In many cases, Ethiopian women traveling to the Arabian Gulf and the Middle East make the decision to go by themselves. However, brokers and agents often deceive potential migrants with false information regarding salaries and job conditions in the destination country (Kebede, 2002; Minaye, 2012).

The migration of women for domestic work on short term contracts to the Arabian Gulf and countries in the Middle East started in the late 1990s and has been increasing steadily since then (Demissie, 2018; Fernandez, 2011). For example, in Kuwait the number of Ethiopian migrant women increased significantly from 6,000 to 40,000 between 2006 and 2010 (Fernandez, 2011). Jones et al. (2014) estimate that about 1,500 girls leave Ethiopia daily to the Arabian Gulf and Middle East. Initially, Lebanon was the destination for Ethiopian migrants (Beydoun, 2006), but later Kuwait, Saudi Arabia, the United Arab Emirates, and Yemen become major destination countries for female Ethiopian migrants.

While some Ethiopian migrants are successful in achieving their migration goals, the majority return with physical, sexual, financial and psychological problems (Ketema, 2014). Some research has found that, in some households, unskilled migrant women work in slave-like conditions, but are unable to leave their abusive employer or return to their home country until the contract period 
ends (Fransen \& Kuschminder, 2009; Jureidini \& Moukarbel, 2006). The physical, sexual, economic, and psychological exploitation of Ethiopian domestic workers in the Arabian Gulf and Middle East is reported consistently (Anbesse, Hanlon, Alem, Packer, \& Whitley, 2009; Kebede, 2002).

Some scholars have tried to analyze why this exploitation occurs. Employment contracts or visa programs that tie a migrant domestic worker to a specific employer are identified as the major mechanism for the abuse and exploitation of women domestic migrants (Mantouvalou, 2015; Pande, 2013; Romero, 2018). Such visa programs provide employers with unchecked power in controlling and exploiting the migrant. Moreover, in most cases domestic workers are not covered by national labor laws, which contributes to their vulnerability and exploitation (Strauss \& McGrath, 2017; Wickramasekara, 2008). Piper (2004) points out that most policy tools issued by states focus on exchanging political and economic benefits between the sending and receiving countries, rather than on the welfare of migrants. Smugglers and traffickers in both sending and receiving countries are also a cause of migrant exploitation in destination countries. There is a need for a migration policy framework that enables states to prosecute traffickers and smugglers in order to minimize the abuse of unskilled women trafficked by illegal brokers (Anteneh, 2011; Fernandez, 2013). In general, the causes of vulnerability and exploitation among this group of migrants are multifaceted and arise from restricted migration schemes, illegal intermediaries, lack of legal and policy frameworks, and the poor economic conditions of the migrants.

In recent years, the migration experience of Ethiopian women domestic workers in the Arabian Gulf countries has been widely studied by social scientists (Anbesse et al., 2009; De Regt, 2010; Fernandez, 2010, 2011; Kebede, 2002; Minaye, 2012). All of these studies adopted a qualitative approach to data collection and analysis and all discuss matters related to the precarious position migrants have in destination countries (De Regt, 2010; Fernandez, 2010; Kebede, 2002), including the motives for migration, the conditions contributing to the vulnerability of the migrants (Kebede, 2002; Minaye, 2012), and the consequences of the migration experience for the social and mental wellbeing of the migrants (Anbesse et al., 2009). The precarious position of Ethiopian as well as Asian female domestic workers in the Arabian Gulf countries is well documented. However, what is missing in the research on the exploitation of domestic migrant workers in the Arabian Gulf and Middle East is how migrant workers cope with their exploitation experiences, particularly upon 
return. Van der Ham, Ujano-Batangan, Ignacio and Wolffers (2015) analyze the immense stress that Asian women migrants experience at different stages of their migration experience. They reveal how both emotion and problem-focused coping mechanisms are used by women migrants during their migration.

Some topics that remains under-researched are how trauma transcends beyond the migration experience (Schweitzer, Melville, Steel, \& Lacherez, 2006), how it affects the lives of the returnees, what coping strategies are used to make sense of past traumatic incidents by returnees, and the impact of trauma on the reintegration process of the returnees. The first gap in the existing literature is that a large amount of the discussion focuses on the experiences that domestic workers have in the host country, neglecting how these experiences may affect their reintegration upon return. Second, an extensive literature review on domestic workers indicates that research on domestic work is dominated by research on migrants from Southeast Asia (Deshingkar, Zeitlyn, \& Holtom, 2014), with the experience of women from Africa receiving little attention. Such knowledge gaps regarding Ethiopian women returnees from the Arabian Gulf inhibit the success of reintegration plans for returnees, particularly in situations of mass deportation, such as the return crisis of 2013/14. The return crisis confronted Ethiopian society with the sudden influx of a massive amount of traumatized female returnees, with limited research on return and reintegration issues to draw on. This makes researches on the reintegration of returnees an urgent public issue.

The 'return crisis' that occurred because of the mass deportation of Ethiopian migrants from Saudi Arabia in 2013/14 raises new questions about how migration schemes for low-skilled workers might contribute to the poor reintegration of returnees into the socio-economic context in Ethiopia. Particularly, the kafala ${ }^{1}$ labor sponsorship scheme, which exists in many Arabian Gulf and Middle Eastern countries has a great impact on the migration of migrant domestic workers, as well as their reintegration upon return to their home country. This system enables migrants to stay in the destination countries for two to three years under the legal and financial responsibility of a specific sponsor, who is also responsible for the repatriation of the migrant worker. Under the kafala sponsorship scheme, most unskilled women migrants are employed in a private household. In most Arab states, households are categorized as a private domain and, therefore, not regulated by the

\footnotetext{
${ }^{1}$ This scheme binds migrant workers to their employer or sponsor in Arabian Gulf countries (Bajracharya \& Sijapati, 2012).
} 
government (Frantz, 2008). Given the fact that migrants serve in private households and that they are under the 'control' of their employer, rather than the state, migrants find themselves in a highly vulnerable position. Exploitation and mistreatment by employers in private households is a common occurrence (Jureidini \& Moukarbel, 2006). Changing employers is not easy for migrant workers, because they need permission and release from their first employer or the sponsor who invited them to the destination country before they can find a new sponsor or employer (Pande, 2012).

The return and reintegration of Ethiopian female migrants in their home country has been an underresearched topic and there are few recent examples of reintegration studies. Based on in-depth interviews with 18 returnees, Ketema (2014) examined the return and reintegration of Ethiopian female returnees and the challenges with the 'empowerment' notion associated with women's migration for domestic work. The author discusses how the migration experiences of women in Arabian Gulf countries impact on their lives. By evaluating the social and economic conditions in the home country and the relationship of the returnees with their family and community, the study concludes that the migration experience is disempowering, rather than empowering. De Regt and Tafesse (2016) conducted a survey among 168 returnees and held 8 in-depth interviews with returnees. They used the concepts of preparedness (Cassarino, 2004) and embeddedness (Ruben, Van Houte \& Davids, 2009) to analyze how the forceful expulsion of returnees affects their socioeconomic reintegration in their home country. They concluded that the returnees were unprepared for their return, which contributed to their low economic and psycho-social reintegration in the home country. Other studies also found poor economic and social reintegration of Ethiopian women returnees, due to their negative experiences in destination countries (Anbesse et al., 2009; Minaye, 2012). While these studies shed some light on the socio-economic reintegration of Ethiopian female return migrants, some aspects of the reintegration process are not explored in detail, such as how the returnees deal with their past traumatic experiences, mobility, stigma and relationship with family and community. In this dissertation, I attempt to fill this gap and provide a holistic view of the reintegration process by integrating both migration experiences and home country socio-cultural issues that may have an impact on the reintegration process in order to build on previous studies, which mainly focus on the aftermath of migration, and enhance our understanding of the reintegration of migrants. 
IOM (Perruchoud \& Redpath-Cross, 2011) defines return as the movement of a person returning to his/her country of origin or habitual residence, usually after spending at least one year in another country, which is also the definition used in this dissertation. Reintegration refers to the "reinclusion or re-incorporation of a person into a group or a process, e.g. of a migrant into the society of his country of origin" (Perruchoud \& Redpath-Cross, 2011 p. 54). The reintegration of returnees into their home society has different dimensions. Economic reintegration refers to the reinsertion of returnees into the economic system of the country of origin, social reintegration is conceived as the development of a personal network and relationships of returnees, and cultural reintegration is the process of reintegration of the returnee to the values, way of living, language, moral principles, and traditions in the country of origin (Perruchoud \& Redpath-Cross, 2011, p. 54). While some scholars argue that reintegration entails the readjustment of returnees to their home countries by fitting into the socio-economic context of the home country, others argue that it entails re-adapting by integrating their new identity and the skills and ideas acquired from exposure to the country of immigration. Van Houte and Davids (2008) propose the concept of re-embeddedness, rather than reintegration, to highlight the importance of returnees finding their own place in the home society, rather than trying to fit into the previous context of the home country.

Building on these concepts, in this dissertation reintegration is defined as the ability of returnees to participate in economic, social and cultural activities in their home country, which requires adapting to the home environment. For example, the migration experience may change the identity of the returnees through exposure to a new religion (from exposure to Christianity to Islam), a new culture, and even new technology, which affects the participation of returnees in various aspects of the home environment upon return. The unit of analysis for this research is the returnees themselves.

In this dissertation, the reintegration of Ethiopian female migrants upon their return is approached using multidisciplinary theoretical concepts (from gender studies, sociology, and psychology), which complement each other and provide a comprehensive platform from which to explain the relationship between the migration experiences and post-return experiences of low-skilled Ethiopian women migrants. More specifically, the study examines how migration experiences under the kafala labor sponsorship scheme shape the individual, family and community life of returnees, including the various social and economic aspects. Understanding a migrant's return 
experiences is not only important to understand the reintegration process for returnees, but it may also help policy makers in formulating reintegration support programs in cases of individual or mass return. This is particularly important considering the large number of Ethiopian women migrating to the Arabian Gulf, both legally and illegally, and the inevitability of their return, given that the labor program to these destinations allows migrants to stay only temporarily.

The findings of this dissertation have both academic and practical significance. Academically, the empirical findings in each chapter add to our understanding of different aspects of the reintegration process. The dissertation contains four empirical chapters. These chapters use different theories from migration studies, gender studies, sociology, and psychology. Chapter 2 approaches the research problem from a psychological perspective using coping theory (Park \& Folkman, 1997); Chapter 3 employs the theory of preparedness from return and reintegration theory (Cassarino, 2004); Chapter 4 applies the concept of intersectionality from gender studies (Crenshaw, 1990; Hankivsky, 2014); and Chapter 5 uses the concept of belonging from sociology (Hagerty, LynchSauer, Patusky, Bouwsema, \& Collier, 1992). By using these theories from different disciplines, the migration and return experience and how it shapes the socio-economic reintegration of Ethiopian female returnees from Arabian Gulf countries is examined from multiple perspectives.

The practical significance of the dissertation relates to the input it provides to reintegration support programs for voluntarily returning, as well as involuntarily deported, returnees. The findings highlight the need for needs-based reintegration strategies to be adopted to promote the successful reintegration of different types of returnees. For example, those who completed their work contract and returned with savings may be assisted with vocational skill training and support to enable them to utilize their resources, while those who are the victims of abuse and exploitation need support to heal from the trauma before delving into economic activities. Moreover, the dissertation points to how migration experiences in destination countries impact on the socio-economic reintegration of the migrants upon return. Hence, it sheds light on the need for migration policies and programs that help prevent some of the problems experienced by migrants during their migration and support the reintegration of returnees, addressing any post-return challenges that they may have.

The next section of this introductory chapter presents a brief review of the relevant literature on return and reintegration (section 1.3); the central research question and sub-questions, and in which 
chapter each is discussed (section 1.4); the data and ethical issues (section 1.5); and, finally, an outline of the dissertation (section 1.6).

\subsection{Return and reintegration: The state of the art}

\subsubsection{Return and reintegration}

Dominant migration theories postulate opposing views on return migration and also on the reintegration of returnees to their home country. The four major theories of return migration are the neo-classical theory, the new economics of labor migration theory, structural theory, and transnational theory (Setrana \& Tonah, 2014). To return is considered to have failed under the neoclassical migration theory, while it is considered a success in the new economics of labor migration theory. The first theory bases its argument on the assumption that migrants are rational beings who maximize their benefit. Accordingly, for neo-classical theorists, migration is initiated because of wage differentials (Borjas, 1989). According to this theory, migrants want to move to the country of immigration as long as there exists an international wage differential; hence, return migrants are considered a failure if they return to their place of origin. Within this framework, migrants return home if they fail to derive the expected benefit of higher earnings at the destination (Thomas, 2008). On the other hand, the new economics of labor migration theory views migration as a household strategy to overcome financial constraints in the immigrant's home country (Stark \& Stark, 1991). According to this theory, return is happens when the migrant household's financial goal is achieved. Return in this case shows that the migration of objectives have been achieved (success), rather than failure (Ammassari, 2004; Cassarino, 2008; De Haas, Fokkema, \& Fihri, 2015). Based on a large survey of Moroccan migrants across Europe, De Haas et al. (2015) analyze whether return is the result of a failed migration experience or because the migrant has achieved their migration objectives, as outlined by neo-classical and new economics of labor migration theories. They conclude that no one theory explains all return cases. Rather, each of the theories provides a partial view of the intention of return migrants. Constant and Massey (2002) reach a similar conclusion. Major criticism of neo-classical and new economics of labor migration theories and the reason for return under these theories is that both focus only on the economic motivation of the returnees. Moreover, how the returnees use the economic resources accumulated from migration and the reintegration of returnees in the home country are not discussed within these frameworks (Cassarino, 2008). 
In contrast to these theories, structural theorists acknowledge the importance of contextual factors in the readjustment of return migrants. They cast doubt on the success/failure analysis of return migration provided by neo-classical and new economics of labor migration theories. Structural theorists do not consider the success of the migration experience abroad as a dominant factor in the decision to return, but instead focus on how well returnees adjust to the culture, norms, and values in the home country. They focus on the expected productivity of the returnees in the country of origin (Setrana \& Tonah, 2014). Hence, the socio-economic and the political situation in the home country guides both the return decision and the reintegration of returnees. According to the structural theory, return and reintegration cannot be understood without taking into account the actual conditions in the home country, such as local power, traditions, and values (Cassarino, 2004, 2008). What is common to the new economics of labor migration theory and structural theory is that both acknowledge the role of families and households in migration, as well as the return and reintegration process (Mensah, 2016). Finally, the transnational approach views return as an experience that demands adaptation to the home country by incorporating new identities acquired due to exposure to the country of immigration. Transnational theories argue that back and forth movement by migrants helps the return and reintegration process, by facilitating the development of social networks and the adaption of migrants to home country changes. Regarding reintegration, while structural theorists focus on readjustment to the home society, transnational theorist focus on the re-adaptation of migrants to the home country (Cassarino, 2004). The significance of context in understanding the return and reintegration of return migrants is emphasized in the structural and transnational theories.

The theories outlined above mostly focus on skilled and permanent labor migrants. Despite this fact, the contribution of these theories to understanding the return decisions of migrants is indisputable. But the argument put forward in this dissertation is that one specific theory cannot explain the return and reintegration process of different types of migrants (this argument is further discussed in the next section). For example, the four major theories described above fail to explain the return and reintegration of low-skilled workers. In this dissertation, the return and reintegration of low-skilled domestic workers is understood mainly through the partial conceptualization provided by the new economics of labor migration theory, structural theory, and transnational theory of return migration. 
The return migrants discussed in this dissertation were returnees who engaged in temporary migration and unskilled/low-skilled laborers in Arabian Gulf and Middle Eastern countries. The migration programs for unskilled domestic workers in many Arabian Gulf and high-income Asian countries are temporary, often involving a two to three year work contract; hence, return is an expected part of the migration process, hopefully after fulfilment of the migration objective. Meanwhile, the conception of return that is provided by the new economics of labor migration theory only partially explains the migration intention and return experience of low-skilled workers to these destinations, as the majority travel to achieve an economic goal for their household. However, the migration setting accessible to most low-skilled migrants entails constraints on resource mobilization and on the pursuit of financial goals, as well as the return objective of the migrants. On the other hand, knowledge contributed by structural theorists and transnational views on the importance of contexts and social relations within the home community helps us to better understand the reintegration process of the returnees. Such theories provide a strong ground for understanding the return and reintegration of unskilled labor migrants, as return takes place within the economic, political, social, and cultural context of the home country.

A wide gap exists in the research in understanding the reintegration process of returnees, in general, and low-skilled workers, in particular. Temporary contract migration in a restricted migration scheme such as the kafala labor sponsorship scheme yields returnees who have finished their contract period without problem; returnees who have experienced physical, psychological, sexual, and financial exploitation and abuse; and those who are deported because of their irregular status in the destination country (Bachtiar \& Prasetyo, 2017; Mulugeta \& Makonnen, 2017). Contextual analysis tailored to the specific migration setting of low-skilled migrants as well as reintegration based on their reason for return and return experience, it is argued, should be adopted (Bachtiar \& Prasetyo, 2017).

\subsubsection{What determines successful reintegration?}

Managing a return crisis requires understanding what factors determine the successful reintegration of return migrants. In simple terms, reintegration can be defined as a return migrant's participation in social, cultural, economic, and political life in their home country after staying in a foreign land for some period (Cassarino, 2008). Social reintegration occurs when returnees have good social relationships and acceptance within their family and community in the home country. 
Cultural and political reintegration involves successfully participating in religious, political, and cultural events, and connecting with norms and values of the home society. Economic reintegration involves becoming productive by generating an income through employment or entrepreneurial efforts by investing the human, social, and financial gains from the migration experience (Cassarino, 2008; Kuschminder, 2014; Ruben et al., 2009). The activities in each dimension are interrelated and affect one another. For example, having a good social network and relationships is crucial in economic, social, cultural, and political reintegration. This helps returnees to acquire information, share values and beliefs, and accrue the social capital needed for successful economic reintegration (Cassarino, 2004). Therefore, the successful reintegration of return migrants is the synergetic output of various activities and actions working to bring about a whole. It is difficult to get a definite and conclusive answer as to what factors determine success in reintegration, as it varies based on different factors such as the migration setting, demographic factors, the return type, and the socio-economic conditions in the home country, among other things. However, in this section I discuss the dominant arguments raised by migration scholars.

Ruben et al. (2009) conducted research involving six countries (Afghanistan, Armenia, Bosnia and Herzegovina, Sierra Leone, Togo, and Vietnam) to understand what affects the success of reintegration or the 'embeddedness' of returnees. By using both qualitative and quantitative data on 178 return migrants, the authors found that demographic factors and the experience of the migrant, including the reason for leaving the home country, the situation in the host country, the length of stay abroad, the conditions of return, and pre-and post-return assistance provided to the returnees affect the reintegration of return migrants (Ruben et al., 2009, p. 914). On the other hand, Cassarino (2004) argues that what determines a returnee's success in reintegration is preparedness to return, which comprises both readiness, which refers to accumulating the required resources that facilitate the return and reintegration processes, and willingness, which refers to the existence of free will accompanied by relevant information about the home country. Complementing this idea, other studies shows that motivation to return and the preparedness of returnees affect the reintegration of return migrants (Cassarino, 2008; De Regt \& Tafesse, 2016; Mensah, 2016; Ruben et al., 2009). Cassarino's return and reintegration analysis suggests that spending longer in the country of immigration helps migrants to mobilize resources and reintegrate well upon return. In line with this, Mensah (2016) found that low-skilled Ghanaian returnees who stayed longer in Libya are better off upon return. The reason for this is that migrants often borrow money and sell 
their property to arrange for their migration, and returning within a short period of time without achieving the migration goal exposes migrants to a double loss: wasting the time and resources used for migration and returning without mobilizing the necessary resources for reintegration (Cassarino, 2004; Mensah, 2016).

A number of studies have confirmed that human and social skills brought from the country of immigration greatly help in the reintegration of return migrants (De Vreyer, Gubert, \& Robilliard, 2010; Ghosh, 2000; Thomas, 2008). Evidence from Uganda shows that return migrants with a college degree have a greater chance of employment than non-migrants. However, returnees without professional or vocational skills or those having low educational qualifications, below high school, do not have a better chance of employment than non-migrants. Another study also suggests that returnees from Organization for Economic Co-operation and Development (OECD) countries earn better in employment and have better entrepreneurial opportunities than returnees from other countries (De Vreyer et al., 2010). The notion that all human or social skills acquired abroad lead to successful reintegration, at least in economic terms, can thus be contested and needs further research Dustman and Glitz (2011) and Dayton-Johnson, Pfeiffer, Schuettler, and Schwinn (2009) argue that in some cases the skills acquired may not be applicable in the home country, where those industries or technologies may not exist. In other cases, for some returnees who resided in the country of migration illegally, despite the fact that they may have brought back skills and competencies from abroad, it may be difficult to secure employment, as the migrants may not have formal certification for these skills (Mensah, 2016). Some of the key factors affecting the reintegration of return migrants mentioned in literature are summarized in figure 1 (not a complete list). 


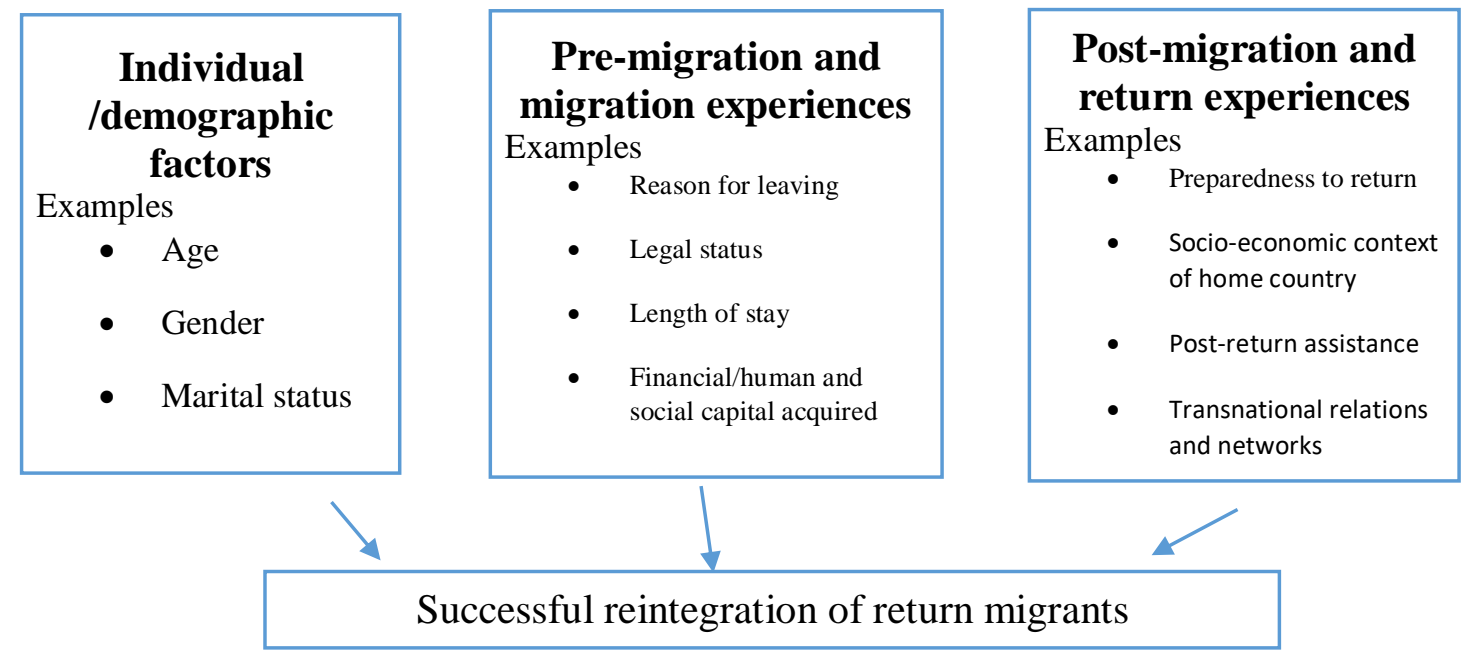

Figure 1. Key factors affecting the reintegration of return migrants

Other scholars emphasize the role of socio-cultural and economic aspects in the home environment in the successful reintegration of return migrants. De Bree, Davids, and De Haas (2010) discuss how transnational relationships are important in facilitating the successful reintegration of return migrants. Transnational contact and relationships, and back and forth movement, prepare for and lead to the better reintegration of return migrants, as returnees are closer to the culture of the home country and its values and have relationships with people in the home country. Return migrants experience many challenges upon return, including feelings of loneliness and alienation (especially for returnees who spend long periods away from their home country), unfavorable living and investment conditions in the home country, infrastructural problems, the high financial and material demands of family members, difficulty forming relationships and re-establishing former relationships, lack of employment opportunities, and disconnection from the cultural norms and values of the home country (Barrett \& Mosca, 2013; Konzett-Smoliner, 2016; Mensah, 2016). Returnees with a family can experience additional problems arising from spouses and children, such as emotional disconnectedness and lack of belonging (De Bree et al., 2010; Vathi \& Duci, 2016). According to Konzett-Smoliner (2016), the reintegration of migrants needs to be evaluated from a family perspective, rather than as an individual project. The experience of reintegration into the economic, social, and cultural conditions in the home country is complex and challenging for many returnees (Arowolo, 2000; Bachtiar \& Prasetyo, 2017; Black \& Gent, 2006; Cassarino, 2004; De Bree et al., 2010; Setrana \& Tonah, 2014; Van Houte \& Davids, 2008). These authors attribute 
the complexity of the process to the migration experience of migrants in destination countries, changes that occur in the home country while migrants are away and the returnee's perception of them, and changes in the identity of the migrant due to exposure to a new culture. In general, from the insights and findings discussed above, it can be seen that many factors affect the successful reintegration of return migrants. And there is no one-size-fits-all formula for successful reintegration.

To sum up, the discussion in section 1.3 shows that return and reintegration theories are developed from the perspective of permanent skilled migrants, and there is less understanding about the return and reintegration process of temporary low-skilled migrants (Bachtiar \& Prasetyo, 2017). Despite the significance of these findings for understanding what factors influence the successful reintegration of return migrants, in some cases some of the factors fail to explain the reintegration of low-skilled, particularly female, domestic migrants who work under the domination of a specific employer and within a labor system that creates vulnerabilities, such as kafala. For example, the kafala labor sponsorship scheme makes it difficult to change employers, which affects resource mobilization and motivation to return. As this dissertation will show, labor migrants in restricted migration schemes and temporary low-skilled migrants have different reintegration experiences than other migrants. The reintegration process for those involved in temporary migration schemes for low-skilled labor migrants, particularly female domestic migrants, is a matter not touched upon in social science debates. Many of the studies focus on the negative migration experiences of the migrants in the destination countries. The reintegration of female domestic returnees needs research attention, as the migration scheme for low-skilled workers does not provide the possibility of permanently residing in the destination country. Returnees must come back to their home country at some point, which calls for a need to understand the reintegration process of the returnees. This is particularly important for low-skilled labor-sending countries, such as Ethiopia where the migration of women to the Arabian Gulf is the most dominant form of migration. The number of women returning from these countries is also increasing substantially. The exact number of returnees in Ethiopia is not known; however, the return crisis in 2013/14 gives an indication of the magnitude of the issue (Kuschminder \& Richard-Guay, 2018).

This dissertation contributes to our knowledge and understanding of the reintegration of return migrants by describing how restricted migration schemes for unskilled female migrants in Arabian 
Gulf countries (the kafala labor sponsorship system) affect the economic, social, and family reintegration process of female returnees in Ethiopia. It also explores issues in the home country that affect the reintegration of unskilled female return migrants from the Arabian Gulf. In contrast to other studies, which acknowledge that motivation to return, readiness and length of stay in the country of immigration do not necessarily result in successful reintegration, the findings of this study show that the personal characteristics of the migrants, migration setting, conditions and socio-cultural values in the home country have a great impact on the reintegration of low-skilled workers.

\subsection{Main research question and sub-questions}

In this dissertation, I examine two aspects of the reintegration process of return migrants: economic reintegration and socio-cultural reintegration. The first aspect relates to how the kafala migration scheme affects the resource mobilization process and reintegration of returnees upon return to their home country. The second aspect looks at how gender and cultural issues in the home country intersect with the migration experience and shape the returnee's relationship with their community, friends, and family ultimately affecting the socio-cultural reintegration process. To analyze these aspects, I draw on theories from different disciplines such as sociology and psychology, as well as from research such as gender and migration studies. The main research question is: How do the migration experiences and home country conditions explain the reintegration of Ethiopian return migrants from the Arabian Gulf? 


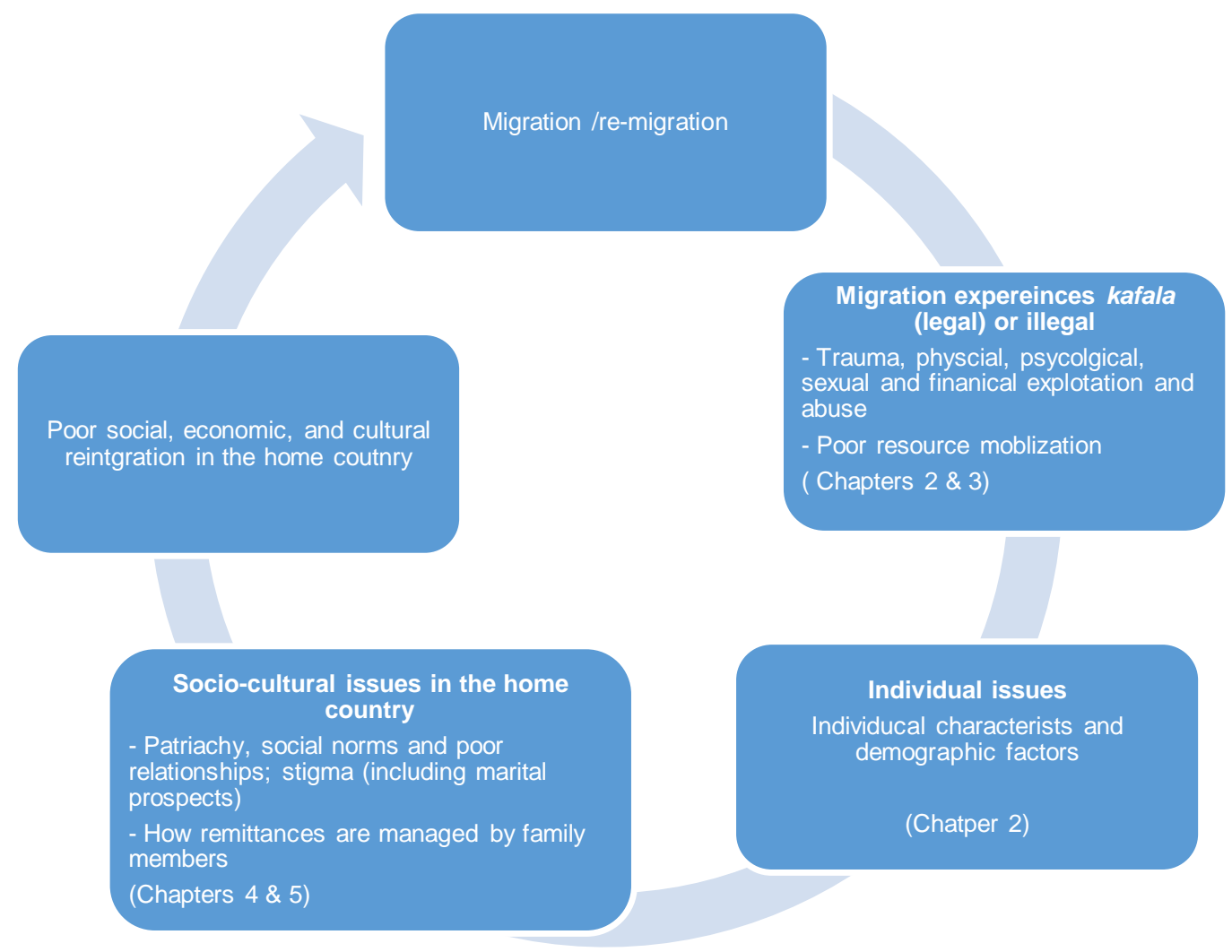

Figure 2. Main elements of the research question included in each chapter and relationship between the elements

Within this overarching question, sub-questions are raised and answered in each chapter.

In Chapter 2, I answer the first sub-question:

What traumatic incidents do Ethiopian women domestic migrants in Arabian Gulf countries experience in the course of their migration and how do returnees cope and make sense of these incidents in their effort to reintegrate into the socio-economic environment of their home country?

A significant number of scholars discuss the horrific, traumatizing experiences of domestic workers, particularly those who serve as live-in maids in Arabian Gulf and Middle Eastern countries (Abu-Habib, 1998; Anbesse et al., 2009; Beydoun, 2006; Gardner, 2012; Jureidini \& Moukarbel, 2006; Minaye, 2012; Pande, 2013). These studies show that physical, psychological, sexual, and financial exploitation and abuse are common experiences in a domestic migrant's life. Beyond the narration of migration experience, little is known about how migrants cope with these 
traumatic incidents, both during migration as well as upon return. There is some evidence that suggests that migrants mainly use stress management strategies during their migration (Pande, 2013; Van der Ham et al., 2015), but what coping mechanisms they use after their return has not yet been examined. This is important, as studies show that the traumatic experiences of migrants take time to heal (Bhugra, 2004; Schweitzer et al., 2006). For Chapter 2, I collected data in four focus group discussions and 36 in-depth individual interviews with Ethiopian female returnees. A coping theory (Park \& Folkman, 1997) from the discipline of psychology was used as a theoretical framework to answer the sub-question raised in this chapter. Based on the data collected, I analyzed the traumatic experiences of migrants while they were in destination countries and the coping mechanisms they adopted upon return to come to terms with their traumatic past. The findings from this empirical chapter show the significance of meaning-based coping strategies in the healing process. The chapter also discusses how these coping mechanisms can enhance the reintegration of returnees.

The following two questions are answered in Chapter 3:

- How do past migration experiences under the kafala labor sponsorship system affect the preparedness to return and economic reintegration of unskilled Ethiopian women returnees?

- To what extent does reintegration assistance and support in the home country enable returnees to build sustainable livelihoods?

As indicated in section 1.2, there is a wide gap in research on the socio-economic reintegration issues of low-skilled workers. Migration and return theories are developed from the perspective of permanent skilled labor migrants and fail to consider the role of the migration setting in the return and reintegration of low-skilled workers. In Chapter 3, I use the theory of preparedness by Cassarino (2004) to highlight the gaps in our understanding of the reintegration process of female domestic workers. Based on data collected in the in-depth interviews and focus group discussions, this chapter shows how the kafala labor sponsorship system affects the resource mobilization process while migrants are in the destination country, as well as their reintegration upon return. A directed approach to content analysis is a useful method of qualitative analysis when "existing theory or prior research exists about a phenomenon that is incomplete or would benefit from further description" (Hsieh \& Shannon, 2005, p. 1281). Hence, in analyzing the data, I used directed 
content analysis to sensitize concepts from the theory of preparedness (Cassarino, 2004), such as 'readiness to return', 'resource mobilization', and 'willingness to return', to guide the analysis. However, the analysis is not limited to directed content analysis; the thematic analysis method was also used to identify patterns in the narrations. In Chapter 3, I discuss how the theory needs to be adapted to be useful to understand the reintegration of domestic migrants governed by a restrictive migration scheme such as kafala. Building on Cassarino's (2004) theory of preparedness, the results of the chapter reveal new knowledge. They show how migration settings and cultural issues in the home country and the personality traits of the migrants are important for the reintegration of return migrants, and not their length of stay or willingness to return. The impact of reintegration assistance provided in the home country upon return is also analyzed, which is missing in the theory of preparedness. The empirical findings show that savings from migration and access to capital are dominant reasons for return migrants being able to participate in economic activities in the home country, suggesting that assistance programs such as vocational skill training should be backed by access to financial capital in both individual return cases and mass deportation cases.

In Chapter 4, I answer the following sub-question:

How do migration experiences to the Arabian Gulf affect the marital prospects of Ethiopian women returnees and their social reintegration in the home country upon return?

Drawing on theories from gender studies, a number of scholars have shown evidence that women's migration for domestic work creates conflict between married partners (Afsar, 2009; Bélanger \& Rahman, 2013; Kifleyesus, 2012; Ullah, 2013). The empowerment of women returnees after their migration, which can lead them to challenge patriarchal thinking, and the long distances involved are considered causes of marital conflict and disruption (Afsar, 2017; Kifleyesus, 2012; Silvey, 2006). Based on an extensive literature review on women's domestic migration, Deshingkar et al. (2014) argue that little is known about the connection between women's migration and marriage, and there is a need for further research to understand the relationship between the two. In response to this call, in Chapter 4 of this dissertation, I use the concept of intersectionality (for a review, see Bastia, 2014; Bilge, 2009; Davis, 2008; Hankivsky, 2014) to examine this issue. Bilge (2009) provides a two-step method to analyze intersectional issues (see Annex 7). This approach suggests first using indicative thematic analysis, followed by a deductive template (which is provided by 
the author) to further analyze the intersection of various categories such as race, class, and gender. Based on this analysis, the findings show that multiple factors interact with each other to place women returnees in a stigmatized position, ultimately affecting their marital prospects and reintegration in the home community. The study concludes by showing the social cost of migration and calling for further research to challenge the overstated positive impact of migration for women domestic workers.

In Chapter 5, I answer the following sub-question:

How do home country social norms and culture shape the interpersonal relationships, sense of belonging and reintegration of Ethiopian female return migrants from the Arabian Gulf?

In this chapter I draw on a theory from sociology called 'sense of belonging' (Hagerty, Williams, Coyne, \& Early, 1996) to analyze returnees' connectedness with their community and environment and to answer the above sub-question. Sense of belonging theory helps to evaluate social relationships and people's connection to their environment. Data gathered through interviews and focus groups was analyzed to identify dominant patterns in relation to returnees' relatedness with family members and their sense of belonging to the community. The empirical findings show that new dynamics emerge that negatively affect returnees' sense of belonging to their home community. The coping strategies used by returnees to deal with stigma are also discussed in the chapter. The chapter shows that returnees' sense of belonging to the community is affected by the socio-cultural norms in the country. These have implications for the reintegration process of the returnees and their remigration intention.

These independent chapters together answer the central research question of how do the migration experiences and home country conditions explain the reintegration of Ethiopian return migrants from the Arabian Gulf? For example, Chapter 2 shows the aftermath of the migration experience and how returnees try to cope with it. To make sense of past migration experiences and proceed with their life, migrants use meaning-based coping strategies such as attributing meaning to past trauma to understand why it happened, benefit seeking, and emphasizing the positive side of the migration experience, which in most cases is linked to how the migration experience changed the living conditions of the migrant's family and seeing the migration experience as a learning experience that can be used for personal development and in the reintegration process. Chapter 3 
shows how restricted migration schemes, such as kafala, interact with home country socio-cultural issues to affect the reintegration process. The main contribution of this dissertation, as well as contributing to the academic debate, is that it stresses the importance of incorporating migration settings and cultural issues in the home country, such as trust between family members, in analyzing the reintegration of returnees. Chapters 4 and 5 also stress the importance of understanding socio-cultural contexts in the reintegration process. The findings of the research show that the reintegration of Ethiopian domestic return migrants from the Arabian Gulf into the socio-economic environment in the home country is the result of multifaceted issues related to the migration scheme, returnees' migration experiences, and the socio-cultural conditions in the home country, and the intersection of these factors to shape the reintegration process of the returnees. The practical implications of these findings, which it is hoped will be used to inform reintegration strategies and policies in managing both individual cases and mass deportations, such as occurred in Ethiopia in 2013/2014, mainly relate to preventive measures and actions that can be taken during the migration process to promote the reintegration of returnees, as well as post-return reintegration support programs. Regarding preventive measures, this dissertation points out that the kafala labor system, which operates in many Arabian Gulf countries, contributes to the illegality of the migrants (which is a major cause of deportation); it also exposes them to various traumatic experiences and affects their ability to save and mobilize resources, which is necessary for the successful reintegration of returnees. Regarding post-return reintegration support programs, the findings underscore the importance of needs-based, customized reintegration assistance programs rather than one-size-fits-all support programs. For example, to manage the return crisis in $2013 / 14$, the main strategy adopted by the Ethiopian government was to enable migrants to generate income; hence, the focus was on providing vocational skill trainings, which were partially useful for some returnees. A detailed analysis of the returnees' migration experiences, family situation, savings (from remittances), and health conditions need also attention. For example, for severely traumatized returnees, providing health and psychological support programs comes first, before income generating programs. According to the findings of this research, however, health related and other socio-cultural issues also need attention to promote the sustainable return and successful reintegration of returnees. 


\subsection{Data collection process and ethical consideration}

In this dissertation my aim was to understand the socio-economic reintegration of women return migrants from the Arabian Gulf. I wanted to understand how the migration experience is linked to the reintegration process and what home country socio-cultural issues intersect with the migration experience of the returnees to impact on the reintegration process, for which qualitative approaches are best suited. A qualitative research approach enables us to capture experiences, perceptions, and feelings that cannot be revealed using a quantitative approach (Shin, Mi \& Seung, 2009). Accordingly, a qualitative approach was used to collect and analyze the data in this study. The socio-economic reintegration experiences of female returnees from Arabian Gulf countries were presented, as experienced and perceived by the returnees, based on their subjective meaning, actions, and social contexts (Fossey, Harvey, McDermott, \& Davidson, 2002, p. 716), while also revealing underlying issues in the narration through careful interpretation. In this section, I briefly describe the data and ethical considerations of the research (see individual chapters for details on methodological approach). The section is divided into four sections. The first section provides general information on the design and field work. The second section presents the sampling strategy and data collection methods, and the third section explains the methods of analysis. The fourth section discusses the ethical considerations followed in collecting, analyzing, and reporting the data.

\subsubsection{Field work in Addis Ababa}

The field work for this dissertation started in January of 2015 and extended to March 2017 in the city of Addis Ababa, the capital of Ethiopia, and home to many ethnic groups. There exists huge differences in the socio-economic conditions of women in Ethiopia based on their location in the country. Women in urban centers like Addis Ababa have better opportunities for education and employment than those in rural areas. Considering the high number of female migrants traveling from rural areas of the country, particularly Amhara, Oromia, and the Southern regions, to the Arabian Gulf and Middle East countries, collecting data from outside Addis Ababa would have provided an enhanced understanding, but it was not feasible given the resources allocated to this research. Hence, I deliberately focused on return migrants located in Addis Ababa, even though many of the participants were from different ethnic and religious backgrounds. 
The field work was started by contacting three local NGOs working on the return and reintegration of Ethiopian women migrants from countries in the Arabian Gulf and a governmental organization of the Ministry of Labor and Social Affairs, all based in Addis Ababa. The first NGO was (Agar Ethiopia www.agarethiopia.com), which focuses the rehabilitation of traumatized returnees, the second was Live Addis (liveaddis.org) and third was Women in Self Employment (WISE; www.wise.org.et). The last two focus on business and vocational skill trainings to enable returnees support themselves economically

To broaden my knowledge on the issue, I held individual interviews with key officials working in reintegration programs for female returnees in Addis Ababa run by local NGOs such as WISE, Agar Ethiopia, Live Addis, and by government organizations such as the Ethiopian Ministry of Labor and Social Affairs. Five directors or coordinators from the NGOs and two officials from the Ministry were interviewed. The key stakeholder interviews were less structured and aimed to identify the stakeholder's role in the reintegration process, any challenges they faced in their reintegration efforts, and the assistance provided. Informal data was gathered by volunteering in the local NGOs' activities, including participating in workshops and training programs organized for returnees, reviewing local media sources on migration and reintegration, and informal conversations with community members about their perception of returnees.

Through the NGOs and other gatekeepers I was able to meet a few returnees. However, all of these returnees were receiving reintegration assistance from the government or NGOs and I wanted to see the difference in the reintegration process of other returnees who did not receive reintegration support after their return; hence, I used the snowball method to locate these returnees. Finding returnees who did not receive reintegration support was not as easy as finding returnees receiving support from NGOs. I faced two major challenges: first, the returnees were dispersed throughout the community, and, second, I lacked an opportunity to develop trust and many of the returnees who I contacted through personal contacts were skeptical about the research. However, I was able to overcome these challenges by having the returnees who I had found through the NGOs introduce other returnees from their community. Having a positive relationship and developing trust with the returnees I had already met through the NGOs helped me to establish a good relationship with the returnees who did not receive support. How many participants to include in the study was not decided at the beginning of the data collection, but guided by data saturation (Guest, Bunce \& 
Johnson 2006). After acquainting myself with the situation, I started to recruit participants for the study. A total of 48 Ethiopian women returnees living in Addis Ababa participated in the qualitative research.

\subsubsection{Sampling and data collection methods}

As I discussed above, I combined a purposeful sampling method (by deliberately focusing on organizations that work with return migrants) and a snowball sampling method (to recruit participants who did not have any relationship with government agencies or NGOs working with returnees). Table 1 shows the sampling methods and number of participants in the study.

Table 1. Sampling method

\begin{tabular}{|l|c|}
\hline Sampling method & No. of respondents \\
\hline Purposeful & 31 \\
\hline Snowball & 17 \\
\hline Total & 48 \\
\hline
\end{tabular}

I incorporated returnees with various migration and return experiences to carefully compare and contrast their socio-economic reintegration process. Table 1 presents a summary of the characteristics of the participants, based on their legal status while in the destination country and their return condition. 
Table 2. Characteristic of participants

\begin{tabular}{|c|c|c|c|c|c|c|c|}
\hline \multirow[b]{2}{*}{ Characteristics } & \multicolumn{3}{|c|}{ Migration experience } & \multicolumn{2}{|c|}{ Return type } & \multicolumn{2}{|c|}{ Reintegration support } \\
\hline & $\begin{array}{l}\text { Legal } \\
(\text { kafala })\end{array}$ & $\begin{array}{l}\text { Illegal } \\
\text { (runaway) }\end{array}$ & $\begin{array}{l}\text { Illegal } \\
\text { (other) }\end{array}$ & Voluntary & $\begin{array}{l}\text { Involuntary } \\
\text { (deported) }\end{array}$ & Received & $\begin{array}{l}\text { Not } \\
\text { received }\end{array}$ \\
\hline $\begin{array}{ll}\text { No. } & \text { of } \\
\text { participants } & \end{array}$ & 15 & 26 & 7 & 28 & 20 & 30 & 18 \\
\hline Total & \multicolumn{3}{|c|}{48} & \multicolumn{2}{|r|}{48} & \multicolumn{2}{|c|}{48} \\
\hline
\end{tabular}

To grasp the general migration process and possible exploitation experiences at each stage, data collection started with focus group discussions, which were followed by individual interviews with some forcefully deported returnees and those who returned voluntarily after finishing their contract. These were preceded by collecting key demographic information through semi-structured questionnaires filled in face-to-face with the returnees.

The data was collected in two phases: from January to March 2015 when, 14 individual interviews and 4 focus group discussions were conducted, and January 2016 to March 2017, when an additional 22 individual interviews with new participants and 6 follow-up interviews with firstphase interview participants were conducted. The data collected in the 42 individual interviews and 4 focus group discussions were used in the analysis and interpretation for this dissertation. The interview and focus group discussion guidelines used can be found Annexes 1 to 4.

\section{Focus group discussions}

Four focus group discussions were organized with returnees with different experience, such as those who received reintegration assistance from Agar Ethiopia and WISE, and those who did not, those who stayed legally and those who stayed illegally, and those stayed for a long time and those who stayed for only a short time. The groups had six, four, eight and eight participants, respectively (see Chapter 2 Methodological approach, for details).

In general, the focus group discussions were helpful in identifying the core issues in migration and in the return and reintegration processes, as well as confirming the accuracy of the data, but they were not without limitations. Hesitation to discuss taboo subjects in Ethiopian culture and 
traumatic experiences (such as rape, drug issues and forced prostitution) was observed in the focus group discussions, perhaps for fear of judgment by other group members. Hence, conducting individual interviews in addition to focus groups was very important.

\section{Individual interviews}

To triangulate the information obtained in the focus group discussions, in-depth personal interviews were held. Data saturation was considered in deciding when to stop the interview process: when no additional information was obtained from the interviews, the interviews were stopped. A total of 42 individual interviews were held with 36 returnees. Non-directive interview questions such as "Tell me briefly about your life before migration", "Tell me your typical day as a migrant in destination country", "Why did you return?", "What are the good or bad experiences you encountered after return", were asked.

All of the participants gave their consent to audio record the interviews. Table 3 presents a summary of the focus group discussions and individual interviews conducted. 
Table 3. Data collection tools

\begin{tabular}{|l|c|c|c|c|}
\hline \multirow{2}{*}{$\begin{array}{l}\text { No. } \\
\text { Nocus group } \\
\text { discussions } \\
\text { participants }\end{array}$} & \multicolumn{2}{|l|}{ Individual interviews } \\
\cline { 3 - 5 } & & First round & \multicolumn{2}{|l|}{ Second round } \\
\cline { 3 - 5 } & 26 & 14 & 22 & 6 \\
\hline Total & & & New & Follow-up \\
\hline
\end{tabular}

\subsubsection{Data analysis}

Data gathered from various sources was integrated in order to analyze the data. A common qualitative procedure was used to analyze the data in all chapters, namely, organizing the data, then coding, identifying and categorizing emerging patterns, integrating field notes and memos, and interpreting the data. In order to facilitate this process, ATLAS.ti qualitative software was used. Both an inductive approach, in which themes emerged from the data, and a deductive approach, in which theoretical concepts were applied to the data, were used. Different qualitative analysis methods, such as thematic analysis (Chapters 2 and 5), a directed approach to content analysis (Chapter 3), and a two-step hybrid approach (Chapter 4), were used. This was dictated by the theoretical framework used and the research question raised in each chapter. The validity of the data was ensured through the triangulation of sources (participants, NGO coordinators, and officials) and methods (focus group discussions, observations, and interviews), as well as member checking, where the data collected and transcribed was re-discussed in the focus group discussions with the participants in the study so that they could confirm the plausibility of the information. In Chapters 2 and 3, the analysis of the data was done collaboratively with other colleagues. This helped to ensure the reliability of the interpretation and coding process.

\subsubsection{Ethical considerations}

The importance of respecting the rights of research participants and ethical considerations is fundamental in both academic and practical action research (Corti, Day, \& Backhouse, 2000; Orb, Eisenhauer, \& Wynaden, 2001). Given that the participants in this dissertation are from vulnerable groups and may have experienced violence and exploitation, the utmost effort was taken to balance 
the rights of the participants with the needs of the research (Orb et al., 2001). Ethical considerations were an integral part of the research design, collection, analysis, and reporting.

All interviews began with an explanation of the purpose and objectives of the research, how the data would be used and reported, the estimated time the discussion or interview might take, and the right to withdraw from the study at any point. Permission was also sought from the participants to record the interview using a voice recorder, and all agreed. Participants were assured of the confidentiality of the data. Informed consent was gathered, in some cases in writing and in other cases verbally, depending on what the participants preferred. The participants were told that there was no financial incentive for participating in the study to protect the integrity of data. No compensation was provided to participants, except for coffee, snacks, and lunch provided during some interviews and focus group discussions, as well as transportation costs after the interview (100 Ethiopian birr).

During the interviews participants sometimes became very emotional while talking about the violence that they had experienced. In all cases, ongoing consent was requested and participants were asked if they wanted to proceed with the interview or to stop or take a break. Surprisingly, many of the participants found it important to share their experiences for the sake of other migrants who are suffering in destination countries and to inform those who were thinking about want to migrating. The participants appeared to feel relieved talking about the violence and associated shame and anger. In fact, some told me that they were unable to talk about these matters even to their family members and were happy to share as long as their identity was not revealed. A few asked me to provide the final results to the Ethiopian government so that they might improve protection for Ethiopian citizens abroad. The majority angrily discussed how the Ethiopian embassies in destination countries failed to protect them.

In analyzing and reporting data, the utmost effort was made to protect the rights of the participants. The transcription of audiotaped interviews was conducted by me and a research assistant. The transcribed documents were also translated from Amharic to English by a linguist. The translated documents were rechecked against the original transcripts for accuracy and consistency of meaning. In all cases, only codes were used to identify the participants, and the research assistants (transcribers and translators) were asked to delete all information afterwards. Numbers were used to identify the research participants instead of names in the transcription, translation, and reporting 
of the results. In some cases, pseudonyms were used in reporting the results of the data. In general, ethics standards for conducting qualitative research were followed and efforts made to balance the goals of the research and the rights of participants.

\subsection{Organization of the thesis}

This study is based on four independent and interrelated empirical studies on the reintegration of Ethiopian women return migrants from the Arabian Gulf. The first chapter provides an introduction in the form of the background, the research context, and a brief literature review on the migration experiences and reintegration of return migrants, mainly domestic workers, and the organization of the paper. The second chapter deals with migration-related traumatic incidents and the coping mechanisms adopted by Ethiopian women return migrants upon their return. The third chapter deals with the economic reintegration of women return migrants and reintegration assistance programs in the home country. The fourth chapter deals with the stigma and marital prospects of the returnees and how these might affect their reintegration process. The fifth chapter deals with the dynamics that migration experiences to the Arabian Gulf bring to relationships between returnees and their families and how these can affect the returnee's sense of belonging. And, finally, in Chapter 6, the main findings, theoretical and practical contributions, and future research directions are presented. 


\section{References}

Abu-Habib, L. (1998). The use and abuse of female domestic workers from Sri Lanka in Lebanon. Gender \& Development, 6(1), 52-56.

Afsar, R. (2009). Unravelling the vicious cycle of recruitment: Labour migration from Bangladesh to the Gulf States. Geneva: ILO.

Afsar, R. (2017). Contextualizing gender and migration in South Asia: Critical insights. Gender, Technology and Development, 15(3), 389-410. doi:10.1177/097185241101500304

Ammassari, S. (2004). From nation-building to entrepreneurship: The impact of élite return migrants in Côte d'Ivoire and Ghana. Population, Space and Place, 10(2), 133-154.

Anbesse, B., Hanlon, C., Alem, A., Packer, S., \& Whitley, R. (2009). Migration and mental health: A study of low-income Ethiopian women working in Middle Eastern countries. International Journal of Social Psychiatry, 55(6), 557-568.

Anteneh, A. (2011). Trafficking in persons overseas for labour purposes: The case of Ethiopian domestic workers. ILO.

Arowolo, O. O. (2000). Return migration and the problem of reintegration. International Migration, 38(5), 59-82.

Bachtiar, P., \& Prasetyo, D. D. (2017). Return migration and various reintegration programs for low-skilled migrant workers in Indonesia: SMERU Research Institute.

Bajracharya, R., \& Sijapati, B. (2012). The Kafala system and its implications for Nepali domestic workers. Policy Brief, 1, Centre for the Study of Labour and Mobility (CESLAM).

Barrett, A., \& Mosca, I. (2013). Social isolation, loneliness and return migration: Evidence from older Irish adults. Journal of Ethnic and Migration Studies, 39(10), 1659-1677.

Bastia, T. (2014). Intersectionality, migration and development. Progress in Development Studies, 14(3), 237-248.

Bélanger, D., \& Rahman, M. (2013). Migrating against all the odds: International labour migration of Bangladeshi women. Current Sociology, 61(3), 356-373.

Belay, Y. D. (2014). Migration and state responsibility: Ethiopian domestic workers in Lebanon. International Journal of Scientific and Research Publications, 4(5), 120.

Beydoun, K. A. (2006). The trafficking of Ethiopian domestic workers into Lebanon: Navigating through a novel passage of the international maid trade. Berkeley Journal of International Law, 24, 1009.

Bhugra, D. (2004). Migration and mental health. Acta Psychiatrica Scandinavica, 109(4), 243-258.

Bilge, S. (2009). Smuggling intersectionality into the study of masculinity: Some methodological challenges. Paper presented at the Feminist Research Methods: An International Conference, University of Stockholm.

Black, R., \& Gent, S. (2006). Sustainable return in post-conflict contexts. International Migration, 44(3), $15-38$.

Borjas, G. J. (1989). Economic theory and international migration. International Migration Review, 23(3), $457-485$.

Cassarino, J.-P. (2004). Theorising return migration: The conceptual approach to return migrants revisited. Florence : European University Institute.

Cassarino, J.-P. (2008). Conditions of modern return migrants - Editorial introduction. International Journal on Multicultural Societies, 10(2), 95-105.

Constant, A., \& Massey, D. S. (2002). Return migration by German guestworkers: Neoclassical versus new economic theories. International Migration, 40(4), 5-38.

Corti, L., Day, A., \& Backhouse, G. (2000). Confidentiality and informed consent: Issues for consideration in the preservation of and provision of access to qualitative data archives. Paper presented at the Forum Qualitative Sozialforschung/Forum: Qualitative Social Research.

Crenshaw, K. (1990). Mapping the margins: Intersectionality, identity politics, and violence against women of color. Stanford Law Review, 43, 1241. 
Davis, K. (2008). Intersectionality as buzzword: A sociology of science perspective on what makes a feminist theory successful. Feminist Theory, 9(1), 67-85.

Dayton-Johnson, J., Pfeiffer, A., Schuettler, K., \& Schwinn, J. (2009). Migration and employment. Unclassified DCD/DAC (2009) 16/ADD, 93.

De Bree, J., Davids, T., \& De Haas, H. (2010). Post-return experiences and transnational belonging of return migrants: A Dutch-Moroccan case study. Global Networks, 10(4), 489-509.

De Haas, H., Fokkema, T., \& Fihri, M. F. (2015). Return migration as failure or success? Journal of international migration and integration, 16(2), 415-429.

De Regt, M. (2010). Ways to come, ways to leave: Gender, mobility, and il/legality among Ethiopian domestic workers in Yemen. Gender \& Society, 24(2), 237-260.

De Regt, M., \& Tafesse, M. (2016). Deported before experiencing the good sides of migration: Ethiopians returning from Saudi Arabia. African and Black Diaspora: An International Journal, 9(2), 228 242.

Demissie, F. (2018). Ethiopian female domestic workers in the Middle East and Gulf States: An introduction. African and Black Diaspora, 11(1), p. 1-5.

Deshingkar, P., Zeitlyn, B., \& Holtom, B. (2014). Does migration for domestic work reduce poverty? A review of the literature and an agenda for research. Migrating out of Poverty RPC.

De Vreyer, P., Gubert, F., \& Robilliard, A.-S. (2010). Are there returns to migration experience? An empirical analysis using data on return migrants and non-migrants in West Africa. Annals of Economics and Statistics/Annales d'économie et de statistique, 307-328.

Dustmann, C., \& Glitz, A. (2011). Migration and education. In: Handbook of the Economics of Education, Vol. 4. Elsevier, pp. 327-439.

Eresso, M. Z. (2018). Sisters on the move: Ethiopia's gendered labour migration milieu. Canadian Journal of African Studies/Revue canadienne des études africaines, 1-20.

Fernandez, B. (2010). Cheap and disposable? The impact of the global economic crisis on the migration of Ethiopian women domestic workers to the Gulf. Gender \& Development, 18(2), 249-262. doi:10.1080/13552074.2010.491335

Fernandez, B. (2011). Household help? Ethiopian women domestic workers' labor migration to the Gulf countries. Asian and Pacific Migration Journal, 20(3-4), 433-457.

Fernandez, B. (2013). Traffickers, brokers, employment agents, and social networks: The regulation of intermediaries in the migration of Ethiopian domestic workers to the Middle East. International Migration Review, 47(4), 814-843.

Fossey, E., Harvey, C., McDermott, F., \& Davidson, L. (2002). Understanding and evaluating qualitative research. Australian and New Zealand Journal of Psychiatry, 36(6), 717-732.

Fransen, S., \& Kuschminder, K. (2009). Migration in Ethiopia: History, current trends and future prospects. Paper Series: Migration and Development Country Profiles, Maastricht Graduate School of Governance.

Frantz, E. (2008). Of maids and madams: Sri Lankan domestic workers and their employers in Jordan. Critical Asian Studies, 40(4), 609-638.

Gardner, A. (2012). Why do they keep coming? Labor migrants in the Gulf states.

Ghosh, B. (2000). Return migration: Journey of hope or despair? United Nations Publications.

Guest, G., Bunce, A., \& Johnson, L. (2006). How many interviews are enough? An experiment with data saturation and variability. Field Methods, 18(1), 59-82.

Hagerty, B. M., Lynch-Sauer, J., Patusky, K. L., Bouwsema, M., \& Collier, P. (1992). Sense of belonging: A vital mental health concept. Archives of Psychiatric Nursing, 6(3), 172-177.

Hagerty, B. M., Williams, R. A., Coyne, J. C., \& Early, M. R. (1996). Sense of belonging and indicators of social and psychological functioning. Archives of Psychiatric Nursing, 10(4), 235-244.

Hankivsky, O. (2014). Intersectionality 101. The Institute for Intersectionality Research \& Policy, SFU, pp. 1-34. 
Hsieh, H.-F., \& Shannon, S. E. (2005). Three approaches to qualitative content analysis. Qualitative Health Research, 15(9), 1277-1288.

Jones, N., Presler-Marshall, E., Tefera, B., Emirie, G., Gebre, B., \& Gezahegne, K. (2014). Rethinking girls on the move: The intersection of poverty, exploitation, and violence experienced by Ethiopian adolescents involved in the Middle East 'maid trade'. A report submitted to Overseas Development Institute and funded by Oak Foundation.

Jureidini, R., \& Moukarbel, N. (2006). Female Sri Lankan domestic workers in Lebanon: A case of 'contract slavery'? Journal of Ethnic and Migration Studies, 30(4), 581-607. doi:10.1080/13691830410001699478

Kebede, E. (2002). Ethiopia: An assessment of the international labour migration situation: The case of female labour migrants: Geneva: ILO.

Ketema, N. (2014). Female Ethiopian migrant domestic workers: An analysis of migration, returnmigration and reintegration experiences.

Kifleyesus, A. (2012). Women who migrate, men who wait: Eritrean labor migration to the Arab Near East. Northeast African Studies, 12(1), 95-127. doi:10.1353/nas.2012.0028

Konzett-Smoliner, S. (2016). Return migration as a 'family project': Exploring the relationship between family life and the readjustment experiences of highly skilled Austrians. Journal of Ethnic and Migration Studies, 42(7), 1094-1114.

Kuschminder, K. (2014). Female return migration and reintegration strategies in Ethiopia. Maastricht University.

Kuschminder, K., Andersson, L., \& Seigel, M. (2018). Migration and multidimensional well-being in Ethiopia: Investigating the role of migrants destinations. Migration and Development, 1-20.

Kuschminder , K., \& Richard-Guay, A. (2018). Reintegration background report (9220309939).

Lecadet, C., \& Tafesse, M. M. (2016). The expulsion of Ethiopian workers from Saudi Arabia (2013-2014). The management of a humanitarian and political crisis/L'expulsion des travailleurs éthiopiens d'Arabie Saoudite (2013-2014): la gestion d'une crise humanitaire et politique. Annales D'ethiopie, $31,1,225-243$

Mantouvalou, V. (2015). 'Am I free now?' Overseas domestic workers in slavery. Journal of Law and Society, 42(3), 329-357.

Mensah, E. A. (2016). Involuntary return migration and reintegration. The case of Ghanaian migrant workers from Libya. Journal of International Migration and Integration, 17(1), 303-323.

Minaye, A. (2012). Trafficked to the Gulf States: The experiences of Ethiopian returnee women. Journal of Community Practice, 20(1-2), 112-133.

Mulugeta, M., \& Makonnen, T. (2017). Illicit cross-border migration in Ethiopia: Causes, patterns and policy responses. Ethiopian Journal of the Social Sciences and Humanities, 13(2), 53-80.

Orb, A., Eisenhauer, L., \& Wynaden, D. (2001). Ethics in qualitative research. Journal of Nursing Scholarship, 33(1), 93-96.

Pande, A. (2012). From 'balcony talk' and 'practical prayers' to illegal collectives: Migrant domestic workers and meso-level resistances in Lebanon. Gender \& Society, 26(3), 382-405.

Pande, A. (2013). 'The paper that you have in your hand is my freedom': Migrant domestic work and the sponsorship (kafala) system in Lebanon. International Migration Review, 47(2), 414-441.

Park, C. L., \& Folkman, S. (1997). Meaning in the context of stress and coping. Review of General Psychology, 1(2), 115-144.

Perruchoud, R., \& J. Redpath-Cross (eds). (2011). International migration law: Glossary on migration. Geneva: International Organization for Migration, Geneva. 
Piper, N. (2004). Rights of foreign workers and the politics of migration in South-East and East Asia. International Migration, 42 (5), 71-97.

Romero, M. (2018). Reflections on globalized care chains and migrant women workers. Critical Sociology, 0896920517748497.

Ruben, R., Van Houte, M., \& Davids, T. (2009). What determines the embeddedness of forced-return migrants? Rethinking the role of pre-and post-return assistance. International Migration Review, 43(4), 908-937.

Schweitzer, R., Melville, F., Steel, Z., \& Lacherez, P. (2006). Trauma, post-migration living difficulties, and social support as predictors of psychological adjustment in resettled Sudanese refugees. Australian and New Zealand Journal of Psychiatry, 40(2), 179-187.

Setrana, M. B., \& Tonah, S. (2014). Return migrants and the challenge of reintegration: The case of returnees to Kumasi Ghana. İrìnkèrindò, 7(Jun), 116-142.

Silvey, R. (2006). Consuming the transnational family: Indonesian migrant domestic workers to Saudi Arabia. Global Networks, 6(1), 23-40.

Stark, O., \& Stark, O. (1991). The migration of labor.

Strauss, K., \& McGrath, S. (2017). Temporary migration, precarious employment and unfree labour relations: Exploring the 'continuum of exploitation' in Canada's Temporary Foreign Worker Program. Geoforum, 78, 199-208.

Tayah, M.-J., \& Atnafu, A. (2016). Promoting and protecting the rights of migrant domestic workers in transit: The case of Ethiopian women migrants. Research Series, ILO, Geneva.

Thomas, K. J. (2008). Return migration in Africa and the relationship between educational attainment and labor market success: Evidence from Uganda. International Migration Review, 42(3), 652-674.

Ullah, A. A. (2013). Mother's land and others' land: 'Stolen' youth of returned female migrants. Gender, Technology and Development, 17(2), 159-178.

Van der Ham, A. J., Ujano-Batangan, M. T., Ignacio, R., \& Wolffers, I. (2015). The dynamics of migrationrelated stress and coping of female domestic workers from the Philippines: An exploratory study. Community Mental Health Journal, 51(1), 14-20.

Van Houte, M., \& Davids, T. (2008). Development and return migration: From policy panacea to migrant perspective sustainability. Third World Quarterly, 29(7), 1411-1429.

Vathi, Z., \& Duci, V. (2016). Making other dreams: The impact of migration on the psychosocial wellbeing of Albanian-origin children and young people upon their families' return to Albania. Childhood, 23(1), 53-68.

Wickramasekara, P. (2008). Globalisation, international labour migration and the rights of migrant workers. Third World Quarterly, 29(7), 1247-1264. 


\title{
CHAPTER 2
}

\section{The Exploitation Narratives and Coping Strategies of Ethiopian Female Return Migrants from the Arabian Gulf ${ }^{2}$}

\begin{abstract}
A large number of unskilled women from least developed countries engage in international migration as domestic workers. Although the transnational migration experiences of these women could be empowering, female migrants are vulnerable to exploitation. This paper explores the migration experiences of Ethiopian women who migrate to Arabian Gulf countries as domestic workers under the kafala labor sponsorship system and how they cope with their traumatic experiences upon return to Ethiopia. Forty-eight Ethiopian female former domestic workers who had returned from Arabian Gulf countries participated in this study. The study found that both female migrants who live with their sponsor/employer and those who run away from their sponsor/employer are exposed to various forms of racialized, gendered and economic exploitation at different stages of the migration process. The study also found that upon returning to Ethiopia, these women use sense-making and benefit-finding strategies to cope with their multiple exploitation experiences.
\end{abstract}

\subsection{Introduction}

Temporary contract migration, facilitated by temporary migration schemes, is becoming increasingly common in many regions of the world, particularly given the growing number of workers in highly feminized sectors like domestic work (Piper, 2004, 2008, 2010; Yeoh \& Ramdas, 2014). Such migration schemes have led to the increased participation of women. Transnational migration can potentially be an empowering experience for women. Many women use temporary contract migration as an escape route from unwanted marriages, abusive relationships, poverty, and dependence on male-dominated patriarchal structures in their home country. Temporary contract migration can also be a way for women to support their families, develop skills or uphold ideals of womanhood (Parreñas, 2005). At the same time, foreign

\footnotetext{
${ }^{2}$ The paper is published in Journal of Gender, Place \& Culture as: Nisrane, B. L., Ossewaarde, R. \& Need, A. (2019). The exploitation narratives and coping strategies of Ethiopian female return migrants from the Arabian Gulf.
} 
countries can leave migrant domestic workers vulnerable to multiple exploitations because of their gender, class, race, religion and nationality (Jureidini \& Moukarbel, 2004; Silvey, 2009; Minaye 2012; Yeoh \& Ramdas, 2014; Yeoh, Platt, Khoo, Lam \& Baey, 2017). Such racialized, gendered and economic exploitation includes deprivation of rest and food, sexual assault including rape, and psychological abuse such as being threatened (Jureidini \& Moukarbel, 2004; Minaye, 2012; Anbesse et al., 2009; Wickramage, De Silva \& Peiris, 2017).

Under existing institutional arrangements for temporary contract migration it is difficult to prevent such multiple exploitation and protect the human rights, physical safety, and psychological health of migrant women. The vulnerability of migrant women is exacerbated by temporary migration schemes that tie migrants to specific sponsors/employers for a specific period of time (Mantouvalou, 2015; Bosmans et al., 2016; Wickramage et al., 2017). Under these schemes, the governments of supply countries provide unskilled migrant workers at a low cost, seeking to develop a comparative advantage over other states in relation to labor supply. Both governments of supply countries and receiving countries benefit from this. Yeoh et al. (2017) explain how Singapore takes advantage of the supply of Indonesian women in this 'migration industry'. In Singapore, Indonesian workers use a work permit system which grants short-term contracts and enables easy repatriation. These migrant workers do not have the right to bring along dependents, marry Singaporean citizens, and are repatriated if found to be pregnant. Such temporary migration schemes are described as operating as "technologies of servitude" (Yeoh et al., 2017, p. 424) and as "machinations of structural and institutionalized violence" (Fluri \& Piedalue, 2017, p. 537). Migrant workers are governed to accept their structurally-servile positions through transnational gendered processes that are marked by racialized, gendered and economic exploitation.

The kafala labor sponsorship system (a system that binds migrant workers to their employer and/or sponsor in Arabian Gulf countries, see Bajracharya \& Sijapati, 2012) in Saudi Arabia, Kuwait, United Arab Emirates, Qatar, Oman, Bahrain, Iraq, Jordan and Lebanon is another example of a temporary migration scheme (Jureidini \& Moukarbel, 2004; Pande, 2013; Demissie, 2018). Under the kafala system, migrant workers enter the destination country under the financial and legal responsibility of a specific employer, and stay with the same employer for the duration of the work contract (Pande, 2013; Mahdavi, 2013). The purpose of tying migrant workers to one employer is twofold: to provide protection for the Arab employer (who bears the financial costs of bringing 
the migrant) and to prevent migrants from permanently settling in the Arabian Gulf destination countries (Frantz, 2013). The Gulf Cooperation Council (GCC) states host more than 15 million foreign workers (Frantz, 2013). In countries like Saudi Arabia and Kuwait, some 90\% of all households employ migrant domestic workers. More than two million temporary domestic workers, from countries like Ethiopia, Somalia, Sri Lanka, Philippines and India, make use of the kafala labor sponsorship system to enter the Arabian Gulf.

The kafala system is criticized by many for producing a readily exploitable workforce, as it creates an unbalanced power relation between employers (kafeel) and migrants (Pande, 2013; Mahdavi, 2013). Numerous human rights groups have reported widespread human trafficking, violence, rape, beating, starvation, excessive domestic work, debt bondage, sexual slavery, and servitude to other households. In the Arabian Gulf suicide rates are high among migrant workers (Dervic et al., 2012). In 2013, in Saudi Arabia, 37\% of the documented suicides were of Ethiopian female domestic workers. And every week one domestic worker commits a suicide in Lebanon (The Guardian, 2012). After returning to their home country, many female migrants suffer from mental disorders (Anbesse, Hanlon, Alem, Packer \& Whitley, 2009; Minaye, 2012) due to the trauma of having been exploited in multiple ways.

While the racialized, gendered and economic exploitation of women migrants, before and during their migration, including at their place of work, has been frequently narrated, especially in relation to Asian migrants, how women cope with their multiple exploitation experiences during their migration and after they return from abroad to their home country is as an under-researched area (Anbesse et al., 2009; Kronfol, Saleh \& Al-Ghafry, 2014; Minaye, 2012; Pande, 2012; Wickramage, De Silva \& Peiris, 2017). More knowledge is needed about the coping mechanisms female domestic returnees use to deal with their traumatic past and make sense of their multiple exploitation experiences, as part of their efforts to reintegrate into their home community. The aim of this article is to explore how Ethiopian female return migrants from Arabian Gulf countries narrate and cope with their racialized, gendered and economic exploitation experiences in the process of resettling back into life in Addis Ababa. To our knowledge, this is the first study of its kind to explore the post-migration coping mechanism of female domestic workers, and it is hoped that it will greatly add to our understanding of these group of migrants and how they cope with the their migration experiences. 
Forty-eight female Ethiopian return migrants, who had served as domestic workers in the Arabian Gulf countries, were interviewed for this study. These women were asked, in individual interviews and focus group discussions, to describe their experiences pre-migration, during the migration journey to the Arabian Gulf countries, and pre- and post-resettlement in the host country. A thematic content analysis was used to find out how the returnees cope with their exploitation experiences in the process of resettlement in Addis Ababa. In the next sections, we briefly discuss the coping strategies of Ethiopian female returnees from the Arabian Gulf, before presenting the methodological approach, followed by the analysis of the interviews and focus group discussions. Finally, we make some concluding remarks

\subsection{Coping strategies: Sense-making and benefit-finding}

The migration of Ethiopian women under the kafala system to places in the Arabian Gulf comes with a high risk of racialized, gendered and economic exploitation during the migration journey and while at work (De Regt, 2010; Minaye, 2012). Such women, particularly those who serve as live-in maids in domestic houses, are typically subjected to physical, sexual and psychological abuse, which can be classified as trauma (Bhugra, 2004; Ladegaard, 2015; Wickramage et al., 2017; Habtamu, Minaye \& Zeleke, 2017). When they return to their home country, these women must reintegrate and cope with their multiple exploitation experiences abroad.

Coping with the trauma of exploitation during the migration experience is different from coping after returning to the home country. Coping with exploitation abroad, as a female migrant domestic worker in the house of the foreign employer, is typically focused on changing the immediate situation. Such coping involves stress management strategies and immediate interactions with the exploiter, in direct, highly-stressful confrontations in a hostile, fundamentally unsafe environment (Pande, 2013; Van der Ham et al., 2015). However, coping with past multiple exploitation experiences in a context of reintegration involves different coping strategies. Returnees no longer face immediate danger, but are haunted by their memories. In their struggle to reintegrate, returnees typically seek to accept their 'fate' and attempt to move on with their lives in their home country, leaving their painful migration experiences behind them. In other words, the coping strategies of migrants are distinctive from returnees. Park and Folkman (1997) point out that victimized or violated people actively look for plausible reasons as to why traumatic incidents 
happen. Traumatized people attribute meaning to their adverse experiences in order to come to terms with them. Coping may also involve looking for perceived benefits. In their strategies, traumatized people make downward comparisons and positively re-interpret their adverse experiences (Park \& Folkman, 1997).

In the context of Ethiopian female return migrants from the Arabian Gulf, it is expected that their coping efforts revolve around a cognitive restructuring process to enable them to resettle in Addis Ababa. It is expected that returnees change their perspective and interpretation of the meaning of the racialized, gendered and economic exploitation they have experienced in the Arabian Gulf, rather than trying to solve the problem of their exploitation itself (problem-focused coping). It is also expected that they try to minimize the distress caused by their multiple exploitations (emotionfocused coping) (Wright, Crawford \& Sebastian, 2007; Lindio-McGovern \& Wallimann, 2009).

In the cognitive restructuring process that traumatized or exploited people undergo, two types of coping strategies can be distinguished: sense-making and benefit-finding (Davis, Nolen-Hoeksema \& Larson, 1998; Davis \& Nolen-Hoeksema, 2001; Currier, Holland \& Neimeyer, 2006; Wright $e t$ al., 2007). Sense-making is where the victim looks for some kind of explanation for the traumatic exploitation experience in order to comprehend it (Park \& Folkman, 1997; Davis et al., 1998). Benefit-finding is pursued in an attempt to get something positive (like personal growth and increased strength) out of the traumatic exploitation experience in order to accept it (Wright et al., 2007; Holland et al., 2006). Benefit-finding is a strategy that involves looking for something good amidst a bad experience. In the context of our enquiry into the coping strategies used by Ethiopian female return migrants from the Arabian Gulf countries to reintegrate into life in Addis Ababa, it is expected that both coping strategies are used in the narrations of their migration life under the kafala labor sponsorship system.

\subsection{Methodological approach}

The data used in this study is based on fieldwork conducted in Addis Ababa, Ethiopia from January to March 2015 and January to March 2016. In collaboration with three local non-governmental organizations (NGOs) working on the return and reintegration of Ethiopian women migrants from countries in the Arabian Gulf, returnees were recruited for participation in the study. One of the NGOs (Agar Ethiopia) focuses on programs related to the rehabilitation of traumatized returnees, 
mainly physically injured and mentally ill female returnees. Upon recovery, this NGO provides them with vocational skills training that might enable these returnees to generate income. The other two NGOs (Live Addis and WISE) mainly provide returnees with vocational skills training and start-up capital for businesses. The researchers participated in different workshops, reintegration assistance training, and social gatherings organized by the three local NGOs, with the aim of creating trust-based relationships with the returnees. These local NGOs selected the first few returnees for the interviews and focus group discussions, after which a snowball sampling method was used with participants referring other returnees, including those who had received support from government and NGOs and those who had not.

The first author of this article conducted the fieldwork. She speaks the same language as the returnees and is of a similar age. This helped the returnees to open up about very personal and sometimes difficult experiences they had in the Arabian Gulf countries. These interviews would not have been possible if the data collector had been foreign or male (Minaye, 2012).

A total of 48 Ethiopian women returnees who live in Addis Ababa participated in this study. The research objective, confidentiality of the discussions, and importance of audiotaping the interviews and group discussions were explained to the participants and their consent obtained. Data saturation - the redundancy of responses on major themes with limited new insights - was used as a guide to determine the appropriate number of participants for the study (Guest, Bunce \& Johnson, 2006). From the 48 participants, 15 lived with their sponsors (legally) throughout their time as a domestic worker in the Arabian Gulf countries. Another 26 of the participants first lived in the host country legally with their sponsors and then, because of the exploitation they experienced, ran away from their sponsors. These women then resided illegally in the host country, as the kafala system makes it illegal to stay in the host country without a sponsor. In addition, 7 participants did not have any sponsor throughout their migration experience. A total of 20 out of the 48 women returned involuntarily and 28 returned voluntarily (see Annex 5 for details). Of the participants in the study, 30 received reintegration assistance from NGOs or the government (in the form of basic business and vocational skills training, assistance to open small shops, and health-related assistance), whereas 18 did not receive any reintegration assistance. The reason for selecting the participants with diverse migration and reintegration experiences was to examine the role of 
kafala, voluntariness/involuntariness and reintegration support programs in the home country in order to evaluate the differences in the coping process and use of coping strategies by returnees.

The data collection process was a two-stage process starting with a focus group discussion and followed by an individual interview. The group discussion topics and semi-structured interview guidelines were prepared in English. The topic themes included general background information on pre-migration, migration, and post-migration (return) experiences. The guidelines were translated from English to Amharic, which is the local language of both the participants and the first author of this paper. To grasp the general migration process and possible exploitation experiences at each stage, data collection was started with focus group discussions. Four focus group discussions with six, four, eight and eight group members, respectively, were held with returnees with diverse migration and return experiences. The focus group discussions helped the researchers to identify the main exploitation experiences of the returnees at the different stages of the migration process.

Hesitation to discuss some traumatic experiences (such as rape and forced prostitution) in the focus group discussions was observed, possibly for fear of judgment by the group members, as these subjects are taboos in Ethiopian culture. To make sure all experiences were captured, including taboo subjects, and to triangulate the information obtained in the focus group discussions, in-depth personal interviews were held. Thirty-six returnees were interviewed to gather detailed information about their exploitation experiences and how they coped with them. The individual interviews provided participants with an opportunity to express their personal experiences, both of the migration and its aftermath, without fear of judgment by others. The returnees shared painful pre-migration, migration, and post-migration (return) experiences and how they coped with the experiences.

To make sure that every experience was captured and no experience lost, every new theme in the individual interviews was well explored till data saturation was reached. Both group discussions and individual interviews were audio-recorded. Focus group discussions lasted on average one hour and forty minutes and individual interviews lasted on average an hour. A transcript was made from the audiotape in Amharic by the first author and a research assistant. The transcribed 
documents were subsequently translated into English by a linguist and rechecked by the first author for consistency.

In analyzing the data, we focused on how the Ethiopian female return migrants who participated in this study described their exploitation experiences and how they cope with these experiences in the aftermath of their migration to the Arabian Gulf countries. We analyzed in depth the interview and focus group discussion transcripts to identify patterns in the returnees' narratives of exploitation at the different stages of the migration process. We focused on where, how, what and by whom their exploitation occurred. Coping strategies were coded in detail (using ATLAS.ti) according to each exploitation experience.

\subsection{Exploitation narratives and coping strategies while in the Arabian Gulf}

The Ethiopian female return migrants we interviewed typically explained that extreme poverty and the desire to change the economic status of their family motivated their migration journey to the Arabian Gulf countries. Almost all of the participants said that the dire economic situation they and their family were in was the main reason for migration. They reported using both legal and illegal agents/brokers to facilitate the migration process. Either way, legal or illegal, their migration process and exploitation experiences in the Arabian Gulf were similar. A great number of the Ethiopian female return migrants in our study reported that deception by both legal and illegal brokers regarding job description, amount of pay, and other issues is common.

Under the kafala system, migrants are bound by law to stay with their sponsor until the end of their contract period, which in most cases is two or three years (Pande 2013). Often their passport is confiscated by their employer and they are prohibited from going out of the house unless accompanied by their employer. The kafala system makes it difficult to change employer, even in the case of human rights violation. In our focus group discussions and interviews, respondents explained that the violation of basic human rights by their employer in their work place (employer's house) was commonplace. Most of the participants in our study mentioned exploitation experiences such as deprivation of food and rest, overwork, confinement, servitude to other households, beating and sexual assault. They also stated that they did not receive any legal protection from the Ethiopian embassy, agents or any official legal body in the Arabian Gulf. We analyzed and compared various coping strategies adopted based on migration experiences such as 
residing legally/illegally in the host country, and return experiences, such as voluntary/involuntary repatriation and receiving/not receiving reintegration assistance from NGOs or the government.

Residing legally in the host county means abiding by the kafala labor system, which requires staying in the employer's house as a live-in maid for the duration of the contract. In this way, temporary migration schemes, such as the kafala system, operate as a 'technology of servitude' (Yeoh et al., 2017). Ethiopian female domestic workers are systematically beaten and deprived of basic needs, so as to break their resistance and make them submit. They are violently governed through racial and gendered processes to make them accept their servile position. Employers are reported to frequently threaten domestic workers and Arab wives play a tyrannical role in the household in the sense that they tend to treat Ethiopian migrant women as their slaves and as potential mistresses.

Respondents who found themselves trapped in this situation of multiple exploitation described it as continuing till the end of the contract period. In this situation of fear and hopelessness, they mentioned feeling weak and ill at times, apathetic and unable to sleep properly, mainly out of fear of being assaulted at night. The thematic analysis of data revealed that migrants used emotionfocused coping strategies to deal with traumatic events while staying in the employer's house. Prayer and crying were frequently mentioned as coping mechanisms. In some cases, tolerating the situation in the hope of a better future was mentioned as a coping strategy.

On the other hand, 26 out of the 48 participants reported trying to cope by escaping from the employer's house, despite the risk. Hence, their coping strategy revolved around actively changing the situation (problem-focused). The narrative of the following participant shows the kind of despair that migrants experience:

Her husband had a gun and I always felt like using it for killing her. I decided to kill her and kill myself too. You think that committing such a crime is a big thing but killing somebody when you lose hope is not difficult. I stayed three months in such a horrible condition. I could not eat and lost a lot of weight. One day I found the opportunity and I ran out of the house in the middle of the night with my night wear only. (Interview 2) 
Most of our respondents narrated how they considered committing, or actually attempted to commit, suicide to escape from the unbearable situation they found themselves in. In our interviews with them, it appeared that the majority of migrant workers experienced extreme despair and a suicidal mental state during their time in the Arabian Gulf. This shows the unbearableness of the exploitation experiences, given that suicide is highly condemned in Ethiopia's religious traditions. In Ethiopia, those who commit suicide are widely regarded as 'condemned sinners' (Alem et al., 1999, p.65).

Given that under the kafala system working without a designated sponsor makes the migrants illegal in the Arabian Gulf region, Ethiopian migrant domestic workers can be easily imprisoned and deported. In other words, escaping the household exposes Ethiopian migrant domestic workers to new traumatic experiences. After escaping from their abusive sponsors, migrants come to depend on illegal brokers and traffickers to find a job and shelter, and, in most cases, the interviewees said that these agents lured them into sexual enslavement.

In sum, in the work place (their employer's house), migrant domestic workers experience multiple exploitations - all of our interviewees reported being exploited to varying degrees - that often converge to create an unbearable situation. Escape from their employer's house, often with the help of an illegal agent, however, can make matters worse, as these agents often force women into prostitution. Regarding coping strategies, both problem-focused coping (escaping from the employer and trying to change the situation) and emotion-focused coping (crying and praying to deal with the distress caused by the migration process) were found to be used as coping mechanisms during migration.

\subsection{Coping strategies upon returning to Addis Ababa}

Once Ethiopian migrant workers return from the Arabian Gulf and resettle in Ethiopia, they are forced to cope with the exploitation they have experienced abroad as migrant workers. From our interviews (from their narratives of coming to terms with their experiences), it appears that the sense-making (attributing cultural meaning or sense to experiences) by returnees is typically racialized. That is, returnees make sense of their exploitation experiences by attributing the 'otherness' of the Arabs as an excuse for their wrongdoing. 
This racialized sense-making is most clearly illustrated by a returnee who escaped the house where she was employed because of physical exploitation (lack of sleep and food deprivation) with the help of an Ethiopian agent. To her dismay, she narrates, she found that she was to live in a house with four Ethiopian male brokers, who all expected to have sexual relations with her. She survived an attempt of rape by one of the men and decided to escape from the brokers' house and move to another city, via a dangerous journey; on her way she was raped by two Saudi policemen. To make sense of what she went through in Saudi Arabia, she has constructed a racialized understanding of her experience in the following way:

I was brave enough to escape from the danger of rape while I was living with the Ethiopian guys, but I was raped by Arab policemen. Thank God there were only two of them. If there were more, they might have raped us in a group... I am glad I was not raped by the Ethiopian men, though, because I would not stop thinking about it, and I might have developed a lifelong hatred and rage towards every Ethiopian man. But with the Arabs, if you think they are people from another country, it is still hard, but it is easier to let go and forgive. I literally prefer to die than to be raped by an Ethiopian man. (Interview 1)

This returnee makes sense of being raped by Saudi Arabian policemen through a racialized explanation: rape fits with being Arab. In her sense-making, rape does not fit with being Ethiopian (rape by Ethiopian men is strongly denounced). This is not a unique experience and narrative, but quite common among Ethiopian returnees. Despite the fact that Ethiopia is highly patriarchal, and domestic violence and masculine dominance is prevalent and implicitly accepted (Kedir \& Admasachew, 2010), our respondents denounced the violence they suffer at the hands of Ethiopians in the Arabian Gulf. From their narratives it was implied that they expect benevolence and Ethiopian solidarity while abroad in a hostile environment. Such violence grossly violates their (nationalistic) expectations. With Arabs, they have lower expectations. Such racialization apparently facilitates sense-making, while at the same time marking the limits of sense-making as a coping strategy. They cannot cope with the experience of being raped by an Ethiopian in the Arabian Gulf. In other words, not all experiences of exploitation can be made sense of by the returnees. Our respondents said that they find it most difficult to make sense of the abusive conduct of Ethiopian agents, given the absence of a racial explanation. These women typically say that they 
cannot understand why their fellow Ethiopians enslaved them, yet they do expect, and perhaps even accept as a sense-making strategy, the tyranny of Arab agents.

To come to terms with their experiences upon return to Addis Ababa, returnees typically need to use more than one coping strategy. In addition to sense-making, benefit-finding appears to be a common strategy used by returnees to come to terms with their experiences in the Arabian Gulf. Returnees typically look for something positive (like having survived) in their experiences and usually articulate this in religious language. They compare their own suffering to even less fortunate domestic workers (including those who did commit suicide), and they imagine the worst situation they could possibly, and plausibly, have been in. In other words, they emphasize that their experiences could have been worse, thereby minimizing their own negative experiences. For instance, those who have been raped or subjected to brutal physical or psychological exploitation, explain that they are thankful that they have been able to return to Addis Ababa safely. They compare themselves with those who lost their life in the Arabian Gulf or who have been disabled or disfigured due to the physical violence of their Arab employers. As one returnee articulated:

Praise God, I didn'tface other bad things... I really regret very much [going to the Arabian Gulf]. I faced all these agonies and troubles... I feel happy because I am alive. When I observe several disabled women returnees, I praise God for making me able. (Interview 9)

Benefit-finding appears to be a common coping strategy among returnees. The vast majority of participants used it. Some returnees try to cope with their experiences by making them a constitutive part of their new life in Addis Ababa. Such returnees develop new life principles in the aftermath of their migration experiences. Such benefit-finding is expressed in terms like:

Allah be praised! Unless you travel somewhere, you would not appreciate the good things in your country. (Interview 19)

Or,

You will be stronger as a person because you pass through a difficult path there and ...you think you should work hard here also. (Focus group discussion 2)

The adoption of such attitudes and consideration of the exploitation experience as a learning experience that is vital to personal growth and has value in the post-migration phase, are not 
uncommon. In other words, from our interviews and focus group discussions it appears that benefit-finding is used as a strategy to distinguish between the past and present, and to distinguish between places. There and then is constructed as a school for present success, which is realized via the capacity for suffering and hard work that has been learned in the Arabian Gulf.

Apart from benefit-finding in their own survival or their own personal development, returnees also find benefits for their family. Returnees typically do not generate the financial and material gains that they expected from domestic work in the Arabian Gulf (Nisrane et al. 2017). The majority of respondents stressed that, as migrant workers, they sent their meager salary almost entirely home to family members in Ethiopia. Almost all of them stressed that they felt betrayed when they learned that their parents, husband or children did not save anything for them. Some of the returnees believed their family had saved enough money so that they would be able to start a small business, as they had dreamed about before migrating to the Arabian Gulf. Very few of the returnees recouped some of the remittances they had sent. The majority of the returnees said that they are financially dependent on their family now. Although returnees tend to be proud of the sacrifices they have made for their family, almost all of them emphasize that this sacrifice has been too extreme. They try to cope with this bitter experience through benefit-seeking. They focus on the blessings that they have brought to their family, typically by comparing their family's condition before and after their migration. That is, they emphasize that their earnings may not have financially benefited them personally, but that they have benefited their families, even if this is marked by betrayal. They emphasize the benefit for their family and de-emphasize the experience of being betrayed by their family and being left with nothing for themselves. The following quote illustrates how benefit is found in personal sacrifice for the family.

Even though I sacrificed a lot and passed through difficult paths, I changed a lot in my family life and I am glad I went... This house is rebuilt again and well-furnished compared to what it used to be. It was about to fall apart. My younger brother and sisters were able to go to a better school, were able to eat better, and were able to dress better. They were able to follow their education without the hassle of financially helping my mom. At least they did not pass through the difficult childhood I passed through. It was better for them. Of course, I did not achieve my ultimate goal, but it changed a lot of things for good in my family. (Interview 1) 
This returnee uses benefit-seeking as a coping strategy by enacting a positive migrationdevelopment nexus (Piper, 2008, p. 1290) in her narrative of suffering. In other words, in the story of this particular returnee, the migration-development nexus is part of a benefit-seeking strategy, marked by her painful migration experience and framed as sacrifice that benefits the whole family, ultimately giving her brother and sisters a future.

To sum up, the returnees interviewed use sense-making and benefit-seeking (both for themselves and their families) as strategies for coping with their exploitation experiences. Racialized sensemaking enables the returnees to look for some kind of explanation that helps them to come to terms with their past in the Arabian Gulf and to make sense of their experiences so that they can go on with their lives. Their sense-making strategies must be distinguished from their benefit-seeking strategies, yet the two strategies cannot be separated. While trying to make sense of their experiences, the majority of the returnees applied benefit-seeking strategies. These include making comparisons with less fortunate domestic workers in the Arabian Gulf, imagining worse scenarios retrospectively to enable them to claim that they could have been even worse off, making their experience a 'school' for personal development, and making stories of personal sacrifice for the greater good of the family. In this way the returnees comfort themselves.

Finally, the researchers tried to determine if there were differences in coping strategy based on return experience (voluntary/involuntary) and receiving reintegration assistance or not; however, the coping strategies used to cope with past trauma were found to be similar for most of the returnees and no difference was seen in the coping process of the returnees based on their migration or return experiences. The support programs provided by the NGOs and the government focused on enabling the returnees to be self-sufficient financially and did not in any way affected their coping process in relation to their past traumatic experiences.

\subsection{Concluding remarks}

In this paper, we reconstruct, on the basis of interviews and focus group discussions, returnee narratives of racialized, gendered and economic exploitation in Arabian Gulf countries and stories of coping with these experiences in the process of resettling in Addis Ababa, as articulated by Ethiopian female return migrants. Returnees who have lived under the kafala system tell of multiple exploitation experiences at different stages of the migration process and in different places 
(by agents and in their employer's house), which are marked by patriarchal constructions of gender, race, class and sexuality, which leave female Ethiopian domestic workers highly vulnerable to exploitation (Fluri \& Piedalue, 2017).

To deal with adverse conditions while in exile, migrants use problem-focused coping (such as escaping from their employer's house) and emotion-focused coping (such as trying to minimize the distress caused by praying or crying). Returnees use sense-making and benefit-seeking as coping strategies upon their return to their home country to come to terms with the aftermath of their traumatic experiences. In benefit-seeking, they try to cope with their migration-related trauma by making downward comparisons with worse-off migrants and by comparing their own situation with possible worse scenarios. Also, they find benefit in the sense that they consider their experiences as the price paid for the betterment of their families or as a way of 'learning the hard way' - a learning that they believe can be of benefit in their lives in Addis Ababa.

Their sense-making strategy is most striking. From our research it appears that racial differences between Arabs and Ethiopians help the Ethiopian returnees to make sense of their traumatic experiences in the Arabian Gulf. Through racialized sense-making returnees manage to understand the exploitation - particularly sexual violence - that they have suffered, in the sense that they stereotype Arab men as rapists, whereas they do not stereotype Ethiopian men in that way. As one implication of such racialized sense-making, returnees could not make sense of abuse and rape by Ethiopian agents who live in the Gulf countries.

In other words, while experiences of exploitation, such as being raped, may be similar, the way of coping may differ. In terms of coping, it makes a difference to the returnees whether they are raped by an Arab or Ethiopian man - and this difference has a major impact on their ability to come to terms with the experience of being raped. This raises the question of why returnees do not try to understand or accept rape and sex trafficking by their own compatriots. This is a puzzling question, especially if we consider that, in patriarchal Ethiopia, violence against Ethiopian women is 'tolerated' at an individual as well as a societal (rural and urban) level (Kedir \& Admasachew, 2010, p. 438). In a study by Kedir and Admasachew (2010), it appears that many Ethiopian women do not view sexual exploitation as a crime and do not report it to the authorities - the exploitation by perpetuators tends to be normalized and masculine domination is tacitly 'accepted' by women. Family pressure to uphold gender conventions, cultural pressure to meet moral standards of gender 
in patriarchal society, and the resistance of men may explain such 'acceptance' (Parreñas, 2005). And yet, the Ethiopian women who participated in our study found it difficult to accept or tolerate the sexual exploitation of their male and female compatriots in the Arabian Gulf. It may well be that the places where the exploitation occurred may have an impact on them accepting or denouncing the violence: the Ethiopian female migrants expected support from their compatriots who live in the Gulf region as a form of Ethiopian solidarity abroad, only to find out that they were deceived. Also, dealing with violence in strange places - outside one's own known surroundings - has an impact on the identity of Ethiopian migrants, which is to say that identity is dynamic and shaped by temporal, power and spatial relations (Silvey, 2006; Van Blerk, 2011; Ye, 2014).

While this paper is one of the first to explore the coping strategies of female return migrants, it is not without limitations. We conducted our study after the migrants returned and had stayed in Addis Ababa for at least a year. Having returned for a year or more may have had an impact on migrants' sense-making process. Perhaps a different result may have been found if interviews and focus group discussions were organized with returnees immediately after their return from the Arabian Gulf, before they were confronted with the reality of resettlement in Addis Ababa. For future studies into returnees' narratives of exploitation and coping strategies, we recommend considering various timespans and their possible impact on sense-making strategies. Moreover, to better understand migration-related trauma and associated coping mechanisms, we recommend expanding the scope of respondents, for instance, to include other types of migrants and destinations, as migrant workers may experience different types of exploitation by smugglers and traffickers and Gulf state authorities (like police officers). 


\section{References}

Anbesse, B., Hanlon, C., Alem, A., Packer, S., \& Whitley, R. (2009). Migration and mental health: A study of low-income Ethiopian women working in Middle Eastern countries. International Journal of Social Psychiatry, 55(6), 557-568.

Bajracharya, R., \& Sijapati, B. (2012). The Kafala system and its implications for Nepali domestic workers. Policy Brief. Kathmandu: Centre for the Study of Labour and Mobility (CESLAM).

Bhugra, D. (2004). Migration, distress and cultural identity. British Medical Bulletin, 69 (1), 129-141.

Bosmans, K., Mousaid, S., De Cuyper, N., Hardonk, S., Louckx, F., \& Vanroelen, C. (2016). Dirty work, dirty worker? Stigmatisation and coping strategies among domestic workers. Journal of Vocational Behavior, 92, 54-67.

Currier, J. M., Holland, J. M., \& Neimeyer, R. A. (2006). Sense-making, grief, and the experience of violent loss: Toward a mediational model. Death Studies, 30(5), 403-428.

Davis, C. G., Nolen-Hoeksema, S., \& Larson, J. (1998). Making sense of loss and benefiting from the experience: Two construals of meaning. Journal of Personality and Social Psychology, 75(2), 561.

Davis, C. G., Wortman, C. B., Lehman, D. R., \& Cohen Silver, R. (2000). Searching for meaning in loss: Are clinical assumptions correct? Death Studies, 24(6), 497-540.

Davis, C. G., \& Nolen-Hoeksema, S. (2001). Loss and meaning: How do people make sense of loss? American Behavioral Scientist, 44(5), 726-741.

Demissie, F. (2018). Ethiopian female domestic workers in the Middle East and Gulf States: An introduction. African and Black Diaspora, 11(1), p. 1-5.

De Regt, M. (2010). Ways to come, ways to leave: Gender, mobility, and il/legality among Ethiopian domestic workers in Yemen. Gender \& Society, 24(2), 237-260.

Dervic, K., Amiri, L., Niederkrotenthaler, T., Yousef, S., Salem, M. O., Voracek, M., \& Sonneck, G. (2012). Suicide rates in the national and expatriate population in Dubai, United Arab Emirates. International Journal of Social Psychiatry, 58(6), 652-656.

Fluri, J. L., \& Piedalue, A. (2017). Embodying violence: Critical geographies of gender, race, and culture. Gender, Place \& Culture, 24(4), 534-544.

Frantz, E. (2013). Jordan's unfree workforce: State-sponsored bonded labour in the Arab region. The Journal of Development Studies, 49(8), 1072-1087.

Guardian, The. (2012). Alem Dechasa's choice: An impossible decision and a lonely death. The Guardian, 9 April 2012.

Guest, G., Bunce, A., \& Johnson, L. (2006). How many interviews are enough? An experiment with data saturation and variability. Field Methods, 18(1), 59-82.

Habtamu, K., Minaye, A., \& Zeleke, W. A. (2017). Prevalence and associated factors of common mental disorders among Ethiopian migrant returnees from the Middle East and South Africa. BMC Psychiatry, 17(1), 144.

Holland, J. M., Currier, J. M., \& Neimeyer, R. A. (2006). Meaning reconstruction in the first two years of bereavement: The role of sense-making and benefit-finding. Omega-Journal of Death and Dying, 53(3), 175-191.

Jureidini, R., \& Moukarbel, N. (2004). Female Sri Lankan domestic workers in Lebanon: A case of contract slavery? Journal of Ethnic and Migration Studies, 30(4), 581-607.

Kebede, E. (2002). Ethiopia: An assessment of the international labour migration situation: The case of female labour migrants. Geneva: International Labour Organization.

Kedir, A., \& Admasachew, L. (2010). Violence against women in Ethiopia. Gender, Place \& Culture: A Journal of Feminist Geography, 17(4), 437-452.

Kronfol, Z., Saleh, M., \& Al-Ghafry, M. (2014). Mental health issues among migrant workers in Gulf Cooperation Council countries: Literature review and case illustrations. Asian Journal of Psychiatry, 10, 109-113.

Ladegaard, H. J. (2015). Coping with trauma in domestic migrant worker narratives: Linguistic, emotional and psychological perspectives. Journal of Sociolinguistics, 19(2), 189-221. 
Lindio-McGovern, L., \& Wallimann, I. (eds). (2009). Globalization and third world women: Exploitation, coping and resistance. Farnham: Ashgate.

Mahdavi, P. (2013). Gender, labour and the law: The nexus of domestic work, human trafficking and the informal economy in the United Arab Emirates. Global Networks, 13(4), 425-440.

Mantouvalou, V. (2015). 'Am I free now?' Overseas domestic workers in slavery. Journal of Law and Society, 42(3), 329-357.

Minaye, A. (2012). Trafficked to the Gulf states: The experiences of Ethiopian returnee women. Journal of Community Practice, 20(1-2), 112-133.

Nisrane, B. L., Morissens, A., Need, A., \& Torenvlied, R. (2017). Economic reintegration of Ethiopian women returned from the Middle East. International Migration. doi:10.1111/imig.12358.

Nisrane, B. L., Ossewaarde, R., \& Need, A. (2019). The exploitation narratives and coping strategies of Ethiopian female return migrants from the Arabian Gulf. Journal of Gender, Place \& Culture.

Pande, A. (2012). From 'balcony talk' and 'practical prayers' to illegal collectives: Migrant domestic workers and meso-level resistances in Lebanon. Gender \& Society, 26(3), 382-405.

Pande, A. (2013). 'The paper that you have in your hand is my freedom': Migrant domestic work and the sponsorship (kafala) system in Lebanon. International Migration Review, 47(2), 414-441.

Park, C. L., \& Folkman, S. (1997). Meaning in the context of stress and coping. Review of General Psychology, 1(2), 115.

Parreñas, R. S. (2005). The gender paradox in the transnational families of Filipino migrant women. Asian and Pacific Migration Journal, 14(3), 243-267.

Perruchoud, R., \& Redpath-Cross, J. (eds). (2011). International migration law: Glossary on migration. Geneva: International Organization for Migration.

Piper, N. (2004). Rights of foreign workers and the politics of migration in South-East and East Asia. International Migration, 42(5), 71-97.

Piper, N. (2008). Feminisation of migration and the social dimensions of development: The Asian case. Third World Quarterly, 29(7), 1287-1303.

Piper, N. (2010). Temporary economic migration and rights activism: An organizational perspective. Ethnic and Racial Studies, 33(1), 108-125.

Shin, K. R., Mi, Y. K., \& Seung, E. C. (2009). Methods and strategies utilized in published qualitative research. Qualitative Health Research, 19(6), 850-858.

Silvey, R. (2006). Geographies of gender and migration: Spatializing social difference. International Migration Review, 40(1), 64-81.

Silvey, R. (2009). Development and geography: Anxious times, anemic geographies, and migration. Progress in Human Geography, 33(4), 507-515.

Stiell, B., \& England, K. (1997). Domestic distinctions: Constructing difference among paid domestic workers in Toronto. Gender, Place \& Culture: A Journal of Feminist Geography, 4(3), 339-360.

Tyner, J. A. (2013). Population geography I: Surplus populations. Progress in Human Geography, 37(5), 701-711.

Van Blerk, L. (2011). Negotiating boundaries: The sex work identities of 'bar girls' in Nazareth, Ethiopia. Gender, Place \& Culture, 18(02), 217-233.

Van der Ham, A. J., Ujano-Batangan, M. T., Ignacio, R., \& Wolffers, I. (2015). The dynamics of migrationrelated stress and coping of female domestic workers from the Philippines: An exploratory study. Community Mental Health Journal, 51(1), 14-20.

Wickramage, K., De Silva, M., \& Peiris, S. (2017). Patterns of abuse amongst Sri Lankan women returning home after working as domestic maids in the Middle East: An exploratory study of medico-legal referrals. Journal of Forensic and Legal Medicine, 45, 1-6.

Wright, M., Crawford, E., \& Sebastian, K. (2007). Positive resolution of childhood sexual abuse experiences: The role of coping, benefit-finding and meaning-making. Journal of Family Violence, 22(7), 597-608.

Ye, J. (2014). Migrant masculinities: Bangladeshi men in Singapore's labour force. Gender, Place \& Culture 21 (8):1012-1028. 
Yeoh, B. S. A., \& Ramdas, K. (2014). Gender, migration, mobility and transnationalism. Gender, Place \& Culture, 21(10), 1197-1213.

Yeoh, B. S. A., Platt, M., Khoo, C. Y., Lam, T., \& Baey, G. (2017). Indonesian domestic workers and the (un)making of transnational livelihoods and provisional futures. Social \& Cultural Geography, $18(3), 415-434$. 


\title{
CHAPTER 3
}

\section{Economic Reintegration of Ethiopian Women Returned From the Middle East ${ }^{3}$}

\begin{abstract}
Current migration studies and policy reviews neglect the vital link between migration experiences of labor migrants and their return and reintegration process. The objective of this study is to highlight the phenomenon and bring the matter to policy makers' attention. This study uses indepth interviews and a series of focus group discussions to explore the relationship between migration experiences and economic reintegration of unskilled Ethiopian women who are return migrants from Middle Eastern countries ${ }^{4}$. Economic reintegration, which in its basic form is about securing a livelihood, is a challenge for most returnees. The reason relates to the migration settings, preparedness and reintegration assistance in the home county. Reintegration assistance for involuntary returnees is beneficial only for those who manage to obtain some savings out of their migration. The findings imply the need for policy improvements regarding the working conditions of female domestic workers in the host countries and reintegration programs in the home countries.
\end{abstract}

\subsection{Introduction}

Ethiopia is one of the largest sending countries of female domestic workers to Middle Eastern countries (De Regt, 2010). About 1,500 girls were estimated to leave each day to the Middle East before the Ethiopian government banned all work-related movement through official channels in 2013. The ban was installed after the reported abuse and exploitation of Ethiopian women in the destination countries (Jones et al., 2014). Unfortunately, the ban did not stop the movement but

\footnotetext{
${ }^{3}$ The paper is published as Nisrane, B. L., Morissens, A., Need, A., \& Torenvlied, R. (2017). Economic reintegration of Ethiopian women returned from the Middle East. International Migration.

${ }^{4}$ The returnees who participated in this study traveled to the Middle Eastern countries of Bahrain, Jordan, Kuwait, Lebanon, Qatar, Saudi Araba, United Arab Emirates, and Yemen, one or more times. In this dissertation the terms Middle Eastern countries and Arabian Gulf countries are used interchangeably because most of the Middle Eastern countries where the participants migrated to are also a member of the six Arabian Gulf Countries (Saudi Arabia, Kuwait, the United Arab Emirates, Qatar, Bahrain, and Oman).
} 
rather caused an increase in the number of women leaving through illegal channels. On the other hand, the return and reintegration of these migrants into the socio-economic context of their country did not get any attention until the expulsion of about 160,000 Ethiopian irregular migrants from Saudi Arabia following the Arab spring. Both the Ethiopian government and local and international NGOs responded to the problem and provided reintegration assistance for the returnees. The assistance included psychological counselling programs; vocational training in various areas such as cooking, hairdressing, urban agriculture like poultry raising and producing construction materials for six to eight weeks; work sheds; credit facilities; and health care for those who were traumatized (De Regt \& Tafesse, 2016). The influence of reintegration assistance and migration experiences on the reintegration process of return migrants is significant (Ruben et al., 2009). However, little is known as to how these factors affect the return and reintegration process of unskilled domestic workers. By analyzing the lived experience of female return migrants from the Middle East, this study answers the following two questions:

- How do past migration experiences under the kafala labor sponsorship system affect the preparedness to return and economic reintegration of unskilled Ethiopian women returnees?

- To what extent does reintegration assistance and support in the home country enable returnees to build sustainable livelihoods?

The answers to these questions add to the understanding of the economic reintegration process of this large but understudied group of labor migrants. The large majority of literature regarding domestic workers concentrated on the financial, human and sexual exploitation and abuse of the migrants, particularly in the Middle Eastern countries. See, for example, the studies by Belay (2014), Beydoun (2006), Fernandez (2010), Jureidini and Moukarbel (2004), and Pande (2013). There is little literature that shows the impact of such precarious migration experiences at the destination and of post-return reintegration assistance programs in the home country on domestic return migrants' ability to build a sustainable livelihood. Our study contributes greatly in this regard. In addition, the answers enlighten policy makers on devising strategies that bring about the successful economic reintegration of return migrants. In this study, the ability of return migrants to secure their livelihood was taken as an indicator of successful economic reintegration (Perruchoud \& Redpath-Cross, 2011). 
The article starts with a brief overview of literature regarding the migration experience of domestic workers in contract labor programs, preparedness, post-return assistance programs and the impact of these on their reintegration in the home country. Next, we present the methods section, followed by results and discussion. In the concluding section, we provide answers to our research questions, discuss the strengths and limitations of our approach and draw conclusions about the policy implications of our findings.

\subsection{Theory}

The migration experience of female domestic migrants is characterized by restricted resource mobilization, limited or no legal protection and precarious working conditions. A number of scholars identify the root causes that put domestic migrant workers in such an underprivileged position. According to Mantouvalou (2015), the fact that female domestic migrants' responsibilities take place inside a house, away from the public eye or and authorities' inspection, contributes to the problem. Other scholars argue that a migration setting that ties domestic workers with a specific employer is the main cause for the constrained migration experience of domestic migrant workers (Belay, 2014; Jureidini \& Moukarbel, 2004; Mahdavi, 2013; Pande, 2013). In our study, the focus is on the migration setting and the labor sponsorship program found in most Middle Eastern countries. Many Middle Eastern countries have a labor sponsorship program called the 'kafala' by which foreign domestic workers are only permitted to enter the host countries with the help of a specific sponsor. The designated sponsor assumes the legal and financial responsibilities of the migrants for a specific length of time (Pande, 2013). Legally, the sponsor is also the employer. However, there are circumstances where citizens act as a sponsor for migrants working for others in exchange for money (Moors \& De Regt, 2008). Hence, it is important to differentiate between the categories of domestic workers that exist in the Middle Eastern countries: first, those who are regular and work under a contract for a specific employer/sponsor who invited them; second, those who run away from their sponsor or enter into the country under the pretext of pilgrimage, or crossing the sea, and in all cases are irregular and work illegally in the country; third, those who buy an 'iquama' (resident permit), which makes them regular in the country even though the process of getting it might not always be legal (De Regt, 2010; Jureidini \& Moukarbel, 2004; Moors \& De Regt, 2008). Domestic workers in the second and third category are better off because they can change employers when there is a need. Meanwhile, domestic workers in the first 
category are vulnerable to exploitation and abuse by sponsors/employers to whom their legal existence is tied (Mahdavi, 2013).

Leaving or changing one's sponsor, who in most cases is also the employer, requires the consent of the sponsor who facilitated the migration; otherwise, it makes the migrant worker an illegal resident in the host country (Jureidini \& Moukarbel, 2004; Mahdavi, 2013; Pande, 2013). Such dependency on sponsors increases migrant domestic workers' vulnerability to exploitation. Physical and psychological exploitation such as overwork, starvation, rape, intimidation, insult, restrictions on movement and social connection, confiscation of passports and financial exploitation such as inability to change workplaces and denial or underpayment of wages are the most common migration features of female domestic workers in the Middle Eastern countries (Fernandez, 2011; Frantz, 2008; Jureidini, 2010; Jureidini \& Moukarbel, 2004; Minaye, 2012; Pande, 2013).

Several studies show that the aftermath of a precarious migration experience on the return and reintegration of female domestic workers is significant. For example, Anbesse et al. (2009) analyzed mental health problems encountered by female domestic workers returning from the Middle East. Their results showed that an increasing number of women returning from the region experience mental disorders because of the extreme hardship they pass through at the destination. Other studies show that social reintegration presents challenges for women returnees such as stigma, broken social and family ties and marital conflicts (Bélanger \& Rahman, 2013; Parreñas, 2005; Ullah, 2013). Inability to change employers, underpayment or denial of wages, limited social contacts and restricted movement are migration experiences that put strain on economic reintegration of contract domestic workers upon return (Minaye, 2012).

On the other hand, based on a study of 168 Ethiopian involuntarily returned domestic workers from Saudi Arabia - both men and women - De Regt and Tafesse (2016) observe that lack of preparedness for return is the primary reason for poor social and economic reintegration of domestic workers. Preparedness constitutes elements of both readiness and willingness to return (Cassarino, 2004). Readiness refers to accumulating the required resources that facilitate the return and reintegration processes, while willingness refers to the existence of free will accompanied by relevant information about the home country. For domestic workers, particularly in the Middle Eastern countries, the labor sponsorship system (kafala) is assumed to affect their preparedness in 
two ways. First, the system provides full control of the legal existence of the domestic migrant to the sponsor. This limits the resources mobilization process of the domestic migrants by putting them in a vulnerable position for physical, psychological and financial exploitation. Second, if female domestic workers escape from their sponsors, even for the reason of exploitation and abuse, they become illegal residents in the country (Pande, 2013). This is assumed to affect both the readiness and willingness of women migrants to return, as they might be deported back to their country if authorities catch them.

Social or economic conditions of the returnee's home country (Cassarino, 2004) and reintegration assistance programs such as financial, material and human reintegration assistance programs also play a role in the reintegration of return migrants (Grazhdani, 2013; Ruben et al., 2009). Unfortunately, the role of reintegration assistance in returnees' reintegration process is the least studied topic in the return and reintegration area. Few studies have examined the impact of postreturn assistance programs on returnees' reintegration processes (see for example De Regt \& Tafesse, 2016; Ruben et al., 2009). In most cases, post-return assistance programs are provided to involuntarily returned migrants, and they focus on short-term goals rather than bringing long-term socio-economic reintegration (Arowolo, 2000; De Regt \& Tafesse, 2016). These studies suggest that in order to bring long-term benefits, assistance programs need not be just an ad hoc response to emergency return programs but rather continuous programs that provide service for both voluntarily and involuntarily returning migrants.

In sum, the above studies indicate the interrelated relationship between migration experience, preparedness, post-return assistance and reintegration of return migrants. Cassarino (2004, p. 173) best summarizes the link between these four variables. According to Cassarino's (2004) preparedness theory, successful reintegration depends on migrants' preparation to return, which requires time, resource mobilization and willingness to return. However, in order to understand the return and reintegration process of unskilled contract labor migrants in the domestic sector, particularly in Middle Eastern contexts, the theory needs to be adapted in three ways. First, the theory of preparedness assumes that all labor migration experiences lead to a smooth accumulation of tangible and intangible resources if optimal time is provided. This may not always be the case for unskilled labor migrants, who often work under the domination of a specific sponsor. Migration settings that tie migrants to a specific sponsor may affect both the readiness and willingness of the 
returnees. Second, the theory needs to incorporate the influence of personality traits and abilities of the migrant to accumulate resources in the host country and use them in the home country, which are also very important for successful reintegration. Third, the theory needs to take into account involuntary return, which is a common phenomenon among domestic workers in the Middle Eastern countries because of disputes with the sponsor or illegal status in the host country. This study adapted the theory of preparedness and included migration settings, personality characteristics and reintegration assistance programs in its analytic framework.

\subsection{Methods}

Qualitative data collection and analysis methods are well suited to explore and understand the lived experience of migrants (Shin et al., 2009). Accordingly, a qualitative approach in collecting and analyzing the data was chosen. Data was collected from January to July 2015 through a focus group discussions and individual interviews. Summaries of the focus group discussions and individual interviews were reported back to study participants and checked for accuracy.

To examine the variation in the reintegration process with differing migration and return experiences, study participants were selected by means of a stratified purposeful sampling method (Patton, 2002). The first stratification criterion was whether or not the participant received reintegration assistance in the home country. Then two additional variables - length of stay in the host country and working with the kafala labor sponsorship system or not - were used.

Two local NGOs working in reintegration of women return migrants from the Middle East were contacted to select women returnees who have received reintegration assistance. The organizations contacted were Women in Self Employment (WISE, www.wise.org.et) and Agar Ethiopia (www.agarethiopia.com). Both are located in the Ethiopian capital, Addis Ababa. To recruit participants who had not received any reintegration assistance, we used a snowball sampling method. We asked the women participants in WISE and Agar to recruit women in their communities who did not receive any reintegration assistance, and then those who were referred brought others until the selection process was completed successfully.

In total, 32 informants were selected equally from the two groups - those who had received reintegration assistance and those who had not. Within these groups, whether they had worked with the kafala sponsorship system or not and length of stay in the host country were further used 
to categorize the participants (Patton, 2002). The sub-categories were used to make comparisons of the returnees' return preparedness (Cassarino, 2004) and of the reintegration processes in the home country. In addition, as reintegration is a process and it needs time, the participants selected had stayed at least one year in their home country since their return. After selecting participants who fit our study design, the objective of the study was explained to the participants and the confidentiality of the discussions was assured. Written consent of the informants was obtained, followed by key demographic information through semi-structured questionnaires.

Out of the 32 women participating in the study, 26 took part in focus group discussions. Four focus group discussions were held. The first group was organized with six returnees who received reintegration assistance and stayed in their host countries for less than five years. The second group consisted of four returnees who received reintegration assistance and stayed more than five years in the host country. The third group consisted of eight returnees who had not received any reintegration assistance and stayed more than five years. The fourth group was organized with eight returnees who had not received any reintegration assistance and stayed in the host country for less than five years. All groups were comprised of women who worked legally, illegally or both in the host country. Annex 1 shows the details of the participants in this study.

The focus group discussions allowed us to observe the general picture of the reintegration process in relation to the different migration and return experiences. To get detailed data on individual experiences and triangulate the information obtained in the focus group discussions, in-depth personal interviews were held with 14 participants using semi-structured interview guidelines. The selection for the individual interviews was made with the same criteria used for the focus group discussions. Data saturation was considered in deciding when to stop the interviewing process. Among the 14 women who took part in the individual interviews, 8 participated in the focus group discussion and 6 did not. When no additional information was obtained from the interviews, the interviewing process was stopped. The in-depth personal interviews provided rich and detailed information on the individual experiences of the women, particularly about those aspects that the returnees felt embarrassed to talk about in the focus groups such as their involvement in drugs or prostitution.

Both the focus group discussion topics and semi-structured interview guidelines were prepared in English and then translated to Amharic, which is the local language of the first author and the 
informants. All discussions were held in Amharic and were audio-recorded. Focus group discussions lasted on average 1 hour and 40 minutes, whereas individual interviews lasted on average an hour. A transcription was made from the audiotape. The transcribed documents were translated into English by a linguist and checked by the first author for consistency of meanings. The results of the focus group discussions were triangulated with the in-depth interview, and both reflected similar outputs.

The first two authors of this paper analyzed the data collaboratively. A combination of a directed approach to content analysis method (Hsieh \& Shannon, 2005) and a thematic analysis method was used to analyze the data. ATLAS.ti software was used to facilitate the coding process. The first, second and third authors of this article agreed on emerging themes, theme categorization and relationships.

\subsection{Results and discussion}

The data collected were used to analyze the lived experiences of women returnees from various Middle Eastern countries, but mainly Saudi Arabia. Most of the returnees had travelled at least twice or more to different countries in the Middle East, predominantly Lebanon, Kuwait and Yemen, before they eventually settled in Saudi Arabia. Only 8 participants out of the 32 lived under their sponsors throughout their migration period. Eighteen of the participants first lived in the host country legally with their sponsors and then ran away from their sponsors to reside in the host country illegally. Six of the participants did not have any sponsor throughout their migration as they entered through the country under the pretext of 'Hajji and Umrah' as Muslim pilgrims and overstayed their visa periods to work illegally in the host country. Annex 1 shows the personal profile of the respondents.

Most of the women in this study could not secure their livelihood after their return and are financially dependent on their family or relatives for their survival. Remigration is found to be a major strategy contemplated by the returnees, as they feel 'unfit' for the socio-economic conditions in the home country.

\subsubsection{Readiness to return}

Readiness, which is defined as mobilizing the resources that are necessary for return and reintegration (Cassarino, 2004), was found to be the main factor for success in economic 
reintegration for the unskilled women returnees. Those who had the most savings were better reintegrated upon their return home. Another significant point our study revealed is that, for female domestic workers returning from Middle Eastern countries, resource mobilization and success in reintegration are not directly related but are rather mediated by the ability to get back the mobilized resources in the home country. Because of their specific migration setting, domestic workers in the Middle East cannot use legal financial institutions by themselves to save their money in the host country during their migration. The legal system encourages the migrants to remit their salary to the home country or keep it with their sponsors or by themselves until they return. This often results in entrusting the money to family members in the home country or to legal residents/sponsors in the host country. Getting the money back from these people proved to be difficult for the women migrants. Most of the women returned to their home country thinking they were 'ready' only to learn nothing had been saved for them upon their arrival in the home country. The following quote from an interview exemplifies the situation.

It was a total shock and feeling of sadness when I first saw the saving book with only 3,000 Birr in it. I was shocked [...] What else can be as bad as knowing your family did not consider the trouble you went through to earn that money? It was very disappointing and in fact it was the first and main problem I faced after returning to home. I was asking myself how on earth my own family don't give a shit about the trouble I went through to earn and send the money, with a hope that one day I would come back and use a part of it for the hair salon I was dreaming to start. It took me a while to let go and accept the situation. (Interview 1)

In most cases, the poor economic condition of the returnee's family in the home country is the reason for using the entrusted money, but that is not always the case. Family members and friends also misuse the savings of the migrants thinking the latter earns it easily. For example, one of the participants for this study told her story like this:

I had a lot of money and sent most of it to my mom to use a part of it and save the rest, but nothing was saved. I had a good feeling coming back home with the hope to start my own business with the money, but there was nothing saved. All my family had their own income and they were not that much in need, so that was why I expected them to save some of the 
money. I was very disappointed, had a fight with my family about it and left home. (Interview 5)

To sum up, readiness was found to be a very important element in successful reintegration. However, the migration setting played a role in getting the resources back in the home country. Ability to get back the entrusted money in the home country was the most commonly shared experience by the participants and a dominant challenge to the economic participation of the returnees.

\subsubsection{Resource mobilization and legal status}

In relation to the resource mobilization process, we found that - paradoxically - the sponsorship system that exposes the women to various physical, psychological and financial forms of exploitation and abuse at the same time enabled the women to save more than those who were working without the sponsorship system. However, this holds true only when the kafala system is executed in accordance with the contract. Denial of pay was a common problem for most women working within the sponsorship system. Generally, women working with a sponsor were paid a smaller salary compared to the runaways or the illegal workers, but they were able to save better because the sponsor covered their living costs. The women working without a sponsor often earned two or three times more than those working with a sponsor, but they were nevertheless unable to save money because of high living costs and unnecessary spending. In most cases, those who worked outside the kafala system found it easier to get involved in prostitution and selling alcohol and drugs to deal with the high living costs or compensate for the time they did not work. Job insecurity is another major problem observed in working without a sponsor. In such cases migrants live on their savings until they find another job. Job insecurity predominantly affects the resource mobilization process of women working without a sponsor and their 'readiness' to return.

The personal traits of the returnees, such as determination to achieve their migration goal and money management skills, also matters a great deal. There were returnees who were determined to achieve their migration goal; even after running away from their sponsor, they were able to accumulate a lot of resources within a short period of time. Married women with kids were more determined to achieve their migration goal and accumulated better resources than non-married ones. However, they were not able to get back the money they had remitted to be saved in their home countries or the materials they had invested in. For example, the following participant in the 
focus group discussion who repatriated voluntarily, a married woman and mother of one, was very successful in achieving her migration goal within 2 years of her stay. She worked with her sponsors for three months. After that, she ran away from them and worked illegally for the rest of the time, doing the same domestic work and saving as much as possible. At the time of the interview, she had no income and she was dependent on her family for her financial needs because her husband spent the money unwisely.

Thank God it was not really bad. I toiled a lot but I saved something.... [M]y husband wasted all the money... When I was there I bought a condominium house, settling all its cost, and I sent all kinds of home furniture and kitchen accessories. The money I was sending was not enough for him. He sold the home furniture and all the things I sent just for drinking. I came to Ethiopia hoping to live a happy life with my husband, as I had done all I could to buy the house and fill the necessary things in it. I even had a plan to have another baby. Believe it or not, I also brought things for my future baby. I was ready to lead a happy life. But it was all a dream. At first I couldn't believe it... I have no money in my hands, as I spent it all for buying the house and home furniture. (Focus Group 3, p. 16)

The above quote shows that the personal behavior and characteristics of the migrants and their determination to achieve their goal has more impact on their resource mobilization process than their legal status or the number of years abroad. From the focus groups and the individual interviews, it became clear that personal behavior matters significantly in mobilizing economic resources. Most participants in our study who worked illegally admit and regret their unnecessary spending while they lived in the host country. A few were able to work without the sponsorship and accumulate more financial resources than those who worked with a sponsor, mainly because of their disciplined behavior and organized lifestyle in the host country.

Overall, the advantages and disadvantages for the resource mobilization process of being a legal or illegal worker counterbalance each other. The former allows the migrant to earn only low pay but provides opportunity for the money to be saved because the sponsor covers all other costs yet it happens only if the sponsor is good and acts according to the contract. The latter provides an opportunity to earn more, but the migrants themselves need to cover the living costs, affecting the likelihood of saving the money required for return. Personal behavior and the influence of acquaintances were also important in mobilizing more resources for those who lived illegally in 
the host country. For successful economic participation in the home country, the ability to get back the entrusted money upon return was more important than legal status. Getting the money back was a problem for both those who lived legally and illegally.

\subsubsection{Resource mobilization and length of stay in host country}

Our study reveals that the number of years stayed in the host country does not improve the ability of the returnees to accumulate resources or to be successful in their reintegration process. In this study, 13 participants out of the 32 stayed in the host country from 6 months to 5 years, 11 stayed 5-10 years and 8 stayed more than a decade. Despite variations in the length of stay in the host country, we did not observe important differences in their economic reintegration process in their country of origin.

The fact that women who stayed longest in the host country could not mobilize more resources than women who stayed a shorter period could be explained by the following three factors. First, a majority of the women send their poor families in the home country money for daily household consumption. Especially if the sending of remittances is combined with low pay, it is difficult to save money. Second, as the length of time in the host country increases, more migrants start working independently without a sponsor. The high living costs and job insecurity are a common challenge for those who work illegally in the host country, making it difficult to save money. Third, for illegal migrants their inability to exit from the host country freely also contributes to prolonging the length of stay in the host country. Due to these factors, migrants who stay longer in the host country do not increase their resources more than migrants who stay for a shorter period of time.

\subsubsection{Willingness to return}

Our participants included both women migrants who returned voluntarily and those who returned involuntarily. 'Voluntary return' was considered throughout the study based on the existence of free will by the returnee to return (Perruchoud \& Redpath-Cross, 2011) except in cases of contract breach or violation of human rights.

The preparedness hierarchy outlined by Cassarino (2004) assumes that those repatriated or expelled are not prepared for their return and hence typically have low success in their reintegration processes in their home country. Our data, which only focused on economic reintegration, shows that in addition to preparedness, personal traits and abilities of the returnee matter. It must be noted here that Cassarino (2004) suggests a broader concept of reintegration, in which returnees are 
actors of change in the economic development of their origin country. However, we argue that securing one's livelihood is the basic form of economic reintegration and contribution to development. Against all odds, those who were not 'willing' to return to their country were sometimes successful in generating income and integrating themselves in economic activities. Out of the nine participants who were able to generate some kind of income, four were returned without their will because of a breach of contract by the sponsor, three were deported forcefully as they were captured working without a resident permit, one was voluntarily repatriated and one returned willingly to accompany her husband. We observed that the personal traits of these returnees like persistence and pro-active behaviors made a difference in their economic participation. This gives insight into the relevance of personal behavior for successful reintegration in addition to preparedness as expressed in terms of readiness and willingness.

Given the migration setting in the Middle East for female domestic workers, there are good reasons why 'willingness' to return might not always result in success in economic reintegration. First, most women who migrate to Middle Eastern destinations have a poor educational profile, with no possibility to improve their education in the host country, which remains the same for those returning both willingly and unwillingly. This poses a challenge to getting returnees employed in the private or public sectors on their return. Most women regret quitting their education in exchange for migrating abroad. A quote from one returnee who stayed in the Middle East for a total of 8 years with different contract jobs illustrates this. After finishing her last contract job, she returned willingly to her country to settle for good, but getting employed to earn a living was a problem for her since she only completed elementary school before leaving to the Middle East.

I regret quitting my study and leaving to the Middle East. When I start looking for a job now, in most cases they ask if I have at least completed grade 10, even for a cleaning job, and that hurts. I could not find a job. (Interview7)

The migration settings in the Middle Eastern countries and the type of work impede the women from developing their education or any other personal skills, and this affects their economic participation upon return, irrespective of the migrant's motivation to return or the length of time stayed abroad.

Second, for most Ethiopian women migrating to the Middle East, the primary migration objective is to improve the deprived economic situation of their family, followed by bringing in some 
financial capital that could enable them to start their own business when they return. In most cases, the former objective prevails and the women are unable to save resources for themselves with the

little money they earn from domestic work within the constrained migration setting. The majority of women were supporting their poor family back home with their daily household consumption. The sudden return of migrants affects the household consumption of the returnees' families negatively. However, since the migrants were not in a condition to save resources for their return, their economic participation in entrepreneurial activities is unlikely, whether they return willingly or unwillingly. According to Cassarino (2008), willingness must be backed by readiness, and migrants may be willing to return but not ready. However, for Ethiopian domestic workers in the Middle Eastern countries, in most cases, readiness cannot be determined beforehand, as migrants accumulate their financial resources in the hands of others, mainly family members in the country of origin.

In general, migration settings, personality traits and the nature of jobs migrants engage in affect the resource mobilization process as well as the reintegration process of female domestic workers.

\subsubsection{Economic reintegration and assistance}

Finally, we examined the impact of assistance and reintegration outcomes. Assistance provided upon return by the government and local or international NGOs includes the provision of medical and counselling assistance, a workplace, vocational skill training for about 3-12 weeks and credit facilities. However, the reintegration assistance did not prove to be life-changing for the returnees in our study. Out of the 22 participants who could not generate any kind of income, 12 received reintegration assistance in vocational skills and were provided small shops to start their businesses. However, they could not use the assistance provided by the government and NGOs, mainly because of a lack of starting capital, bureaucracy and infrastructural problems associated with the workplaces provided. The government also facilitated credit options for the women, but they could not use them because the returnees perceived the interest rate as prohibitively high. Table 1 shows the source of income in relation to reintegration assistance provided. 
Table 1. Sources of income and reintegration assistance

\begin{tabular}{|c|c|c|}
\hline $\begin{array}{l}\text { No. } \\
\text { participants }\end{array}$ & $\begin{array}{l}\text { Sources of income } \\
\text { from Dec } 2015-\text { Feb } 2016\end{array}$ & Reintegration support provided \\
\hline 12 & None & $\begin{array}{l}\text { Basic business skills, workplace, training in food preparation \& } \\
\text { hairdressing }\end{array}$ \\
\hline 10 & None & None \\
\hline 2 & Catering business & $\begin{array}{l}\text { Basic business skills, workplace, training in food preparation \& credit } \\
\text { facility }\end{array}$ \\
\hline 1 & Catering business & None \\
\hline 1 & $\begin{array}{l}\text { Small vegetable and fruit } \\
\text { shop }\end{array}$ & Basic business skills \\
\hline 1 & $\begin{array}{l}\text { Employment (saleswoman } \\
\text { in supermarket) }\end{array}$ & Basic business skills, workplace, training in hairdressing \\
\hline 1 & $\begin{array}{l}\text { Employment (saleswoman } \\
\text { in a supermarket) }\end{array}$ & None \\
\hline 1 & Own hair salon & Basic business skills and training in hairdressing \\
\hline 1 & Laundry worker & None \\
\hline 1 & Day shift house maid & None \\
\hline $1 *$ & - & - \\
\hline $\mathrm{N}=32$ & & \\
\hline
\end{tabular}

Source: Field work, Addis Ababa, December 2015

Our study revealed that those who received reintegration assistance were better reintegrated than those who did not receive any assistance at all. The assistance focused on enabling the women to participate in entrepreneurial activities. Nevertheless, this rarely succeeded because migrants did not have savings from their migration and had difficulty obtaining loans. Hence, reintegration assistance was more useful to those who had some savings.

\subsection{Conclusion}

Using a qualitative approach, this article addressed the question of how past migration experiences under the kafala labor sponsorship system affect the economic reintegration of unskilled Ethiopian women returnees. The kafala labor sponsorship system enables domestic workers to enter the host 
country under the financial and legal responsibility of a specific sponsor/employer. We examined the impact of such a restrictive labor sponsorship program on those who work with their sponsors throughout their contract period (legal domestic workers) and on those who ran away from sponsors or entered the destination country through pilgrimage or crossing the sea - in all cases illegal workers.

We found that women working with a sponsor were paid a smaller salary compared to the runaways or the illegal workers, but they were able to save more because the sponsor covered their living costs. Underpayment or denial of wages, inability to change employers, constrained social contact and movement affected the resource mobilization process of domestic workers working with a sponsor. The women working without a sponsor often earned two or three times more than those working with a sponsor, but they were nevertheless unable to save money because of high living costs, job insecurity and unnecessary spending. Saving money required for return and reintegration was difficult for both groups.

The kafala system does not provide a legal right for domestic migrants to use financial institutions by themselves for saving, sending and other services in the host country. This compelled the migrants to send almost their entire salary to family members in the home country. Most women returned to their home country thinking they were prepared for their return but then learned that nothing had been saved for them upon their arrival. For successful economic participation in the home country, the ability to get back the entrusted money upon return was more important than legal status. Inability to get the money back was a major reintegration problem for almost all returnees.

The number of years stayed in the host country did not affect the ability of the returnees to accumulate resources or to be successful in their reintegration process. This was because as the length of time in the host country increased, more migrants started working independently without a sponsor. The high living costs and job insecurity made saving money difficult. In addition, for illegal migrants their inability to exit from the host country freely also contributes to prolonging the length of stay in the host country without necessarily accumulating other resources. In general, the study results showed how the kafala labor sponsorship system interferes with the resource mobilization process and preparedness of domestic migrants, which later has impact on their economic reintegration in the home country. 
Our study also revealed that the personal behavior of migrants and the influence of acquaintances were important factors in the mobilization of resources for those who lived illegally in the host country. Personal characteristics and behaviors such as determination to achieve migration goals, money management skills and marital status influenced both the resource mobilization process at the destination and economic reintegration in the home country. This finding complements previous research (De Regt \& Tafesse, 2016; Van Houte \& Davids, 2008) that indicated the influence of individual characteristics on the reintegration of return migrants.

The second question addressed was to what extent reintegration assistance and support in the home country enabled returnees to build a sustainable livelihood. In our study, the assistance provided for involuntary returnees was found to be beneficial only for those who brought some savings from the host country or for those who were able to get back the money they had entrusted to family members. Similar to Ruben et al. (2009), our findings confirmed that reintegration assistance provided by the government and/or NGOs is helpful when human development skills training is accompanied by financial assistance. The combination of financial means with vocational skills training allows the returnees to start the small businesses that most returnees aspire to establish.

Overall, the results of our study showed the vital link between migration experiences and economic reintegration of female domestic worker returnees. This study used the lived experiences of a small number of women returnees who were employed in the domestic services market. Future research may enhance and strengthen our findings by focusing on a larger number of participants, including both men and women and covering different employment sectors. In addition, as the current study focused only on economic aspects of the reintegration process, future studies could also contribute by focusing on the social reintegration process.

Our findings have three major policy implications aimed at alleviating the precarious situation of returnees in both the sending and receiving countries. First, legal procedures that allow the women to access financial institutions without the help of sponsors are important. Access to financial institutions would allow migrant women to avoid remitting their money to family members or entrusting it to their sponsors or others. Policy makers in both the home country and the host countries need to set up or strengthen the legal framework in this regard. Second, preventing breaches of contract and financial exploitation by sponsors and providing migrant domestic workers the freedom to change sponsors would relieve bottlenecks in the resource mobilization 
process. Policy makers should enact a legal framework that offers better employment protection and conditions. Third, assistance programs in the home country are helpful in the reintegration process. However, human capital or vocational skills training will only help returnees to sustain their livelihood when facilitated by access to financial capital. In addition, follow-up procedures for the start-up businesses and the provision of financial and professional assistance to sustain the businesses is important. 


\section{References}

Ammassari, S. (2004). From nation-building to entrepreneurship: The impact of elite return migrants in Côte d'Ivoire and Ghana. Population, Space and Place, 10(2), 133-154.

Anbesse, B., Hanlon, C., Alem, A., Packer, S., \& Whitley, R. (2009). Migration and mental health: A study of low-income Ethiopian women working in Middle Eastern countries. International Journal of Social Psychiatry, 55(6), 557-568.

Arif, G. (1998). Reintegration of Pakistani return migrants from the Middle East in the domestic labour market. The Pakistan Development Review, 37(2), 99-124.

Arowolo, O. O. (2000). Return migration and the problem of reintegration. International Migration, 38(5), $59-82$.

Bélanger, D., \& Rahman, M. (2013). Migrating against all the odds: International labour migration of Bangladeshi women. Current Sociology, 61(3), 356-373.

Belay, Y. D. (2014). Migration and state responsibility: Ethiopian domestic workers in Lebanon. International Journal of Scientific and Research Publications, 4(5): 120.

Beydoun, K. A. (2006). The trafficking of Ethiopian domestic workers into Lebanon: Navigating through a novel passage of the international maid trade. Berkeley Journal of International Law 24(3).

Cassarino, J.-P. (2004). Theorising return migration: The conceptual approach to return migrants revisited. International Journal on Multicultural Societies, 6(2), 253-279.

Davids, T., \& Houte, M. V. (2008). Remigration, development and mixed embeddedness: An agenda for qualitative research? International Journal on Multicultural Societies, 10(2).

De Bree, J., Davids, T., \& De Haas, H. (2010). Post-return experiences and transnational belonging of return migrants: A Dutch-Moroccan case study. Global Networks, 10(4), 489-509.

De Regt, M. (2010). Ways to come, ways to leave gender: Mobility, and il/legality among Ethiopian domestic workers in Yemen. Gender \& Society, 24(2), 237-260.

De Regt, M., \& Tafesse, M. (2016). Deported before experiencing the good sides of migration: Ethiopians returning from Saudi Arabia. African and Black Diaspora: An International Journal, 9(2), 1-15.

Fernandez, B. (2010). Cheap and disposable? The impact of the global economic crisis on the migration of Ethiopian women domestic workers to the Gulf. Gender \& Development, 18(2), 249-262.

Hsieh, H.-F., \& Shannon, S.E. (2005). Three approaches to qualitative content analysis. Qualitative Health Research, 15(9), 1277-1288.

Jones, N., Presler-Marshall, E., Tefera, B., Emirie, G., Gebre, B., \& Gezahegne, K. (2014). Rethinking girls on the move: The intersection of poverty, exploitation and violence experienced by Ethiopian adolescents involved in the middle east 'maid trade'. Report submitted to Overseas Development Institute and funded by Oak Foundation.

Jureidini, R., \& Moukarbel, N. (2004). Female Sri Lankan domestic workers in Lebanon: A case of contract slavery? Journal of Ethnic and Migration Studies, 30(4), 581-607.

Kveder, C. L. M., \& Flahaux, M.-L. (2013). Returning to Dakar: A mixed methods analysis of the role of migration experience for occupational status. World Development, 45, 223-238.

Mahdavi, P. (2013). Gender, labour and the law: The nexus of domestic work, human trafficking and the informal economy in the United Arab Emirates. Global Networks, 13(4), 425-440.

Minaye, A. (2012). Trafficked to the Gulf states: The experiences of Ethiopian returnee women. Journal of Community Practice, 20(1-2), 112-133.

Moors, A., \& De Regt, M. (2008). Migrant domestic workers in the Middle East. In: Schrover, M., Van der Leun, J., Lucassen, L., \& Quispel, C. (eds), Illegal Migration and Gender in a Global and Historical Perspective. Amsterdam: Amsterdam University Press.

Pande, A. (2013). 'The paper that you have in your hand is my freedom': Migrant domestic work and the sponsorship (kafala) system in Lebanon. International Migration Review, 47(2), 414-441.

Parutis, V. (2013). Returning 'home': East European migrants' discourses of return. International Migration, $52(5)$. 
Patton, M. Q. (2002). Qualitative Research \& Evaluation Methods. Thousand Oaks, CA: Sage Publications, Inc.

Perruchoud, R., \& Redpath-Cross, J. (eds). (2011). International migration law: Glossary on migration. Geneva: International Organization for Migration.

Ruben, R., Van Houte, M., \& Davids, T. (2009). What determines the embeddedness of forced-return migrants? Rethinking the role of pre-and post-return assistance. International Migration Review, 43(4), 908-937.

Schuster, L., \& Majidi, N. (2013). What happens post-deportation? The experience of deported Afghans. Migration Studies, 1(2), 221-240.

Shin, K. R., Mi, Y. K., \& Seung, E. C. (2009). Methods and strategies utilized in published qualitative research. Qualitative Health Research, 19(6), 850-858.

Sinatti, G. (2011). 'Mobile transmigrants' or 'unsettled returnees'? Myth of return and permanent resettlement among Senegalese migrants. Population, Space and Place, 17(2), 153-166.

Thomas, K. J. (2008). Return migration in Africa and the relationship between educational attainment and labor market success: Evidence from Uganda. International Migration Review, 42(3), 652-674.

Ullah, A. A. (2013). Mother's land and others' land: 'Stolen' youth of returned female migrants. Gender, Technology and Development, 17(2), 159-178.

Van Houte, M., \& Davids, T. (2008). Development and return migration: From policy panacea to migrant perspective sustainability. Third World Quarterly, 29(7), 1411-1429.

Van Meeteren, M., Engbersen, G., Snel, E., \& Faber, M. (2014). Understanding different post-return experiences. Comparative Migration Studies, 2(3), 335-360. 


\title{
CHAPTER 4
}

\section{"I Should Get Married as Soon as Possible, but the Relationships I Start Do Not Work": Marital Prospects of Female Return Migrants from the Arabian Gulf}

\begin{abstract}
This study seeks to understand how the intersection of migration, gender and age shape the marital prospects of Ethiopian female domestic workers returning from the Arabian Gulf and the Middle East. The study found that gendered attitudes in Ethiopian society rooted in patriarchy interact with age and the migration experiences of returnees to create stigma and marginalization, excluding the returnees from the highly-desired social institution of marriage. It was also found that returnees tended to dissociate themselves from other returnees or keep their experiences secret to cope with stigma and marginalization and increase their marital prospects. The study shows how the stigma and marginalization experienced by Ethiopian female returnees from Arabian Gulf and Middle East countries affects their social reintegration in the home country and can trigger remigration intention.
\end{abstract}

\subsection{Introduction}

The interest to understand the relationship between the migration of women and their family has increased significantly in the past few years. Accordingly, this chapter explores the impact of female migration on the migrant's family and marital relations from different perspectives. A number of studies show that the migration of women for labor purpose is an uplifting and empowering experience for the women, and their family, mainly because of the financial gains, but also because of the exposure of the migrant to a new culture, which can result in improvements in living status upon return (Asis, 2002). Particularly married return migrants were able to provide better for their children and were psychologically empowered to challenge gendered roles and gender-based oppression (Bélanger \& Rahman, 2013). On the other hand negative impacts on children left behind were observed in migrant households where women migrated for labor purposes (Hugo \& Ukwatta, 2010). As well as the challenges posed by the migration experience, female return migrants also need to deal with any changes that have taken place in their absence. 
For example, attachments and ties with children, spouses and other family members can change (Asis, 2002). A study on Eritrean female domestic migrants highlights the existence of more divorce in Eritrean households with migrant wives, than in households with non-migrant wives (Kifleyesus, 2012). Negative attitudes towards migration and the violation of gender norms resulting from the migration experiences of women, which can threaten the masculinity of men, have been found to be some of the main reason for marriage disruption and conflict (Kifleyesus, 2012). The long distance between couples in a relationship also creates conflict, and men often marry other women in the absence of their wives (De Regt \& Tafesse, 2016).

The migration experience particularly impacts on the marital prospects of unmarried female migrants, which has received relatively scant attention. However, there are some studies that explore the relationship between female labor migration and the marital prospects of returnees. For example, Ullah (2013) recounts the experience of female return migrants from four Asian countries, showing how staying abroad for a long period of time diminished the marital prospects and possibility of being a mother for many of the returnees. The author highlights that the financial gains reaped by these women from migration did not compensate them for the intangible loss they experienced on account of not being married or becoming a mother.

Marriage, family and motherhood are important parts of life for many women (Coontz, 2004; Sharp \& Ganong, 2011). The importance of these aspects in women's life may be less in some societies, and more in others. In patriarchal societies, like Ethiopia, being married and having children is an honor that makes womanhood complete (Muwonwa, 2017). For women, being unmarried and without children is socially undesirable and those who have passed the expected marital age without getting married are often stigmatized (Ntoimoa \& Isiugo-Abanihe, 2014). As the number of women participating in labor migration is increasing (Afsar, 2011), and as marriage is still regarded as an important part of women's identity(Sharp \& Ganong, 2011), exploring how migration impacts on the lives of unmarried women upon their return in various socio-cultural settings is valuable. The main research question we aim to answer in this article is how do migration experiences to the Arabian Gulf affect the marital prospects of Ethiopian women returnees and their social reintegration in the home country upon return? The question is approached using the concept of intersectionality, which helps to identify various interrelated and overlapping factors that may have an impact on the social reintegration of women returnees. 
In this article, we focus on the lived experiences of African women migrants. African women are involved in labor migration to the Arabian Gulf and Middle Eastern countries extensively, however, their experiences are not as well documented as their Asian counterparts (De Regt, 2010). By taking Ethiopian female returnees from Saudi Arabia, Lebanon, Yemen, Kuwait and Bahrain, as a case study and drawing upon qualitative data collected through in-depth interviews and focus group discussions, we unfold how the marital prospects of returnees are shaped by the intersection of their migration experience, gender and age. Ethiopia is a good case for this study, because, unlike Asian migrants who are usually married with children at the time of migration (Ukwatta, 2010), most Ethiopian women migrants who travel to the Arabian Gulf for domestic work are single (Fernandez, 2011; Jones et al., 2014; Kebede, 2002).

The article uses the concept of intersectionality to understand the experiences of returnees. Intersectionality is useful in identifying the sources of oppression and disadvantage faced by some groups, as a result of the interaction of various social categories, such as race/ethnicity, age, disability/ability, gender, nationality, religion, and migration status (Hankivsky, 2014; Nash, 2008). Often, studies using intersectionality to examine women domestic migrants' life focus on classical categories such as gender, class and race, as well as the experiences of such women during their stay in the destination country. However, this article, also explores stigma and marginalization experiences that occur within the migrant's own country upon their return, which provides us with a new perspective on the experiences of female domestic workers post migration. Unraveling the intersection of migration, gender and age also helps us to understand the reintegration challenges associated with the experiences of female migrants and highlights the opportunity cost of the economic gains associated with migration and the intangible social costs for the women themselves, which is often overlooked in the literature. Beyond academic

significance, this article sheds light on the post-migration experience of returnees, which requires policy attention to facilitate the successful reintegration of female returnees. In the next section, we briefly discuss the concept of intersectionality, followed by a description of the methods used in this study, the findings and analysis, and a short conclusion.

\subsection{The concept of intersectionality}

In the last few decades, the concept of intersectionality has been used to dissect the various socially-constructed, interrelated and tacitly-embedded factors oppressing women and other 
marginalized groups (Bastia, 2014; Knapp, 2005). Intersectionality is defined as "the interaction between gender, race, and other categories of difference in individual lives, social practices, institutional arrangements, and cultural ideologies and the outcomes of these interactions in terms of power" (Davis, 2008, p. 68). Hankivsky (2014) argues that these interactions are the result of the systems and structures of power, which are connected to one another, such as through laws, government policies, and religious or social organizations. Hence, systems and structures of power may both create, or be a result of the interaction of, various social categories. In this article, the concept of intersectionality is used to examine the intersectional impact of migration, gender and age in shaping the marital prospects of female returnees from the Arabian Gulf and Middle East.

The use of the concept of intersectionality to understand a migrant's life and experiences is increasing (Bastia, 2014; Bürkner, 2012; Nash, 2008). Migration involves the interconnection of various social divisions and categories, which raises the need to explore these connections at the local, national and global levels (Anthias, 2012). On the other hand, Näre (2013) argues that migration by itself has become a social category. Migration, together with other social categories, shapes the lives of those who are involved in it.

The concept of intersectionality is used to show how different social categories contribute to women migrants' precarious situation in destination countries (see, for example, Stiell \& England, 1997; Beydoun, 2006; Liang, 2011; Anderson, 2007). Recruitment agencies and brokers play a large role in how the intersection of various social categories shapes the experiences of migrant domestic workers (Deshingkar, 2018). They use race to classify and characterize domestic migrants. Moreover, domestic workers are trained and guided by agents and brokers to modify their behavior and suppress their ethnic identity to impress employers in destination countries (Liang, 2011). Hence, through brokers, the process of marginalizing domestic workers before and after their migration is strengthened, rather than challenged (Liang, 2011).

Gender and racial ideologies that start at the time of recruitment of domestic workers continue throughout their employment. The power dynamics between the employer and migrant, and their relationship, are shaped by various interlocking factors (Stiell \& England, 1997). Differences in race and 'foreignness' is a reason to employ migrants in the United Kingdom, as a distinction in social class makes domestic worker-employer relations easier (Bridget Anderson, 2007). De Regt (2010) also notes that people from Yemen do not employ domestic workers from their own 
country, and migrants from Asia or Africa are prefered to ensure control and authority. Often a more subtle way is used to describe domestic migrants and preferences by employers, such as docility, language ability, loyalty, and social relationships (Benedict Anderson, 2006). In general, different social categories intersect in the employment of domestic workers, as well as in their relationships with employers.

The intersection of migration and gender is visible in women return migrants' lives, often putting them in a marginalized social position. This makes their reintegration in the home community difficult. For example, Bangladeshi return migrants (Afsar, 2009; Bélanger \& Rahman, 2013; Dannecker, 2005) and Nepalese female return migrants (Thimothy \& Sasikumar, 2012) are stigmatized and marginalized upon their return, because of the gendered attitude that women's place is in the home. In these contexts, migration is considered a threat to norms about femininity and women's roles. Female migrants are perceived to have led a sexually-loose lifestyle while abroad, which is a threat to their marriage or marital prospects upon their return (Afsar, 2009; Bélanger \& Rahman, 2013; Dannecker, 2005; Thimothy \& Sasikumar, 2012; Ullah, 2013). On the other hand, De Regt and Tafesse (2016) note that Ethiopian women returning from the Arabian Gulf are perceived to have been sexually abused, which makes them undesirable for marital relationships. The study by $\mathrm{Yu}$ (2015) also focused on the return context. The study exhibited how the migration experience changed the identity of the women positively and negatively, as well as their relationship with the local environment.

In sum, the concept of intersectionality is used in this study to identify how multiple social categories interact to create oppression and disadvantage for some groups in society. The intersection between gender, race and class in shaping the experiences of domestic migrant workers and their subordinate status in destination countries has been well examined, particularly before and during their migration experience. However, the stigma and marginalization that female domestic returnees experience upon return is still in need of further research attention. This study attempts to contribute in this regard by examining how migration experience intersects with gender and age in shaping the marital prospects of Ethiopian female migrants returning from various Arabian Gulf and Middle Eastern countries and how it affects their socio-cultural reintegration in the home community. 


\subsection{Methods}

This study is based on qualitative data collected in Addis Ababa, Ethiopia from January 2015 to March 2017. A total of 48 female returnees, who at the time of the data collection were living in the capital (Addis Ababa), participated in the study. The majority of Ethiopian women who migrate to the Arabian Gulf are between the ages of 20 to 46, less educated, single, or divorced with children (Demissie, 2018; Jones et al., 2014; Kebede, 2002; Tayah \& Atnafu, 2016). Almost all of the participants in this study were single; only seven were married or had been married (three of them were divorced because of conflict related to their migration) and had children. Seventeen of the returnees had children before their migration, most as a result of love affairs they had outside of marriage, and had never been married. Half of the migrants were participants of vocational skill training organized by three local non-government organizations (NGOs) working in the area of reintegration of returnees in Addis Ababa: Agar Ethiopia, WISE and Live Addis. With the help of these organization, voluntary participants were selected for the study; snowball sampling was then used to recruit women from the community, who were not part of any reintegration support programs by NGOs or the government. The participants were provided with information on the purpose of the study and gave their consent to participate in focus group discussions as well as individual interviews.

A semi-structured interview guideline, which was first prepared in English and then translated into Amharic (the local language), was used for both the focus group discussions and individual interviews. To identify general themes in the intersection of social categories, data collection started with 4 focus group discussions with 26 returnees, followed by in-depth interviews. A total of 42 individual interviews were held with 36 returnees (some of the returnees were re-interviewed at different time intervals to capture changes in their social reintegration and marital status/relationships). All discussions and interviews were audio taped with the consent of the participants. The first author and a research assistant made a verbatim transcription of the audiotaped interviews. The transcribed documents were translated into English by a language translator and rechecked against the original transcripts for accuracy and consistency of meaning.

To analyze and interpret the data, a two-step hybrid approach was used (Bilge, 2009). This approach uses both inductive thematic analysis and a deductive template approach. As a first step, the focus group discussion and individual interview transcripts were coded to identify emergent 
themes, patterns and connections regarding the martial prospects of the returnees. A consistent pattern was observed in relation to the stigma and marginalization that female returnees from the Arabian Gulf and Middle East experience when seeking to enter into a marital relationship. As a second step, an analytical template informed by intersectionality was used (see Annex 7 for details) and the coded documents re-read to identify intersections between social categories. Three important intersections were observed as affecting the marital prospects of the returnees and stigma and marginalization they were experiencing. These salient categories were migration, gender and the age of migrants. In the next section we discuss in detail how the intersection between these three social categories affects the marital prospects of the returnees and the stigma and marginalization they experience, along with the strategies used by the returnees to deal with stigma and marginalization and increase their martial prospects. Pseudonyms are used in all narrations to protect the anonymity of the participants.

\subsection{Findings}

\subsubsection{Marriage and motherhood}

In Ethiopia, marriage as well as motherhood are important aspects of womanhood. Unmarried women and those without child are stigmatized and looked down upon. Our study found that, generally, women over the age of 30 desperately want to get married and have children. Many of the respondents stated that they are actively seeking a marital relationship. Surprisingly, for many of them, the driving force behind actively seeking a marital relationship is not the desire for a loving relationship, but their age: 'I do not want to have a boyfriend, I want to get married. I don't want to go out with boys. I don't want to waste my time hanging with them. I want to settle down" (Interview 19). As exemplified in this quote, the returnee wants to avoid wasting the time required for dating and is seeking a relationship that leads to marriage within a short period of time. As well as age, the returnees also mentioned pressure from their family and society. The returnees said that they are constantly reminded by close family members and the community that they need to get married.

It is really hard for a woman to start a family when it is too late, you know. After I came here I started a relationship with a guy. I really want to get married and have children. Everybody in the family, my mom and relatives are telling me that time is passing and 
getting late for me. They are really concerned that I may not have kids. I am not sure what the future holds for us, but I think he just needs me for a while. (Interview 2)

The returnees explained how difficult it is to deal with stigma and marginalization in an environment in which passing the traditional age of marriage is not the norm for a woman. To be a mother through a formal marital relationship is the norm and having children outside of marriage is not socially acceptable in Ethiopia. Those who have children outside of marriage are often stigmatized and called names that belittle their social status, such as 'dikala' Few returnees (particularly those who are in their late 30s) try to fulfill their desire to have children without getting married first. Pressure to conform to the society's expectation of womanhood by getting married and having children was exacerbated by the fact that the majority migrate in their early to mid-20s and return in their 30s. The following excerpt from an interview with a returnee who entered a relationship mainly to have a child exemplifies this situation:

I am getting older and decided to have a child before it is too late. Otherwise, it will be very difficult to have a child if you pass a certain age... You can get money any time you want to have it, but not a child. As I told you I got into this just to get a child, not a married life. He does not even have a stable income. I did not want to live with him. Whatever the case I believe a woman should have a child. The main thing is having a child. I know a lot of women coming from Arab countries, who find it difficult to have a child because they spent their young age trying to get money and help their parents, brothers and sisters. When they came back, they tried to start a family of their own, but it was impossible to get a child. A man won't stay in his married life if he doesn't get a child. As a result, these women travel back to the Arab country, because of the frustration of not having a child. I did not want that to happen to me. (Interview 3)

This is not, however, an easy road for many of the returnees. The women are not only challenged economically, but also socially. The stigma and marginalization of unmarried women with children is strong. On the other hand, it is difficult to live in a society that perceives marriage and motherhood as core to a woman's identity. Hence, having a child without necessarily getting married may reflect the returnee's desire to fulfill cultural expectations of womanhood, at least partially. 
Surprisingly, the majority of the returnees were presented with a marriage proposal while they were in the host country, however, they said they refused to accept these proposals because their main objective was to achieve their migration goal, they were relatively young at the time, and marriages that take place while the migrant is in the host country are seen as more beneficiary to the man than the woman. There was a common consensus among the returnees that men who propose marriage to a migrant women while they are in the destination countries often do so to financially and sexually exploit the women.

When I was there, there were a lot of proposals from people who wanted to marry me, but there was no interest from my side. It is not fair for a woman to get married while she is working there. The guys, they marry you, they don't work, but spend what you have earned; they don't allow you to spend your own money for even for a telephone card and you cannot help your family back home. But for them, they spend your money on whatever they want, they help their family, have affairs with a lot of women... how could I get married seeing all this. A lot of my friends regret marrying while they were there. One can't call this a marriage, rather it is slavery - being a slave to a man. I did not want to do that. Moreover you don't know who they are, where they are from in Ethiopia, who knows they might have a wife in Ethiopia. (Interview 3)

In summary, age is an important variable in the decision to marry for Ethiopian women return migrants. Marriage was highly desired among the returnees, mainly to conform to the societal norm of womanhood.

\subsubsection{Stigma and marginalization}

The intersection of migration, gender and age were dominant themes in the narrations of the returnees, affecting their marital prospects negatively. A consistent pattern was observed in the data, with returnees reporting that they were marginalized because they are perceived to have led a 'loose' sexual life while abroad.

After finding out I had lived in an Arab country he told me he doesn't want to be with me anymore. He did not need any other reason. He said he would never trust a woman coming from an Arab country telling him she only had a relationship with a single guy. (Interview 11) 
In the above quote it is implied that gendered ideologies, which require the reserved sexual identity of women as a prerequisite for entering into a marital relationship, is assumed to be violated by the freedom migration provides.

In analyzing the data, we found that gendered attitudes that require women's chastity are not the only problem associated with low martial prospects and the marginalization of female returnees from the Arabian Gulf and the Middle East. Women's martial age was also an issue. Most of the participants in our study migrated in their early or mid-20s, unmarried, and some (17 out of 48) were single mothers. They stayed abroad for an average of 8 years (maximum 22 years, minimum 6 months). For most of the respondents, by the time they returned they were over 30, even 40, negatively affecting their marital prospects. The returnees said they regretted wasting their youth abroad and the fact that their marital prospects had decreased. Tigist, a 35-year-old (at the time of the interview) returnee, who had recently started dating, fulfilled one desirable factor that may positively contribute to her marriage prospects - chastity; however, she expects that her age will pose a threat to her marital prospects:

He is three years younger than I am. He knows that I have had no sexual relations with guys [a virgin] before, but you know the age difference might cause a bit of a problem in our relationship. That's my fear. (Interview 2)

In the quote, we see the intersection of migration, gender (gendered attitudes) and age impacting on the returnee's marital prospects.

\subsubsection{Dealing with stigma: Strategies for coping}

In the previous section we discussed how the intersection of migration, gender and age place female migrant returnees in a marginalized social positon, which affects their marital prospects differently from non-migrant women and their male counterparts. Stigma and marginalization, stemming from society's negative attitudes towards migrant women and assumptions about their migration experiences, is a major issue faced by returnees. The stigma of being single in a society where marriage and motherhood are core to womanhood is another. In this section, we show how the returnees try to cope with this stigma and marginalization in their effort to reintegrate back into the home community. 
To deal with negative perceptions associated with promiscuity and leading a 'loose' sexual lifestyle, many of the returnees disassociate themselves from other migrants as a strategy. Expressions such as: "Of course, there are women who work as a prostitute or go out with men for money" or "They don't believe you when you tell them that you were working on a contract base" are used to differentiate themselves from other 'bad' or 'promiscuous' returnees. Staying as a livein maid in an employer's house signifies restricted sexual freedom and, hence, is often used as a strategy to make this distinction between 'good' and 'bad' returnees. Hence, separating oneself from the 'others' is a common strategy used to avoid stigma and to increase martial prospects. This strategy was not only used in the narration of the returnees about their relationships with men, but was also observed in the group discussions, in which the women were reluctant to mention if they worked as a 'freelancer' (in different households, living independently from a sponsor, which is often associated with sex work and having multiple relationships to cover living costs and for entertainment purposes), for fear of judgment, even by women who had similar experiences. After a reasonable time had been spent with the first author of this article and trust developed, the returnees were more open about their experiences (such as prostitution or having multiple sexual partners) in the individual interviews, which they were not comfortable talking about in the group discussion.

The second common strategy used to avoid stigma and increase martial prospects was secrecy. For example, a returnee who was in a relationship narrated her experiences as follows:

Interviewee: [...] he broke up with me when he found out that I had been to an Arab country. He was very angry, because I didn't tell him....

Researcher: Why didn't you tell him?

Interviewee: Because I was afraid that our relationship might end. Oh, it is really hard. When I think about it, I lose hope.

Researcher: Why do you lose hope?

Interviewee: I cannot change or hide that part of my life. My return from the Arabian Gulf has had a negative impact on me, let alone on men. Even other women look down on us in this regard. I regret going there. (Interview 15) 
Another returnee, Nesanet, who stayed abroad for eight years and desperately wants to get married and have children, mentioned that she has also repeatedly experienced rejection by men. Following her experiences of rejection, she tried to avoid stigma and marginalization by using secrecy: "Time is running very fast and it is not in my favor. Like I said, I don't want to speak about my experience in the Middle East; people only use it to say bad things about you" (Interview 7).

As indicated in the above two quotes, and also shared by other participants in the study, returnees use secrecy as a strategy to avoid stigma and increase their marital prospects. However, this strategy often yields a short-lived relationship; as the experience of living in the Arabian Gulf or Middle East unfolds, the relationship often stops.

Finally, while migrants often experience marginalization in their desire to start a marital relationship, in some cases we also found that the returnees themselves avoid socializing with others for fear of possible negative treatment (self-stigmatization) or past sexual violence.

When I was a little girl I heard stories about women working in the Middle East becoming rich by working as a prostitute. I had no such experience and that is not the reason why I feel ashamed, but I have the feeling that the people around me, including my friends, don't like me at all. (Interview 3)

Women's negative experiences during migration can kill the desire to get married in returnees, instilling a hatred of men and fear of intimate relationships. For example, Hanna experienced sexual violence at the hands of her boyfriend before her migration and by employers and brokers while she was in the host country. The psychological trauma of being raped by her intimate partner and sexual violence during her migration abroad impacted on her self-worth and she developed hatred and anger against men in general. She describes her feelings as follows:

Men want to use me. If I approach someone, does he love me, care for me? No. He just asks to take me to bed, straight away. I generally don't trust anyone. I believe they are phony. Even if I have interest, I am scared to get close to men. (Interview 23)

The above quote shows that the returnee thinks that she is perceived as a sexual object by men. It is evident that stigma and stereotypes associated with female returnees from the Arabian Gulf and Middle East affect the social reintegration of returnees. This makes female returnees from the Arabian Gulf and Middle East more marginalized than other non-migrant women or women who 
migrated to other foreign countries. Hence, gender on its own fails to capture the experience of the returnees, or their migration experience and status in the host country. The negative perception of domestic worker migrants who return from the Arabian Gulf and Middle East leads to stigma and marginalization after they return, which makes social reintegration into the community in their home country difficult.

Next to negative perceptions about them due to their migration experience, the stigma of staying single beyond the usual marital age is another reason why women are stigmatized. The returnees in our study acknowledged the stress of dealing with their loved ones always reminding them that 'time is ticking'. This finding revealed pressure from family and relatives, pushing women to enter into sometimes unfulfilling marital relationship or to re-migrate. One returnee explained:

I wanted to go back because I was not fitting in here. Compared to my friends who did not migrate, I was in a bad situation. Seeing all my friends live their own life, married with children, except me was frustrating. (Interview 7)

The stigma associated with being single and not conforming to the perceived societal ideal of womanhood seemed to decrease for those once married, but now divorced or separated. Never married women are often referred as 'kumo ker' in the local language, which cannot be translated literally, but refers to how unmarried women are seen as below the standard required for womanhood. In the Ethiopian context, having children is desirable socially, and women without children are stigmatized. When the possibility of marriage diminished, a few of the women who participated in this study opted to have a child out of wedlock. Paradoxically, having a child out of wedlock seems to be interpreted differently before migration and after return. Before migration, it entails breaking the norm about sex before marriage and enduring the stigma that follows, which some participants tried to escape through migration. After return, it is accepted by the returnees as a blessing.

\subsection{Discussion}

Gender provides a lens through which to understand the experiences of women. However, there are also other social categories that intersect with gender to shape women's experiences. This study found gender, migration and age intersected to negatively affect female returnees' marital prospects, as well as their social reintegration into their home country. The following three findings 
came out of the research clearly. First, the study found that the norm that ascribes reserved sexual behavior for Ethiopian women is perceived to be violated by the 'freedom' that migration to the Arabian Gulf and Middle East provides. Ethiopia is a country with a traditional and patriarchal social structure (Fransen \& Kuschminder, 2009). In patriarchal societies like Ethiopia men often choose their marital partner (Kifetew, 2006). As in many patriarchal societies, they are also the breadwinners and decision makers in the household.

In Ethiopia, women having multiple sexual partners, with or without marriage, are denounced, while men's sexual freedom is tacitly accepted as the norm (Molla, Berhane, \& Lindtjørn, 2008). This double standard regarding men and women's sexuality was acknowledged by some of the participants in our study. Expressions like 'a man is a man' and 'of course, he is a man' were used to describe men's infidelity in a marriage or intimate relationship as normal. Women's sexual experiences are scrutinized and often determine their marital prospects in the Ethiopian context. Confirming the chaste rule is a study by Molla et al. (2008), which notes that in rural villages in Ethiopia virginity is still used to secure marriage. This highlights how migration can threaten the marital prospects of female returnees in Ethiopia.

This study also found that, Ethiopian women who return from the Arabian Gulf and Middle East are typically seen as promiscuous. Other findings also show that migrant women who are involved in domestic work are often stereotyped.. They are often viewed as promiscuous and easy-going women who sell their bodies in exchange for money (Dannecker, 2005; Hoang \& Yeoh, 2015). These attitudes are carried over to their origin country upon their return and used as tools to stigmatize and marginalize these women (Dannecker, 2005). Some returnees in our study reported having multiple sexual partners while they were abroad as a way to deal with the economic pressure in the host country, escape an exploitative employer, or better enjoy life and freedom. Similar findings were found among Asian migrants in the Arabian Gulf (Mahdavi, 2013) and Taiwan (Hoang \& Yeoh, 2015).

Studies suggest that sexual violence is tacitly embodied within masculine cultures, reflecting men's dominance and power over women (Walby, 1989), which presents an intersection between gender and migration. We found that, sexual violence had a significant impact on the returnees' marital prospects and their desire to become involve in an intimate relationship. Similar findings show that the aftermath of the psychological trauma and sexual violence that female migrants often 
experience in destination countries greatly affects the relationships that migrants have after they return (Ketema, 2014).

The migration experience of domestic workers in the Arabian Gulf and Middle East often entails physical, psychological and sexual abuse (Jureidini \& Moukarbel, 2006). More than half of our participants experienced sexual violence in the destination countries, perpetrated either by their Arab employer or Ethiopian agent (see also, Nisrane, Ossewaarde, \& Need, 2019). On the one hand, sexually-abused Ethiopian women are typically pictured as exploited beings and sexual objects, who do not deserve love and care and who are not a good prospect for marriage (see also De Regt \& Tafesse, 2016). On the other hand, the trauma that comes from experiencing sexual violence brings about feelings of shame, terror and hatred of men in returnee women. As a result of both of these factors, we found that the marital prospects of returnees were low. Studies suggest that sexual violence is tacitly embodied within masculine cultures, reflecting men's dominance and power over women (Walby, 1989). Migration can provide an opportunity for migrant women to explore their sexuality, or it can make them victims of sexual exploitation; both situations contradict society's perception of an ideal woman for marital relations.

To cope with the stigma and stereotypes attached to their perceived sexual behavior or victimhood, the majority of the returnee women who we interviewed use secrecy or disassociate themselves from other returnees as a coping strategy. They acknowledged that some of the Ethiopian migrant women in the Arabian Gulf and Middle East are involved in prostitution or have multiple sexual partners, but not them. They externalize the issue of sexual experience as applying only to 'others'. A study by Thimothy and Sasikumar (2012) also confirms that Nepalese women returnees from the Arabian Gulf refrain from sharing their experiences, because of the negative attitudes of society and stigma involved, which is partly due to activists and the media in the Nepal raising awareness about the negative experiences of women migrating in the Arabian Gulf.

Another important finding was that the age of returnees had a compounding effect, together with gendered attitudes towards sexuality and migration, on the marital prospects of returnees. As with gendered norms about sexual behavior ascribed to men and women, there is also a double standard in relation to the ideal marital age for men and women. Women are expected to get married and have children at a younger age than their male counterparts. This relates to the fact that to have a normal marital life women are expected to fulfill the role of motherhood (Mehari, 2013). 
According to the Ethiopian Demographic and Health Survey 2011, the average age of marriage for women in urban areas is 21.4 and in rural areas 18. In that survey, among the women studied in the age range $25-49,63 \%$ were married by age 18 and $77 \%$ by age 20 (CSA-Ethiopia, 2011). Most of the participants in this study migrated in their early to mid-20s, unmarried, and stayed abroad for more than a decade. Upon their return, they were in their 30s (some in their 40s) and found that their marital prospects had diminished. Younger girls are preferred for marriage in Ethiopia because of the tacitly embedded role of motherhood in the identity of womanhood; hence, passing the expected marital age for women is a threat to their marital prospects. In addition, childlessness is a major factor in divorce among married couples in Ethiopia (Tilson \& Larsen, 2000), strengthening the vital role of motherhood in marital relationship. Coping with being single in a male-dominated society that believes womanhood is associated with marriage and motherhood appeared to be difficult for many of the returnees who participated in this study.

An interesting finding about the impact of the intersection of gender and migration on the martial prospects of the returnees that requires for further research was that returnees are also assumed to have financial resources. Paradoxically, the returnees claim that men approach them if they think they have resources. This contradicts the traditional assumption of masculinity, i.e., that men are the breadwinners. Some studies in other traditional societies indicate that men are intimidated by women who have economic resources, are independent, are well-educated and earn more than them (see, for example, Ntoimo \& Isiugo-Abanihe, 2014). In the current study, however, men reportedly looked for women with economic resources; however, this does not guarantee that the relationship will move on to marriage. Our participants did not display visible economic changes because of their migration experience (see also, Nisrane, Morissens, Need, \& Torenvlied, 2017) and, hence, it was difficult to project what might have happened if they had been able to successfully accumulate economic resources from their migration. This requires further research, but it highlights the possibility that in order to overcome the stigma associated with their migration (such as violation of the chaste rule or passing the accepted marital age), women need to have good economic resources. This also implies that gender roles and relationships are not fixed and can change due to various social forces, such as migration, which might equip women with economic resources. 
To sum up, Ethiopia is inherently a patriarchal society, which influences many social and gender role relations, and the norms about marital relationships are no an exception. Gendered attitudes implicitly embedded in patriarchal cultures that ascribe norms about women's identity, such as the desired marital age and chastity before marriage, interact with the migration experience of women to decrease their prospects of marriage.

\subsection{Conclusion}

This study sheds light on how the intersection of migration, gender and age affect the marital prospects of Ethiopian female returnees from the Arabian Gulf and Middle East, how they cope with stigma and marginalization and, finally, the implications of such stigma and marginalization for their reintegration in their home country.

There are some points this article did not address and that call future research. First a number of Ethiopian women migrate from rural parts of the country, however, this research is based on data collected from women returnees in Addis Ababa. There are differences about gender roles, gendered attitudes and masculine dominance between the capital city and rural areas. Hence, a different result might be found based on where returnees are located. It is recommended that future research incorporate the experience of women returnees from different rural areas to strengthen the findings. Second, this study is based on returnees' perceptions and experiences; the findings could be strengthened by including the perception of men and society towards returnees. Finally, understanding the differences (or similarities) between the reintegration process for men and women will enhance our understanding the intersection of gender and migration. Hence, comparative research is recommended to understand the role of gender dynamics in return migration and reintegration.

The findings in this article have implications for the reintegration of returnees. Inability to conform to societal expectations about womanhood, the stigma and marginalization that female returnees experience because of their perceived or real sexual freedom, and the pressure of being unmarried beyond a certain age may hinder their social reintegration and trigger remigration intention. The marginalization that unskilled female return migrants experience in their home country, such as reveal in this study, or other marginalized identities created by the intersection of social categories, need further attention by stakeholders to improve the social reintegration of female domestic migrants in their home country. Moreover, the counterbalancing effect of the economic gains and 
social losses that female migration brings for the women themselves, and their families, needs to be examined more closely in order to avoid overstating the benefits of female migration for women and their families. 


\section{References}

Afsar, R. (2009). Unravelling the vicious cycle of recruitment: Labour migration from Bangladesh to the Gulf States: Geneva: ILO.

Afsar, R. (2011). Contextualizing gender and migration in South Asia Critical Insights. Gender, Technology and Development, 15(3), 389-410.

Anderson, B. (2006). Imagined communities: Reflections on the origin and spread of nationalism: Verso Books.

Anderson, B. (2007). A very private business: Exploring the demand for migrant domestic workers. European Journal of Women's Studies, 14(3), 247-264.

Anthias, F. (2012). Transnational mobilities, migration research and intersectionality. In: Versita.

Asis, M. M. (2002). From the life stories of Filipino women: Personal and family agendas in migration. Asian and Pacific Migration Journal, 11(1), 67-93.

Bastia, T. (2014). Intersectionality, migration and development. Progress in Development Studies, 14(3), 237-248.

Bélanger, D., \& Rahman, M. (2013). Migrating against all the odds: International labour migration of Bangladeshi women. Current Sociology, 61(3), 356-373. doi:10.1177/0011392113484453

Beydoun, K. A. (2006). The trafficking of Ethiopian domestic workers into Lebanon: Navigating through a novel passage of the international maid trade. Berkeley Journal of International Law, 24, 1009.

Bilge, S. (2009). Smuggling intersectionality into the study of masculinity: Some methodological challenges. Paper presented at 'Feminist research methods: An international conference', University of Stockholm.

Bürkner, H. J. (2012). Intersectionality: How gender studies might inspire the analysis of social inequality among migrants. Population, Space and Place, 18(2), 181-195.

Coontz, S. (2004). The world historical transformation of marriage. Journal of Marriage and Family, 66(4), 974-979.

CSA-Ethiopia, I. (2011). International: Ethiopia Demographic and Health Survey 2011. Maryland, USA: Central Statistical Agency of Ethiopia and ICF International Addis Ababa, Ethiopia and Calverton.

Dannecker, P. (2005). Transnational migration and the transformation of gender relations: The case of Bangladeshi labour migrants. Current Sociology, 53(4), 655-674.

Davis, K. (2008). Intersectionality as buzzword: A sociology of science perspective on what makes a feminist theory successful. Feminist theory, 9(1), 67-85.

De Regt, M. (2010). Ways to come, ways to leave: Gender, mobility, and il/legality among Ethiopian domestic workers in Yemen. Gender \& Society, 24(2), 237-260.

De Regt, M., \& Tafesse, M. (2016). Deported before experiencing the good sides of migration: Ethiopians returning from Saudi Arabia. African and Black Diaspora: An International Journal, 9(2), 228242.

Demissie, F. (2018). Ethiopian female domestic workers in the Middle East and Gulf States: An introduction. African and Black Diaspora, 11(1), 1-5.

Deshingkar, P. (2018). The making and unmaking of precarious, ideal subjects-migration brokerage in the Global South. Journal of Ethnic and Migration Studies.

Fernandez, B. (2011). Household help? Ethiopian women domestic workers' labor migration to the Gulf countries. Asian and Pacific Migration Journal, 20(3-4), 433-457.

Fransen, S., \& Kuschminder, K. (2009). Migration in Ethiopia: History, current trends and future prospects. Paper Series: Migration and Development Country Profiles, Maastricht Graduate School of Governance.

Hankivsky, O. (2014). Willem The Institute for Intersectionality Research \& Policy, SFU, pp. 1-34.

Hoang, L. A., \& Yeoh, B. S. (2015). 'I'd do it for love or for money': Vietnamese women in Taiwan and the social construction of female migrant sexuality. Gender, Place \& Culture, 22(5), 591-607.

Hugo, G., \& Ukwatta, S. (2010). Sri Lankan female domestic workers overseas - The impact on their children. Asian and Pacific Migration Journal, 19(2), 237-263. 
Jones, N., Presler-Marshall, E., Tefera, B., Emirie, G., Gebre, B., \& Gezahegne, K. (2014). Rethinking girls on the move: The intersection of poverty, exploitation, and violence experienced by Ethiopian adolescents involved in the Middle East 'maid trade'. A report submitted to Overseas Development Institute and funded by Oak Foundation.

Jureidini, R., \& Moukarbel, N. (2006). Female Sri Lankan domestic workers in Lebanon: a case of 'contract slavery'? Journal of Ethnic and Migration Studies, 30(4), 581-607. doi:10.1080/13691830410001699478

Kebede, E. (2002). Ethiopia: An assessment of the international labour migration situation: The case of female labour migrants. Geneva: ILO.

Ketema, N. (2014). Female Ethiopian migrant domestic workers: An analysis of migration, returnmigration and reintegration experiences.

Kifetew, K. (2006). Gender and cross cultural dynamics in Ethiopia. Agenda, 20(68), 122-127.

Kifleyesus, A. (2012). Women who migrate, men who wait: Eritrean labor migration to the Arab Near East. Northeast African Studies, 12(1), 95-127. doi:10.1353/nas.2012.0028

Knapp, G.-A. (2005). Race, class, gender: Reclaiming baggage in fast travelling theories. European Journal of Women's Studies, 12(3), 249-265.

Liang, L.-F. (2011). The making of an 'ideal' live-in migrant care worker: Recruiting, training, matching and disciplining. Ethnic and Racial Studies, 34(11), 1815-1834.

Mahdavi, P. (2013). Gender, labour and the law: The nexus of domestic work, human trafficking and the informal economy in the United Arab Emirates. Global Networks, 13(4), 425-440.

Mehari, H. (2013). Divorce: Common causes and socio-economic costs - A survey of divorced individuals in Mekelle City. Mekelle University,

Molla, M., Berhane, Y., \& Lindtjørn, B. (2008). Traditional values of virginity and sexual behaviour in rural Ethiopian youth: Results from a cross-sectional study. BMC Public Health, 8(1), 9.

Muwonwa, N. (2017). 'Dying to be women': Explorations and implications of narrative parameters of female youth sexuality in Zimbabwe. African Journal of AIDS Research, 16(3), 185-191.

Näre, L. (2013). Migrancy, gender and social class in domestic labour and social care in Italy: An intersectional analysis of demand. Journal of Ethnic and Migration Studies, 39(4), 601-623.

Nash, J. C. (2008). Re-thinking intersectionality. Feminist review, 89(1), 1-15.

Nisrane, B. L., Morissens, A., Need, A., \& Torenvlied, R. (2017). Economic reintegration of Ethiopian women returned from the Middle East. International Migration, 55(6), 122-136.

Nisrane, B. L., Ossewaarde, R., \& Need, A. (2019). The exploitation narratives and coping strategies of Ethiopian women return migrants from the Arabian Gulf. Gender, Place \& Culture, 1-19.

Ntoimo, L. F., \& Isiugo-Abanihe, U. (2014a). Patriarchy and singlehood among women in Lagos, Nigeria. Journal of Family Issues, 35(14), 1980-2008.

Ntoimo, L., \& Isiugo-Abanihe, U. (2014b). Single and stigmatised? Gender \& Behaviour, 12(4).

Sharp, E. A., \& Ganong, L. (2011). 'I'm a loser, I'm not married, let's just all look at me': Ever-single women's perceptions of their social environment. Journal of Family Issues, 32(7), 956-980.

Stiell, B., \& England, K. (1997). Domestic distinctions: Constructing difference among paid domestic workers in Toronto. Gender, Place \& Culture: A Journal of Feminist Geography, 4(3), 339-360.

Tayah, M.-J., \& Atnafu, A. (2016). Promoting and protecting the rights of migrant domestic workers in transit: The case of Ethiopian women migrants. Research Series, ILO, Geneva.

Thimothy, R., \& Sasikumar, S. (2012). Migration of women workers from South Asia to the Gulf: VV Giri National Labour Institute.

Tilson, D., \& Larsen, U. (2000). Divorce in Ethiopia: The impact of early marriage and childlessness. Journal of Biosocial Science, 32(3), 355-372.

Ukwatta, S. (2010). Sri Lankan female domestic workers overseas: Mothering their children from a distance. Journal of Population Research, 27(2), 107-131.

Ullah, A. A. (2013). Mother's land and others' land: 'Stolen' youth of returned female migrants. Gender, Technology and Development, 17(2), 159-178.

Walby, S. (1989). Theorising patriarchy. Sociology, 23(2), 213-234. 
/ Yu, X. (2015). The sociocultural effects of returnee overseas Filipino workers in the Philippines. Norsk Geografisk Tidsskrift-Norwegian Journal of Geography, 69(1), 47-58. 


\title{
CHAPTER 5
}

\section{Home, but Not at Home: Sense of Belonging, Reintegration and Remigration Intention of Female Ethiopian Returnees from the Arabian Gulf}

\begin{abstract}
Studies regarding women domestic workers and their reintegration concentrated on the horrible migration experiences the migrants had in the host country. Despite the horrors however female return migrants from the Arabian Gulf re-migrate back to the exploitative and abusive working conditions in the host countries. Hence necessitating to examine post return conditions that play a role in re-migration intention other than poor economic conditions of the returnees. Post return experiences in the home country and their impact on the reintegration process are often neglected in the scholarly debate. In response to this gap this study explored social factors in the home country that affect interpersonal and interrelatedness of the returnees to their community upon return. Betrayal by close family members, social expectation associated with traveling abroad, and negative social perceptions were identified as factors that hinder positive relationship between the returnees and the community. These factors intersect and often overlap between each other and together create a feeling of low sense belongingness among the returnees. Negative interaction with the home environment and low sense of belonging to the home community are found to be a trigger for further remigration intention. The implications for reintegration of women return migrants and policy interventions are discussed.
\end{abstract}

\footnotetext{
${ }^{5}$ The paper is published on a book chapter as Nisrane, B. L (2019), Home, but not Home: Sense of Belonging: Reintegration and Remigration Intention of Female Ethiopian Returnees from the Arabian Gulf. In Van Reisen, M, Mawere, M., Gebre-Egziabher, K.A \&Stokmans (eds), Roaming Africa: Migration Resilience and Social Protection, Bamenda, Cameroon, Langaa Research \& Publishing.
} 


\subsection{Introduction}

While the migration experiences of domestic workers in Arabian Gulf countries ${ }^{6}$ and high-income Asian countries has received increased attention of late (Demissie, 2018; Gikuru, 2013; Human Rights Watch, 2014), their reintegration in their home country upon return has not been well explored. In general, studies on female domestic workers and their reintegration have concentrated on their negative migration experiences (Anbesse, Hanlon, Alem, Packer, \& Whitley, 2009; De Regt \& Tafesse, 2016; Frantz, 2008; Gikuru, 2013; Jureidini \& Moukarbel, 2004; Ketema, 2014; Wickramage, De Silva \& Peiris, 2017). This chapter looks at the reintegration of Ethiopian female domestic migrants into their home country upon return from the Arabian Gulf, with a particular focus on the role of interpersonal relationships and sense of belonging. It also examines the effect of their post-migration experiences on their intention to re-migrate.

\subsubsection{Migration to the Arabian Gulf}

The migration of female domestic workers to the Arabian Gulf usually takes the form of temporary migration, whereby migrants are invited to the host country by a particular employer for a specific duration, in most cases two or three years. After arrival in the destination country, whether the migrant has positive or negative experiences depends on the subjective behavior of the sponsor or employer. Even though some migrants have positive migration experiences, the majority have negative experiences (Jureidini \& Moukarbel, 2004; Ketema, 2014; Nisrane, Morissens, Need, \& Torenvlied, 2017).

The migration experience of domestic workers in the Arabian Gulf has been equated with slavery by some scholars (Jureidini \& Moukarbel, 2004). African female migrants, mostly from Kenya, Ethiopia, or Uganda, are subjected to various forms of physical, sexual, verbal and financial abuse (Gikuru, 2013; Minaye, 2012). Excessive workload, constrained movement and isolation, starvation, forced servitude, rape, and denial or underpayment of wages are recurrent issues (Anbesse et al., 2009; Gikuru, 2013; Minaye, 2012). Migration experiences such as these have a significant impact on the reintegration of return migrants (Cassarino, 2004; Ketema, 2014; Nisrane et al., 2017; Van Houte \& De Koning, 2008).

\footnotetext{
${ }^{6}$ The Arabian Gulf countries (also referred to as Gulf Cooperation Council countries) are Kuwait, Oman, Saudi Arabia, United Arab Emirates, Qatar and Bahrain.
} 
Some point to the kafala labor sponsorship system, which is found in most Arabian Gulf countries, as being linked to the exploitation and abuse of domestic migrant workers (Mahdavi, 2013; Murray, 2013; Pande, 2013). However, human trafficking activities also play a significant role in their vulnerability and suffering (Fernandez, 2013; Minaye \& Zeleke, 2015).

\subsubsection{Coming home: The difficult task of reintegrating}

Cassarino (2004) argues that the successful reintegration of returnees requires mobilizing financial, social and human capital in the host countries. However, domestic migrants in the Arabian Gulf have limited options for accruing such capital. This directly affects their economic reintegration upon return. Structural barriers associated with the kafala system - such as inability to change employer, financial exploitation by employers, and inability to access financial institutions - constrain the economic reintegration of returnees (Nisrane et al., 2017). In addition, physical, sexual, and psychological abuse and exploitation during migration affect the mental and physical health of returnees, playing an adverse role in their economic and social reintegration (Anbesse et al., 2009; Habtamu, Minaye, \& Zeleke, 2017).

However, despite the exploitative and abusive working conditions, women often re-migrate to Arabian Gulf countries (Gardner, 2012). This calls for an examination of the post-return conditions affecting reintegration and remigration intention.

This chapter answers two main questions. First, what new dynamics in interpersonal relationships unfold in female Ethiopian former domestic migrants' (hereinafter called returnees ${ }^{7}$ ) lives after returning from the Arabian Gulf? And, second, how do female Ethiopian returnees' interpersonal relationships affect their sense of belonging and, in turn, their reintegration into their home country and remigration intention? The study builds on existing studies that aim to understand the reintegration of female return migrants from the Arabian Gulf by focusing on the changes that the migration experience brings to the social relationships of the returnees. It also pushes the discussion of their reintegration one step further by moving beyond migration experiences and identifying social factors embodied in the home country context that affect the successful reintegration of returnees and possible social issues that trigger remigration. It is hoped that the

\footnotetext{
${ }^{7}$ As all the returnees who participated in this study were former domestic workers, the terms former domestic migrants and returnees are used interchangeably in this chapter.
} 
findings of this study will help to develop various social support programs that facilitate the social and economic reintegration of returnees from Arabian Gulf countries. The next sections present the conceptual framework for the study (sense of belonging theory), the method used to collect the data, followed by the findings, concluding remarks and policy recommendations.

\subsection{Sense of belonging theory}

Relationships and interrelatedness with the environment are what makes life meaningful (Lambert et al., 2013; Stillman \& Baumeister, 2009); they are the essence of our day-to-day life. Relatedness to others in the environment, which is most often used to express interpersonal attachment, is a fundamental human need that helps individuals obtain social support and makes their life meaningful (Hagerty, Lynch-Sauer, Patusky, \& Bouwsema, 1993). An individual's relatedness to others in the environment is best conceptualized using 'sense of belonging' theory. A sense of belonging is defined as the evaluative feeling or perception that people have of their acceptance in their environment by the people around them or the degree to which they 'fit in' (Hagerty, LynchSauer, Patusky, Bouwsema, \& Collier, 1992). Hagerty et al. (1992) state that for someone to belong the following antecedents must exist: energy and desire for meaningful involvement and shared characteristics with other people in the environment. The opposite of belonging and connectedness is social exclusion, which refers to a person's perception of being excluded and rejected from a desired relationship, which can be as painful as physical pain (MacDonald \& Leary, 2005). Relationships and positive interactions with others are vital for people to function well in their environment.

A number of empirical studies have shown that people who are more socially integrated and who have healthy relationships with others have better general wellbeing and adjust better (Baumeister \& Leary, 1995; Cacioppo \& Cacioppo, 2014; Cohen, 2004; Hagerty, Williams, Coyne, \& Early, 1996). Positive interpersonal relationships with others are associated with a high level of cognitive and social achievement (Martin \& Dowson, 2009). Conversely, negative interactions have an adverse effect on health and wellbeing (Baumeister \& Leary, 1995). The importance of having positive relationships with those around us is not limited to health and wellbeing, but extends to

other facets of our life. Individuals become more productive through social interactions and by connecting to the environment (Kitchen, Williams, \& Chowhan, 2012; Levett-Jones \& Lathlean, 2008; Levitt \& Jaworsky, 2007; Pooley, Cohen, \& Pike, 2005; Prusak \& Cohen, 2001). Hence, 
positive relationships are important in the reintegration of female returnees from the Arabian Gulf. In line with this, Cassarino (2004) asserts that having social networks and relationships is vital to the reintegration of return migrants, as they provide crucial emotional support, which facilitates the economic and social reintegration of return migrants (Cassarino, 2004).

However, there are factors that may inhibit people's desire to interact with their community and lead to a low sense of belonging, such as stigma and poverty (Stewart, Makwarimba, Reutter, Veenstra, Raphael, \& Love, 2009; Walton \& Cohen, 2007). Based on a comparative study of high income and low income people in Canada, Stewart et al. (2009) acknowledge that being poor, ashamed or stereotyped, limits people's ability to initiate and maintain social relationships. Stigma has been found to have a negative impact on the social relationships of Asian female domestic returnees from Arabian Gulf countries (Bélanger \& Rahman, 2013; Dannecker, 2005). Past traumatic incidents also affect returnees' social interactions and sense of belonging to their home community. The findings of Ketema (2014) found that sexually abused female returnees from the Arabian Gulf find it difficult to create healthy relationships with men in their home community after their return. Positive social relationships and a sense of belonging are important for the economic and social development of returnees, as well as their integration into the home community.

Sense of belonging theory helps to evaluate social relationships and people's connection to their environment. It has two attributes: first, valued involvement, which is "the experience of feeling valued, needed and accepted" and, second, 'fit', which refers to a "person's perception that his or her characteristics articulate with or complement the system or environment" (Hagerty et al., 1992, p. 173). Sense of belonging is a psychological state and social interactions, companionship, membership and networks are the means by which belongingness is observed physically (Hagerty et al., 1992; Lee \& Robbins, 1995). Return migrants' interactions with their family, friends and community indicate their sense of belonging to their community. It must be noted, however, that sense of belonging not only refers to positive interactions with others, but also to positive, meaningful, and long-term bonds with members of the community that bring about a feeling of being valued and fitting into the environment (Baumeister \& Leary, 1995).

Based on the above conceptualizations, in this study, sense of belonging is defined as a returnee's feeling of being loved and accepted as a valued member of the community and of fitting into their 
environment, evidenced by positive social interactions and the reciprocity of love within the community. By analyzing the lived experience of female Ethiopian returnees from domestic work in the Arabian Gulf, this study aims to examine the new dynamics that the migration experience brings to the interpersonal relationships of returnees and evaluates their sense of belonging to the home environment and how it affects their reintegration and remigration intention.

\subsection{Methodology}

This ethnographic study is based on field work conducted in Addis Ababa, Ethiopia by the author from January 2015 to March 2017. The findings presented in this chapter are part of a larger study that focuses on the socio-economic reintegration of Ethiopian female return migrants (see Nisrane et al., 2017). The data was collected through focus group discussions and in-depth individual interviews with 48 female Ethiopian former domestic workers who had returned from Arabian Gulf countries and where living in the capital Addis Ababa. The returnees were recruited through purposeful and snowball sampling methods (see Table 1). As reintegration is a matter that requires time, all selected participants had been residing in their home country for at least a year and the majority for three years at the time of data collection.

Table 1. Sampling method used to select respondents for interviews and focus group discussions

\begin{tabular}{|l|l|l|}
\hline Sampling method & Referred by & No. of respondents \\
\hline Purposeful & Agar Ethiopia & 11 \\
\hline & Live Addis & 12 \\
\hline & WISE & 8 \\
\hline Snowballing & Other respondents & 17 \\
\hline Total & & 48 \\
\hline
\end{tabular}

Data for this study was collected in two phases. In the first phase, from January to March 2015, 14 individual interviews were conducted. In the second phase, from January 2016 to March 2017, 22 individual interviews were conducted with new respondents and 6 follow-up interviews with interviewees from the first phase. Follow-up interviews helped to show changes in the social and economic reintegration of returnees after a year's interval. A total of 26 returnees participated in 
the focus group discussions (14 of these also participated in the individual interviews) in both phases.

Semi-structured interview and focus group discussion topics were prepared in English, translated to Amharic (local language) and then back to English for the analysis. The major discussion themes focused on economic and social reintegration, as well as migration experiences in the host country. Probing questions were used as needed. Individual interviews and focus group discussions were conducted in the local language (Amharic) at places chosen by the respondents, including their homes, cafeterias and parks, training centers and, in some cases, the interviewer's house or office. The returnees were fully informed of the research objectives and assured about the confidentially of the information provided. Written or oral consent was obtained. Focus group discussions lasted on average 1 hour and 40 minutes, whereas individual interviews lasted on average 1 hour.

Ethnographic studies also rely also on informal data collected through informal interviews and field notes (Agar \& Hobbs, 1982). Accordingly, the field data for this study is complemented by field notes taken at various personal and social events in the return migrant's community, including weddings, children's birthday parties, graduation ceremonies, and meetings/training organized by local non-government organizations (NGOs). To give a new perspective on issues surrounding the social and economic reintegration of female returnees and to substantiate the data, interviews were also conducted with three coordinators and representatives of local NGOs (Agar Ethiopia, Live Addis, WISE) and one official from the Ethiopian Ministry of Labor and Social Affairs using a semi-structured interview guideline. The interview questions asked of NGO coordinators focused on what major social and economic reintegration challenges returnees face and what social support is provided by NGOs and the government to ensure their successful reintegration.

All discussions and interviews were audio taped. A transcript was made from the audiotape in Amharic by the author and a research assistant. The transcribed documents were subsequently translated into English by a linguist and rechecked by the author for consistency of meaning with the original transcripts. The individual interviews provided detailed accounts of experiences, in contrast to the focus group discussions, which were more general. However, both forms of data collection yielded similar findings and the results complement each other. After re-reading the interviews and focus group discussion transcripts, relevant data (related to returnees' interpersonal relationships and sense of belonging to their community) were selected from the interview 
transcripts and focus group discussions. In the first stage of analysis, themes that showed changes in the interpersonal relationships of returnees with people in their home community because of the migration experiences were identified and coded to identify shared experiences and differences. ATLAS.ti qualitative software was used to facilitate the coding process for the data from both the focus group discussions and individual interviews. A comparison was made to delineate specific categories in the description of situations, interpersonal relationships, and migration and return settings. In the second stage, identified themes were further analyzed to identify their relationship with home country socio-cultural settings and attitudes. The attributes of sense of belonging, such as the feeling loved, fitting in, and being accepted, were often explicitly found in the narrations and sometimes implied, despite the fact that the questions focused on general migration and reintegration experiences and challenges. In the final stage, the relationship between sense of belonging and reintegration and remigration intention was analyzed and is presented in the next section, with quotes that represent the most common experiences of returnees.

\subsection{Findings: Interpersonal relationships, belonging and reintegration}

The study found that the social relationships of female migrants change dramatically upon their return. Three major themes emerged as affecting the interpersonal relationships of returnees with members of their family and community: first, conflict between returnees and close family members related to betrayal; second, the expectation of members of their family and community that returnees had resources; and third, stigma and negative social perceptions of returnees held by members of their family and community. These factors intersect and overlap with each other, together creating a low sense of belonging among returnees to the home community. They are also linked to the poor reintegration of returnees into their home country and the emergence of remigration intention.

\subsubsection{Conflict with family related to betrayal}

The need to belong is characterized by stable, positive, and conflict-free social contact with individuals to whom a person feels connected (Baumeister \& Leary, 1995). In this study, it was found that conflict often arises between close family members ${ }^{8}$ and the returnees from Arabian

\footnotetext{
8 'Family' in this study refers to parents, siblings, spouse and, in some cases, close relatives such as uncles, aunts and cousins.
} 
Gulf countries. The study also found that family was at the heart of the migration process, with economic deprivation of the family being mentioned as the main reason for the migration of female migrants in the first place. Forty percent (40\%) of the returnees measured their success by what they did for their family members, even if they had no income or savings for themselves upon return. Supporting parents in household consumption, sending siblings to a better school, supporting family members to obtain better health care, renovating the family house and buying household furniture were mentioned by returnees as some of the benefits of their migration. The vast majority $(81 \%)$ of respondents reported not having their own income and being dependent on their families financially upon return. For some, receiving the blessing of their parents ('mirkat' in the local language) is the best reward for their toil in a foreign country. One participant, who stayed in Saudi Arabia for 22 years supporting her family, and had no savings or income at the time of data collection, reported being happy regardless of the fact that she was now dependent on her family for her financial needs.

I am happy I could make my family happy. Of course, they [her family] did not save any money for me but, I don't complain much because my family's happiness is my reward. That makes me a very happy woman. Happiness is not always measured in terms of money [...]. To tell the truth, I couldn't change anything for myself. I am not changed at all. I am 41 years old now and I live with my family. (Focus group discussion 4, p. 5, Addis Ababa, 2015)

The above quote illustrates the love and sacrifice of some returnees for their family. It also reveals a sense of loss and dissatisfaction on the part of the returnee for losing her youth in a foreign land and being financially dependent on her family in her 40s. This kind of narration was common among returnees. In most cases returnees used such a narration to accept the fact that their migration experience did not benefit them directly. Most returnees mentioned often that they regretted leaving their education to go to the Arabian Gulf in order to improve the living conditions of their family, although a few reported being happy about their decision. Many returnees are elementary or high-school dropouts, which makes it difficult for them to find even low-skilled jobs upon their return. High inflation and lack of savings and marketable skills makes it difficult for returnees to participate in income generating activities in their home country. The average length of stay in the host country for the participants in this study was 8 years (minimum 6 months; 
maximum 22 years). Some returnees described how time flies and how their youthful beauty was lost in a foreign land striving to help their family and not themselves.

Paradoxically, despite their claim that their migration was for the sake of their family, almost all of the returnees expected their family to save money from the remittances they sent and reported feeling betrayed that they did not. In most cases, the family members of returnees spent the money without saving any for the returnees. Only three returnees who participated in this study reported that their family members saved some of the money they sent and that they were able to use it for their reintegration. The majority sent remittances to their parents and siblings, while a few sent it to their husband or fiancée. Some returnees who sent money to their partner later learnt that the money was wasted on alcohol and drugs, an affair or even marriage with another woman. Based on the narrations of the participants in the individual interviews, some returnees (40\%) specifically told their family members how much to use and how much to save, others (44\%) trusted family members to save as much as they could and some (16\%) either said nothing about saving or saved money in their own account. A few participants tried to understand the dire economic condition that their family was in and did not blame them for not saving money; however, about half of the participants reported feeling betrayed. One returnee shared the following: "I sent all the money I have worked for to them [her family]. When you find out that your own family do not keep their word, you feel betrayed. Thus, you want to go back" (Interview 23, Addis Ababa, 2015). As reflected in her narration, this returnee seems to feel betrayed because the action she is complaining about involved people she perceived to be close to her.

Besides violation of trust, there are other factors that are a source of conflict between returnees and their family members. For example, when the sacrifice made for the family and their response is not congruent it can negatively affect the interpersonal relationships between the returnee and their family members: "I quarrel with my family and tell them that I have suffered a lot for their sake. But when you are broke, nobody cares. This makes you sick. When you have money, they like you" (Interview 27, Addis Ababa, 2017). As live-in domestic workers often send their entire salary ${ }^{9}$ to their family members, they are financially dependent on family members upon their return, which is another source of conflict between the returnees and their family members. The

\footnotetext{
${ }^{9}$ Under the kafala system, migrant domestic workers are only allowed to work as a live-in maid for one sponsor and prevented from going out, hence, they often send their entire salary home as they do not have local expenses.
} 
returnees claim they are regarded as a burden. Regret and disappointment is clear when they talk and when they reflect on what the future holds for them without any savings or marketable skills to enable them to successfully reintegrate into their home country. In both focus group discussions and individual interviews, not only negative interactions and lack of reciprocity were problems, the returnees' sense of being valued, loved, and accepted was also low.

The returnees seem to be trapped in a vicious cycle of going and coming. The majority of returnees who participated in this study had migrated more than twice to Arabian Gulf countries. As is reflected in the above quotes, betrayal, particularly by close members, not only results in a low sense of belonging, but also gives rise to an intention to re-migrate. The study found that, next to economic reasons, negative interactions and low sense of belonging in the family and community are the main reasons for female returnees from Arabian Gulf countries to re-migrate. Fifty percent $(50 \%)$ of the returnees said they may consider going back if the official route is opened (at the time of the field work it was closed by the Ethiopian government following the reported exploitation and abuse of Ethiopians in destination countries). By the end of data collection, $8 \%$ of the returnees who participated in the study had left through illegal means, $20 \%$ said that they did not want to go back, while the rest were undecided. One participant shared the following: "I get upset when I look at my life. I benefited neither here nor there. This always make me ask questions such as where will I end up and what is my destiny" (Interview 28, Addis Ababa, 2017).

In summary, $84 \%$ of the returnees expected their family members to save some of the money they sent home for their reintegration upon return. However, trust-based remittance management appeared to be counterproductive to the reintegration of the returnees for two reasons. First, the violation of trust and lack of reciprocity (not getting enough love or recognition for the sacrifice they made for their family) disrupted interpersonal relationships between family members. Second, migrants' families generally did not save any of the remittances, which meant that returnees did not have any financial capital to use for reintegration. Negative interpersonal interactions meant that the returnees did not receive from the emotional support required to successfully reintegrate back into the community. In addition to creating conflict and negative social interactions, betrayal by their close family members affected the returnees' perception of being loved and valued. When the expected reciprocal love was not received from family members, the returnees questioned whether the sacrifice they had made for their family by working in the Arabian Gulf countries was 
worth it. Feelings of regret, disappointment and hopelessness were reflected in the discussions with returnees. The sense of belonging to the family (being valued and needed and fitting in) was low for most returnees. In some cases, negative social interactions and low sense of belonging in the community were found to be a source of remigration intention.

\subsubsection{Expectation of resources}

As well as conflict with close family members, this study found that social expectations associated with working abroad also negatively affect the interpersonal relationships of returnees. There is a strong conception in Ethiopian society that people who migrate abroad come back with a lot of money. Return migrants are confronted with this assumption and are expected to bring financial and material gifts, not only for nuclear family members, but also for members of their extended family, close neighbors and friends. In relation to this, three themes emerged: first, pressure to meet social expectations; second, the shame associated with not meeting social expectations; and third, being rejected for not meeting social expectations. These factors negatively affected the personal interactions of returnees and their sense of belonging to the community, creating a barrier to their successful reintegration.

Trying to bring various financial and material gifts for family members, relatives and others is a very stressful experience for returning migrants. The migration experience of female domestic migrants in the Arabian Gulf is characterized by inability to change employers and financial exploitation, including underpayment and denial of wages. In addition, the migrants send their money periodically to family members in the home country, making saving or buying gifts extremely difficult, if not impossible. The majority of returnees reported trying to meet this expectation, even if they did not agree with the norm or did not have the financial resources to do so. Returnees think about and prepare for this expectation before they return to their home. ' $E k u b$ ', a traditional Ethiopian financial cooperative, is one form of social membership that is practiced among freelance migrants ${ }^{10}$ that enables returnees to buy gifts upon their return. This system is followed by close friends who trust each other and members contribute money periodically ahead of time for a specific purpose. Some are able to bring gifts for close as well as extended family

\footnotetext{
${ }^{10}$ Freelance migrants are those who work in the host country independently from a sponsor or for a fake sponsor, in other words, illegally.
} 
members, neighbors and friends. However, family members and relatives sometimes do not find the quality or type of gift satisfactory.

Most returnees care about this social norm of gift giving, although it is described by many as 'yulignta' (being too concerned about the opinion of others). Family members also want to show off the fact that they have sent a daughter abroad by giving gifts to relatives, neighbors and friends. Most of the returnees cannot meet this expectation, at least at the level that satisfies their relatives, neighbors and friends, for various reasons. This affects their interpersonal relationships and sense of belonging in the community, as they have to deal with the rejection that comes with not fulfilling the norm. For example, one returnee described the irony of the social norm and how it forced her to isolate herself:

I was frustrated and used to lock myself up in the house. All your relatives expect you to give them money or a gift. If you migrate to the Arabian Gulf or two months with a salary of 3,000 birr [USD 100] and one works within the country with a salary of 50,000 [USD 1,667], just because that individual went abroad people expect that person to come with a bag full of money. Most of my relatives were disappointed in me as they were expecting something from me... I was frustrated so much and regret coming back here. I had nothing, but my relatives did not understand or did not want to understand at all the situation I was in. (Interview 1, Addis Ababa, 2015)

The rejection and shame this returnee experienced is well reflected in her narrative and was a common experience among the other returnees who participated in the study. As a result, the returnee's interpersonal relationships with significant others were affected and she had a low sense of belonging (feeling loved and valued and fitting into the environment) to the extent that she questioned whether returning was the right decision. The sense of shame associated with not being able to satisfy social expectations and coming home empty handed is strong. Some returnees explain how the shame of coming home empty handed prolonged their stay in the host country with a lot of suffering and isolated them after they returned home. Social expectations have a great impact on the social relationships of returnees and their sense of belonging. The social interactions and relationships of female return migrants is also affected by the shame associated with a failed migration experience and inability to continue the role of bread winner for the family. The data 
also shows that the majority of returnees live with the guilt and shame associated with an unaccomplished migration goal, which the migrants generally respond to by isolating themselves:

If you don't have money, nobody loves you even your family, friends or your boyfriend. If you are broke nobody likes to be around you [...]. You see, people need you when you have money. I don't have money so nobody wants me and I don't need them also. I really don't have social engagements. (Interview 10, Addis Ababa, 2015)

Being valued and respected is one element of belonging. Most returnees believe that their family members love them and respect them only when they are a source of income. This creates uncertainty in terms of fitting in to the environment when they do not have financial resources.

Not being valued or respected is not the only issue for return migrants, they also experience rejection for coming home empty handed. For example, one returnee, who had a very bad migration experience with high isolation, heavy workload, denial of salary for one year, starvation, and psychological trauma (threat of being killed by her employer), was extremely happy to come back to her home country alive. However, her close family members did not accept her warmly, instead she experienced rejection and exclusion:

My relatives expected me to give them some money. When they realised that I had nothing, they started to keep away, hate me [...]. I kept my distance from my relatives as they couldn't accept me with an empty hand [...]. I don't understand why my relatives blame me for not giving them money. They expect a lot just because I went to the Arabian Gulf. Only God knows what I have been through. They think I have money and I don't want to share it with them. That is really very disappointing. (Interview 9, Addis Ababa, 2015)

Such rejection plays an adverse role in the reintegration of returnees. As belonging focuses on the quality of relationships and the strength of the bonds in interpersonal relationships. The fact that conflict arises mostly with close family members affects returnees' sense of belonging. The study found that returnees experienced various traumatic incidents at the hands of their employers and agents (both Ethiopian and Arab) while in the host country. Few migrants had a good migration experience. Most stated that they were subjected to sexual abuse, starvation, psychological trauma such as death threats, attempted killing, isolation, beating, overwork, forced servitude to other households, and degrading verbal comments. These factors by themselves have impact on the 
interpersonal relationships of returnees and their connectedness to others in their community. For example, as documented in this study and a study by Ketema (2014), women who are sexually abused exhibit low or no interest in becoming involved in another intimate relationship upon return. In addition to traumatizing experiences in the host countries, experiencing rejection from loved ones upon return may have undesirable consequences, affecting both the mental and physical health of returnees (MacDonald \& Leary, 2005) and their social and economic reintegration.

The expectation that returnees have a significant amount of material and financial resources is not limited to family members and relatives of returnees. Returnees also reported that it was difficult to start or maintain spousal relationships because of this belief. In Ethiopian society, men are regarded as the provider for their family, however, changes in this gender role requirements were also evidenced by the data. In this study, the participants acknowledged that it was hard to trust men and that their romantic relationships often ended if the returnee did not accumulate financial or material resources from their migration. The majority of respondents claimed that men approached them thinking that they have money and, when they find out that they don't, no longer want to be with them. The following quote from one of the interviews exemplifies this:

I had a boyfriend before traveling to the Arabian Gulf. But he married another woman while I was there [...]. He cheated on me. I worked hard to build our future. I used to send a lot of money to him, but he wasted it all on another woman. It was devastating. I don't trust men anymore [...]. Once my friend arranged a date for me. She introduced me to a guy. On our second date, he asked me how much money I have. He said, "I bet you have a lot of money; I heard you returned from Arabian Gulf'. (Field work 2015, Addis Ababa, Interview 28)

Violation of trust, rejection and not being valued for who they are, but what they might have, were dominant themes in the narrations of returnees in relation to their post-return experiences. Repeated rejection and betrayal by men led the returnees to avoid social interactions: "I don't trust anyone. What I believe is that they will take advantage of me and leave me alone just as my family did. Therefore, I don't trust anyone" (Interview 23, Addis Ababa, 2017). This contradicts the strong desire of most returnees to start their own family. Inability to form a family and have children is considered to be one of the major costs of the migration experience by returnees. The returnees regret wasting their youth in a foreign country and feel that their marriage prospects have 
declined. They also acknowledge the pressure from parents and the community. Only 7 of the 48 returnees who participated in this study are married or have been married (three divorced because of conflict related to the migration) and have children. The relationship between marital partners is also spoilt by lack of trust and perceived or real infidelity. However, seventeen of the returnees had children, mainly out of wedlock and before their migration. Almost all of the returnees reported that they left their children in the care of their mothers when they migrated. The returnees also reported that their children sometimes rejecting them due to the long separation, which resulted in low or no attachment.

I always have a fight with my daughter and have no peace at home [...]. We have not been together for long and she doesn't like me at all. She doesn't have a tiny bit of love or respect for me. I worked so hard in a foreign land to change her future, but lost the love of my child. (Interview 10, Addis Ababa, 2015)

In summary, rejection by close family members or others because of expectations that the returnees have financial or material resources impacts on the various interpersonal relationships of the returnees and raises uncertainty about how they fit into the home environment. The vast majority of returnees respond to this rejection by isolating themselves and avoiding social interactions. This finding is in line with other studies on relatedness, which found that people who are less connected feel distant and perceive themselves to be outsiders, often finding it difficult to interact with the social world (Lee, Draper, \& Lee, 2001). Inability to meet expectations was frustrating for most returnees. Having no or few financial resources was a shameful experience and often made returnees restrict their social engagements. This strengthens other findings that postulate that being poor restricts people's desire for relationships and sense of belonging (Stewart et al., 2009). Being financially dependent on their families after return is common among the returnees. At the same time, stepping down from the expected status attached to working abroad was a shameful experience and a barrier to becoming involved in a low paying job for some of the returnees. In general, the above findings indicate that the social expectations on returnees create a low sense of belonging because of rejection, shame and doubts about fitting into the environment. Not meeting people's expectations results in rejection by society in the home country and self-isolation by the returnees. This may affect the social and economic reintegration of returnees and their remigration intention. 


\subsubsection{Negative perceptions and stigma}

Negative perceptions and stigma can lead to poor interpersonal relationships and, hence, affect people's relatedness to their environment and sense of belonging. Social perceptions of the migration experience of women to the Arabian Gulf are generally negative. The returnees described being stereotyped and stigmatized by people in their home community. Two dominant stereotypes were associated with female returnees from the Arabian Gulf. First, the returnees were identified as mentally unfit (weird or crazy) and, second, they were considered promiscuous and associated with sex work or prostitution. These stereotypes and stigma created a barrier to migrants interacting with people in the community. The migration experience puts a mark of disgrace on the female returnees for life. The returnees explained how difficult it is to deal with such negative perceptions given the fact that they cannot exclude the migration experience from their life. For example, one returnee who was rejected by her own family, as they thought she was working as prostitute while she was in the host country and wrongly associated her weight loss with HIV infection, explained the feeling of isolation, betrayal and rejection she felt:

I hated going outside and meeting people. I didn't even agree with my family and I was crying all the time. I didn't go out and I stayed home for a long time [...]. At the beginning, I even wanted to be a prostitute or go back there again. I tried to commit suicide once [...]. When I came back here at first, I did not work and did not have any money. I guess my family expected a lot from me. I came here with empty pockets. [...]. When my employers took me to the office and I knew they were going to send me back to my country, I was really disappointed and tried to kill myself. (Interview 23, Addis Ababa, 2017)

This quote shows the stigma, rejection and isolation that the returnee experienced. This returnee migrated to the Arabian Gulf twice and how her family treated her after she returned the first time caused her to attempt suicide. There is evidence that suicidal ideation (Kissane \& McLaren, 2006; Vanderhorst \& McLaren, 2005) and the experience of stigma (Walton \& Cohen, 2007) are associated with a low sense of belonging. The majority of returnees reported experiencing stigma and rejection from people with whom they had desired relationships. This shows that the 'home country' is not always an environment in which returnees feel at home - a home they aspire to return to and feel safe, loved, valued and accepted in. Negative interactions and conflict with family members was a trigger for some returnees to migrate again. Returnees reported travelling 
back to Arabian Gulf countries on multiple work contracts (see also Fernandez, 2010). Economic reasons were often mentioned as a cause, such as unemployment or low wages. However, negative social interactions with family members also contribute greatly.

The returnees admitted that the negative perceptions of returnees had some truth (some returnees had been engaged in sex work in the Arabian Gulf), but they are disappointed that all returnees are judged because of the activities of some women. There are female migrants who are locked in the house and never see the sun until the end of their contract, others are sexually abused or raped. However, these returnees are also perceived as a 'bad' woman. Regarding being involved in prostitution, the returnees reported that many migrants escape from their sponsor because of exploitation and abuse or to earn a better income (becoming 'freelance migrants'). This act immediately changes the status of the migrants in the host country from legal to illegal. The runaways need to sustain themselves economically and often turn to sex work. The returnees also admitted that many returnees from the Arabian Gulf suffer from mental health problems and attribute the cause to ill treatment, the poisoning of migrants by employers (to keep them for longer or to avoid paying their salary), isolation and other traumatic experiences in the host country (see Anbesse et al., 2009 and Habtamu et al., 2107 for similar findings).

Their migration experiences influenced the behavior of some returnees. The returnees who participated in this study admitted that they are easily irritated, speak loudly, isolate themselves, wear a lot of makeup and jewelry, use strong perfume, dress in colorful or sparkly clothes, and wear a lot of accessories. The respondents provided an explanation for some of these behaviors; for example, speaking loudly is associated with the 'mukeyaf' (air conditioner) in the houses in the Arabian Gulf - it makes noise, so every member of the house speaks loudly. Irritability is often associated with frustration and shame is associated with failed migration and being financially dependent on their family instead of being a provider. Dressing colorfully and using a lot of makeup relate to their identification with the host country culture.

Sense of belonging encompasses feeling valued and loved by others (Baumeister \& Leary, 1995). Most returnees stated that they are not taken seriously in most interactions with their family members and in the community and that they are not desired for marital relationships. Some returnees reported hiding their migration experience for fear of rejection and so as not to jeopardize their relationships, including intimate relationships. Stereotyping greatly damages their desire to 
form a family or maintain already established marital relationships. This puts pressure on the returnees, as marriage is highly valued in Ethiopia and regarded as completing womanhood. Not fulfilling this desired relationship can cause alienation and detachment from society. The study found that stereotypes and shame are a cause of poor social interaction and low sense of belonging in returnees' lives. Some of the participants in this study are isolated and do not feel accepted in the community, as evidenced by the following quote:

[...] I did not experience anything bad, but working in the Arabian Gulf made me fearful. I felt ashamed. I could not go along with friends. I became sensitive to what people were saying and felt like they were trying to hurt my feelings. I didn't want to go out and meet friends, but rather chose to stay in the house. (Interview 3, Addis Ababa, 2015)

Stereotypes associated with the migration experience bring about changes in the self-perception of returnees, their social interactions and sense of belonging. The perceptions of others affect a person's self-worth (Buckley, Winkel, \& Leary, 2004). It challenges their feeling of fitness for and acceptance in the social environment, which adversely affects their social and economic reintegration. Another indication that returnees suffer isolation, have poor social interaction and a low sense of belonging is that $80 \%$ of returnees reported staying home most of the time and only going out for weddings and funerals; the rest mentioned going to churches or mosques, in addition to mandatory social engagements such as funerals. This limited social interaction also relates to their limited economic resources (Nisrane et al., 2017). However, shame associated with unachieved migration goals, stigma and negative social perceptions contributes to this behavior.

\subsection{Conclusion and recommendations}

This study investigated the new dynamics that unfold in the interpersonal relationships of female Ethiopian domestic migrants upon their return from the Arabian Gulf. It also looked at how their interpersonal relationships affect the returnees' sense of belonging, reintegration and remigration intention. It found that negative social interactions resulting from betrayal by close family members, social expectations about money and gifts, and negative social perceptions of returnees affected their sense of belonging to the home community. These factors impacted on the returnees' feeling of being loved and valued and raised uncertainty about them fitting into the home environment. In turn, these factors influenced the returnees' desire to stay in their home country and their remigration intention. 
Negative interpersonal interactions mean that returnees do not receive the emotional support required to successfully reintegrate into the home community. Not being accepted, or even being rejected, by people in the community, including by close family members, and inability to bring about significant economic changes in their own life, apart from their family's life, made the returnees question whether they fit into the home environment and whether migrating to the Arabian Gulf was worthwhile in the first place. About $50 \%$ of the returnees said that they may consider going back if the official route was reopened, $8 \%$ had already left through illegal means by the end of data collection, $20 \%$ said that they do not want to go back, while the rest were undecided. The study indicated that negative social interactions was among the factors influencing remigration intention, as was low sense of belonging. Low sense of belonging, next to economic reasons, explains why returnees are willing to return to the Arabian Gulf, despite the risk of exploitative and abusive working conditions. Hence, reintegrating into the home community is not only dependent on the migration experiences of the returnees in the host country, but intertwined with various social issues in the home country. Positive social interactions and a sense of belonging are important for return migrants to successfully reintegrate, socially and economically.

For the returnees who participated in the study, the migration experience did not bring about personal economic gains and improved social status, as expected. Instead they incurred social costs that cannot be measured in monetary terms. The study found that although the family of the migrants experienced some positive economic and social changes, the majority of returnees did not have any savings of their own from their migration, making them economically dependent on their family upon return. This study casts doubt on the claim by other studies that migration to the Arabian Gulf is an empowering experience for women and leads to upward movement on the social ladder (Kifleyesus, 2012), in line with Ketema (2014).

This study provides valuable insights into how home country social issues may impact on the reintegration of female domestic workers returning to Ethiopia from the Arabian Gulf and their intention to re-migrate. It serves as a starting point for the further analysis of experiences and issues facing returnees in the home country in relation to reintegration. It also provides a self-evaluation of the returnees' sense of belonging to their home community. However, it has some limitations related to its scope, which might guide future researchers. First, the participants in this study were all living in Addis Ababa, whereas a significant number of women migrate to the Arabian Gulf 
from rural parts of Ethiopia. Hence, the social perceptions and social interactions uncovered in this study may not represent returnees in rural areas. Second, this study used the personal stories of returnees to evaluate social perceptions. Triangulating the results by using various sources, such as family and community members, is suggested for future research. Third, this study found that female returnees are perceived as socially unfit because of stereotypes associated with their migration. Similar findings were made in other studies conducted in Asia (Bélanger \& Rahman, 2013; Dannecker, 2005). This similarity may arise because of the existence of a patriarchal social structure in both places. However, our study did not analyze patriarchy or gender roles, which was the case in the other studies. Indeed social perceptions and the treatment of male and female returnees are different. The majority of participants in this study acknowledged that Ethiopian men generally lead a loose lifestyle, having many intimate relationships with women, including exploiting vulnerable female migrants while in the host country. ${ }^{11}$ However, the stereotype of promiscuity is mainly associated with female returnees. This study did not include the accounts of male returnees, so is unable to answer whether a difference exists in the treatment of female and male returnees. However, it is important to see if patriarchy plays a role and it is suggested that future researchers explore this issue.

The experience of belonging is not only beneficial to the returnees, it also impacts on the community and society at large. A sense of belonging is associated with a higher level of achievement and productivity, which impacts on the community and society over a period of time. Hence, it would be beneficial to society at large to implement policy interventions to improve the reintegration of Ethiopian female domestic migrants returning from the Arabian Gulf. Four policy recommendations can be drawn from this study.

- First, social support and counselling programs that address problems with interpersonal relationships should be encouraged.

- Second, one reason why migrants send their entire salary to family members in their home country is because they do not have anywhere to save it while they are in the host country

\footnotetext{
${ }^{11}$ They persuade the migrants to escape from their sponsors, once the women leave their employers they become illegal, hence, the agents and brokers force the migrants into sexual relationship in exchange for job placement and a house where they can stay.
} 
(Nisrane et al., 2017). The option they have is to either keep it with them or save it with their employer, both of which are risky. Hence, creating a remittance system that cultivates the independence of migrants will help them to develop positive relationships upon their return, as well as facilitate better economic reintegration through savings.

- Third, depending on family members for financial needs is a cause of negative interactions and low sense of belonging. Hence, educational programs and vocational training should be provided to returnees, especially given that many of the migrants are elementary or highschool dropouts.

- Finally, to address the issues of unrealistic social expectations and negative social perceptions, media campaigns should be run to change the society's attitude to returnees. 


\section{References}

Agar, M., \& Hobbs, J. R. (1982). Interpreting discourse: Coherence and the analysis of ethnographic interviews. Discourse Processes, 5(1), 1-32.

Anbesse, B., Hanlon, C., Alem, A., Packer, S., \& Whitley, R. (2009). Migration and mental health: A study of low-income Ethiopian women working in Middle Eastern countries. International Journal of Social Psychiatry, 55(6), 557-568.

Bajracharya, R., \& Sijapati, B. (2012). The Kafala system and its implications for Nepali domestic workers. Policy Brief, 1, Centre for the Study of Labour and Mobility (CESLAM).

Baumeister, R. F., \& Leary, M. R. (1995). The need to belong: Desire for interpersonal attachments as a fundamental human motivation. Psychological Bulletin, 117(3), 497.

Bélanger, D., \& Rahman, M. (2013). Migrating against all the odds: International labour migration of Bangladeshi women. Current Sociology, 61(3), 356-373.

Buckley, K. E., Winkel, R. E., \& Leary, M. R. (2004). Reactions to acceptance and rejection: Effects of level and sequence of relational evaluation. Journal of Experimental Social Psychology, 40(1), 1428.

Cacioppo, J. T., \& Cacioppo, S. (2014). Social relationships and health: The toxic effects of perceived social isolation. Social and Personality Psychology Compass, 8(2), 58-72.

Cassarino, J.-P. (2004). Theorising return migration: The conceptual approach to return migrants revisited. International Journal on Multicultural Societies, 6(2), 253-279.

Cohen, S. (2004). Social relationships and health. American Psychologist, 59(8), 676-684.

Dannecker, P. (2005). Transnational migration and the transformation of gender relations: The case of Bangladeshi labour migrants. Current Sociology, 53(4), 655-674.

Demissie, F. (2018). Ethiopian female domestic workers in the Middle East and Gulf States: an introduction. African and Black Diaspora, 11(1), 1-5.

De Regt, M., \& Tafesse, M. (2016). Deported before experiencing the good sides of migration: Ethiopians returning from Saudi Arabia. African and Black Diaspora: An International Journal, 9(2), 1-15.

Fernandez, B. (2010). Cheap and disposable? The impact of the global economic crisis on the migration of Ethiopian women domestic workers to the Gulf. Gender \& Development, 18(2), 249-262.

Fernandez, B. (2013). Traffickers, brokers, employment agents, and social networks: The regulation of intermediaries in the migration of Ethiopian domestic workers to the Middle East. International Migration Review, 47(4), 814-843.

Frantz, E. (2008). Of maids and madams: Sri Lankan domestic workers and their employers in Jordan. Critical Asian Studies, 40(4), 609-638.

Gikuru, C. M. (2013). The plight of Kenyan domestic workers in Gulf Countries. Master's dissertation, International Studies, University of San Francisco.

Habtamu, K., Minaye, A., \& Zeleke, W. A. (2017). Prevalence and associated factors of common mental disorders among Ethiopian migrant returnees from the Middle East and South Africa. BMC Psychiatry, 17(1), 144.

Hagerty, B., Lynch-Sauer, J., Patusky, K., \& Bouwsema, M. (1993). An emerging theory of human relatedness. Journal of Nursing Scholarship, 25(4), 291-296.

Hagerty, B., Lynch-Sauer, J., Patusky, K., Bouwsema, M., \& Collier, P. (1992). Sense of belonging: A vital mental health concept. Archives of Psychiatric Nursing, 6(3), 172-177.

Hagerty, B. M., Williams, R. A., Coyne, J. C., \& Early, M. R. (1996). Sense of belonging and indicators of social and psychological functioning. Archives of Psychiatric Nursing, 10(4), 235-244.

Human Rights Watch. (2014). 'I already bought you': Abuse and exploitation of female migrant domestic workers in the United Arab Emirates. Retrieved from: https://www.hrw.org/report/2014/10/22/ialready-bought-you/abuse-and-exploitation-female-migrant-domestic-workers-united (accessed 26 September 2018). 
Jones, N., Presler-Marshall, E., Tefera, B., Emirie, G., Gebre, B., \& Gezahegne, K. (2014). Rethinking girls on the move: The intersection of poverty, exploitation, and violence experienced by Ethiopian adolescents involved in the Middle East 'maid trade'. A report submitted to Overseas Development Institute and funded by Oak Foundation.

Jureidini, R., \& Moukarbel, N. (2004). Female Sri Lankan domestic workers in Lebanon: A case of contract slavery? Journal of Ethnic and Migration Studies, 30(4), 581-607.

Ketema, N. B. (2014). Female Ethiopian migrant domestic workers: An analysis of migration, returnmigration and reintegration experiences. University of Oregon.

Kissane, M., \& McLaren, S. (2006). Sense of belonging as a predictor of reasons for living in older adults. Death Studies, 30(3), 243-258.

Kitchen, P., Williams, A., \& Chowhan, J. (2012). Sense of belonging and mental health in Hamilton, Ontario: An intra-urban analysis. Social Indicators Research, 108(2), 277-297.

Lambert, N. M., Stillman, T. F., Hicks, J. A., Kamble, S., Baumeister, R. F., \& Fincham, F. D. (2013). To belong is to matter: Sense of belonging enhances meaning in life. Personality and Social Psychology Bulletin, 39(11), 1418-1427.

Lee, R. M., Draper, M., \& Lee, S. (2001). Social connectedness, dysfunctional interpersonal behaviors, and psychological distress: Testing a mediator model. Journal of Counseling Psychology, 48(3), 310.

Lee, R. M., \& Robbins, S. B. (1995). Measuring belongingness: The social connectedness and the social assurance scales. Journal of Counseling Psychology, 42(2), 232.

Levett-Jones, T., \& Lathlean, J. (2008). Belongingness: A prerequisite for nursing students' clinical learning. Nurse Education in Practice, 8(2), 103-111.

Levitt, P., \& Jaworsky, B. N. (2007). Transnational migration studies: Past developments and future trends. Annual Review of Sociology, 33, 129-156.

MacDonald, G., \& Leary, M. R. (2005). Why does social exclusion hurt? The relationship between social and physical pain. Psychological Bulletin, 131(2), 202.

Mahdavi, P. (2013). Gender, labour and the law: The nexus of domestic work, human trafficking and the informal economy in the United Arab Emirates. Global Networks, 13(4), 425-440.

Martin, A. J., \& Dowson, M. (2009). Interpersonal relationships, motivation, engagement, and achievement: Yields for theory, current issues, and educational practice. Review of Educational Research, 79(1), 327-365.

Minaye, A. (2012). Trafficked to the Gulf States: The experiences of Ethiopian returnee women. Journal of Community Practice, 20(1-2), 112-133.

Minaye, A., \& Zeleke, W. (2015). Re-conceptualizing human trafficking: The experiences of Ethiopian returnee migrants. Journal of Trafficking, Organized Crime and Security, 1(1), 9-23.

Murray, H. E. (2013). Hope for reform springs eternal: How the sponsorship system, domestic laws and traditional customs fail to protect migrant domestic workers in GCC countries. Cornell International Law Journal, 45, 461.

Nisrane, B. L., Morissens, A., Need, A., \& Torenvlied, R. (2017). Economic reintegration of Ethiopian women returned from the Middle East. International Migration, 55(6), 122-136.

Pande, A. (2013). The paper that you have in your hand is my freedom: Migrant domestic work and the sponsorship (kafala) system in Lebanon. International Migration Review, 47(2), 414-441.

Pooley, J. A., Cohen, L., \& Pike, L. T. (2005). Can sense of community inform social capital? The Social Science Journal, 42(1), 71-79.

Prusak, L., \& Cohen, D. (2001). How to invest in social capital. Harvard Business Review, 79(6), 86-93, 147.

Stewart, M. J., Makwarimba, E., Reutter, L. I., Veenstra, G., Raphael, D., \& Love, R. (2009). Poverty, sense of belonging and experiences of social isolation. Journal of Poverty, 13(2), 173-195.

Stillman, T. F., \& Baumeister, R. F. (2009). Uncertainty, belongingness, and four needs for meaning. Psychological Inquiry, 20(4), 249-251.

Ullah, A. A. (2013). Mother's Land and Others' Land:"Stolen" Youth of Returned Female Migrants. Gender, Technology and Development, 17(2), 159-178. 
Vanderhorst, R. K., \& McLaren, S. (2005). Social relationships as predictors of depression and suicidal ideation in older adults. Aging \& Mental Health, 9(6), 517-525.

Van Houte, M., \& De Koning, M. (2008). Towards a better embeddedness? Monitoring assistance to involuntary returning migrants from Western countries. A report prepared for Bureau Maatwerk bij Terugkeer (Mediation Agency for Return) Cordaid, the Netherlands. Retrieved from: https://www.ru.nl/publish/pages/533483/towardsabetterembeddedness.pdf (accessed 18 February 2019).

Walton, G. M., \& Cohen, G. L. (2007). A question of belonging: Race, social fit, and achievement. Journal of Personality and Social Psychology, 92(1), 82.

Wickramage, K., De Silva, M., \& Peiris, S. (2017). Patterns of abuse amongst Sri Lankan women returning home after working as domestic maids in the Middle East: An exploratory study of medico-legal referrals. Journal of Forensic and Legal Medicine, 45, 1-6. 


\section{CHAPTER 6}

\section{Summary of Main Findings and Conclusion}

In the wake of the mass deportation of around 163,000 illegal Ethiopian residents from Saudi Arabia in 2013/14, Ethiopia experienced a return crisis. This forced the government, as well as international and local non-governmental organizations (NGOs), to respond by helping returnees reintegrate into the socio-economic context of their home country. The crisis also gained the attention of many researchers, and academic efforts were undertaken to understand the different facets of the problem. How the sudden expulsion affected the reintegration of returnees, the traumatic experiences migrants went through on their way back to their home countries, and what reintegration challenges return migrants are facing are some of the questions that received scholars' attention (De Regt \& Tafesse, 2016; Jones et al., 2014; Mulugeta \& Makonnen, 2017). This dissertation contributes by providing insights into the academic and practical aspects of the socio-economic reintegration of Ethiopian female returnees from the Arabian Gulf. This final chapter sets out the main findings of each chapter (section 6.1), the theoretical contribution of the study (section 6.2), the limitations of the research and suggestions for future research (section 6.3), practical implications of the findings (section 6.4), and concluding remarks (section 6.5).

\subsection{Main findings}

The main research question of this dissertation is: How do the migration experiences and home country conditions explain the reintegration of Ethiopian return migrants from the Arabian Gulf? Combined, the findings presented in each chapter show that the socio-economic reintegration of female returnees from Arabian Gulf is affected by multifaceted issues that intersect which other. For example, the migration scheme for unskilled labor migrants (kafala) in the Arabian Gulf places the migrants in a precarious position and exposes them to negative experiences, which affect their economic and socio-cultural reintegration upon return. The migration experiences of the women also intersect with various socio-cultural issues (conditions) in the home country, such as gender norms and expectations, which together have a subtle negative impact on the socio-cultural reintegration of returnees, particularly in terms of their relationships and belongingness in the home community. This section sets out the findings from the individual chapters on each of the sub-questions. 


\subsubsection{Exploitation narratives and coping strategies of Ethiopian female return migrants from the Arabian Gulf}

Chapter 2 looked at the question: What traumatic incidents do Ethiopian women domestic migrants in the Arabian Gulf countries experience in the course of their migration and how do returnees cope and make sense of these incidents in their effort to reintegrate into the socio-economic environment of their home country?

Physical, psychological, financial, and sexual exploitation and abuse were common in the migration experiences of the returnees, and sexual harassment and abuse cases were particularly prevalent. While these findings are consistent with other studies (Abu-Habib, 1998; Fernandez, 2010; Jureidini \& Moukarbel, 2006; Kebede, 2002; Pande, 2013), the focus of the chapter was on what coping mechanisms are adopted to deal with exploitation experiences. Coping with exploitation while migrants are in the destination country involves stress management strategies and immediate interaction with the exploiter. Escaping from employers and working as 'freelancers' was a strategy that migrants employed to deal with extreme violation and exploitation. The kafala labor sponsorship system binds migrants to their employer/sponsor throughout their migration period. When migrants go 'freelance' to escape from their employer's house, they automatically become illegal migrants under the law. In cases of exploitation and violation, going freelance was used as a mechanism to resist the unchecked power of employers over domestic migrants. This partially explains how the kafala system indirectly produces irregular migrants who are vulnerable to exploitation. This creates a circular problem. The kafala labor system exposes migrants to exploitation and abuse by employers, then the migrants leave their sponsor to freelance, which further exposes them to sometimes even more traumatic conditions, such as forced sexual slavery by illegal brokers (mainly Ethiopians). This ultimately affects the return and reintegration process of the migrants in their home country.

Traumatic incidents and exploitation experiences have a long-term impact on migrants (Bhugra, 2004), but how returnees come to terms with their past traumatic incidents and make sense of them after their return to their home country is a neglected area in the research and academic debate. This study found that Ethiopian women returnees try to minimize the distress caused by their multiple exploitation experiences and make sense of their past trauma by using meaning-making and benefit-seeking coping strategies. For example, returnees try to understand the sexual, physical, and psychological exploitation they have suffered at the hands of Arab employers by 
using racialized sense-making. The returnees believe that the difference in race between them and their employers contributed to their suffering, although this fails to help them understand suffering inflicted by Ethiopian agents or brokers. In benefit-seeking, the returnees predominantly view the suffering they experienced during their migration as the price paid for the betterment of their families. They also try to cope with their migration-related trauma by making downward comparisons with 'worse-off' migrants and comparing their situation to possible worse scenarios. These findings are useful to help understand how the returnees heal and move on with their life, which is important for their successful socio-economic reintegration in their home country.

\subsubsection{Economic reintegration of Ethiopian women returnees from the Arabian Gulf}

Chapter 3 asked: How do past migration experiences under the kafala labor sponsorship system affect the preparedness to return and economic reintegration of unskilled Ethiopian women returnees? And: To what extent does reintegration assistance and support in the home country enable returnees to build sustainable livelihoods?

In this chapter, the concept of preparedness (Cassarino, 2004) was used to compare and contrast experiences of migrants with different migration (legal/illegal) and return experiences (voluntarily/involuntarily), as well as those who had received reintegration assistance and those who had not. The kafala labor sponsorship system affects migrants' preparedness and economic reintegration in two ways. First, the system forces migrants to stay under the domination of a specific sponsor. This limits the resource mobilization process of the domestic migrants by making them vulnerable to physical, psychological, and financial exploitation and preventing them from finding better employment opportunities. Second, if female domestic workers escape from their sponsors, they are categorized as illegal residents in the country, which makes securing a job and mobilizing resources much more difficult.

Regarding the difference between those who work under the kafala system (legally) and those who work independently without a specific sponsor (in most cases illegally), it was found that those who were working with a sponsor were able to send more money home than those who worked without a sponsor, provided they had a good employer. However, in most cases, as employers have full control of the migrant's stay in the host country, migrants reported experiencing financial exploitation, such as a denial of payment or underpayment. It must be noted, however, that migrants working with a sponsor as a live-in maid are paid less than those who run away and work 
independently. The ones who are working with sponsors were able to save (remit) more because the sponsor covered their living costs. Meanwhile, migrants who run away from their sponsors and work independently (freelancers) were paid better wages, but manage to save little because of high living costs, job insecurity, and unnecessary spending. Unlike other studies, the results of this research found that length of stay in the destination country and returning voluntarily or involuntarily did not affect the ability of the returnees to accumulate resources or the successful of their reintegration. This was because as the length of time in the host country increased, more migrants started working independently without a sponsor, which increased their living costs in the destination country and minimized their savings. In addition, illegal migrants cannot exit the host country unless they pay a high fine for the number of years they stayed illegally in the destination country. This prolongs the length of stay in the host country without necessarily adding to the accumulation of resources.

In conclusion, the chapter shows that personal characteristics and behaviors such as the determination to achieve migration goals, money management skills, and marital status, influenced both resource mobilization in the host country and economic reintegration in the home country. The majority of the returnees were remitting almost their entire earnings to their family in the home country for household consumption and for their own future reintegration. Trust and the high level of social attachment that exists between family members in Ethiopian society explains why the majority of the migrants sent their entire earnings to their family. However, in this specific study, this negatively impacted on the economic reintegration of returnees, as they were unable to save any money for themselves and were sometimes betrayed by their own family members. This shows that, unlike other migration settings, resource mobilization in destination counties and successful reintegration are not directly related in Ethiopia, but are rather mediated by the ability of returnees to access some of the money they send to family members upon their return. It also shows how the cultural context, values, and norms of the home country influence the reintegration process of return migrants.

\subsubsection{Marital prospects of women return migrants from the Arabian Gulf}

In Chapter 4: How do migration experiences to the Arabian Gulf affect the marital prospects of Ethiopian women returnees and their social reintegration in the home country upon return? 
Using the concept of intersectionality, in this chapter the study examined post-return migration experiences, the marginalization and stigma that migrant women experience upon their return, and the impact this has on their social reintegration. While a gender attitude that requires chastity or reserved sexual behavior applies to all women in the Ethiopian context, women who migrate to the Arabian Gulf countries face an additional challenge in relation to marital relationships that is not faced by women who did not migrate or by their male counterparts. Stigma and disruption in the marital relationship for female return migrants in the Asian context have been examined (Afsar, 2011; Bélanger \& Rahman, 2013; Dannecker, 2005). These studies conclude that the stigma and marginalization women experience, particularly regarding marital issues, is linked to the patriarchal notion that women's place is in the home and the gendered view that discourages women from assuming a breadwinning role, as well as the perceived sexual freedom that migrants have. However, this study argues that focusing only on gendered attitudes as an analytic framework does not provide a holistic understanding of the situation. As evidenced in Chapter 4, using an intersectional analytic approach reveals other factors that intersect with gendered attitudes to create the stigmatized position of the returnees regarding marital relations. For example, younger women are preferred for a marital relationship in Ethiopia to guarantee that they are able to bear child. Female migrants often migrate to the Arabian Gulf at a young age and have surpassed the desired marital age for women in Ethiopia upon their return. This creates problems in starting a marital relationship, in addition to problems with stigma, due to the gender attitude that requires women's chastity. The psychological trauma resulting from the sexual violence some women experience in the destination countries was also found to intersect with the gender and age of the returnees. This trauma affected the returnees' self-worth and made them afraid of having an intimate relationship with men after their return.

In conclusion, it was evidenced that the attitudes implicitly embedded in patriarchal culture intersect with age and the sexual violence experienced by the migrants abroad to negatively affect the marital prospects of returnees and their resettlement. To deal with the stigma and negative perceptions of migrants associated with promiscuity, many of the returnees engaged in secrecy or distinguished themselves from 'others' assumed to be involved in prostitution. In addition to society's negative perception of their migration experience, the stigma of staying single beyond a certain age is another reason women are stigmatized. In some cases, pressure from family and relatives push women to enter into an unfulfilling marital relationships or re-migrate abroad. 
Although economic reasons are often mentioned as driving the remigration intention of Ethiopian female migrants (Fernandez, 2010), the findings of this study show that socio-cultural challenges also play a role. If migrants are unable to (re-)adjust to the values, norms, and social institutions in the home country, they feel alienated and will have a low sense of belonging to the community. The findings presented in this chapter bring culture, norms, and social values to the forefront of the discussion on social reintegration.

\subsubsection{Role of interpersonal relationships and a sense of belonging in the home country}

Chapter 5 sought to answer the question: How do home country social norms and culture shape the interpersonal relationships, sense of belonging and reintegration of Ethiopian female return migrants from the Arabian Gulf?

The social relationships of female return migrants with their family members and other people in

their home community change dramatically upon return. Violations of trust, rejection, and not being valued for who they are, but rather what they might have, were dominant themes creating conflict between the returnees and their loved ones. The high expectations of family members (in terms of financial and material support) and inability to meet expectations, as well as having no or few financial resources was a shameful experience that led returnees to restrict their social interaction and sometimes became a cause of remigration intention. Being financially dependent on their families after return was a common experience among the returnees who took part in this study. As also indicated in Chapter 4, returnees are stereotyped as being promiscuous and mentally unfit, and this affects the interpersonal relationships of the returnees with people in their community and family members. This is particularly important in understanding the social reintegration of returnees. Both Chapters 4 and 5 emphasize the understated impact of sociocultural factors on reintegration, as well as the remigration intention of female return migrants from the Arabian Gulf. Surprisingly, in the individual interviews as well as focus group discussions, participants themselves emphasized economic difficulties as a source of reintegration problems and remigration intention. However, deeper investigation into their narrations revealed hidden socio-cultural issues affecting social reintegration, as well as driving remigration intentions. Using an inductive approach was helpful to reveal these hidden socio-cultural reasons for unsuccessful reintegration and the emergence of remigration intention, besides the commonly mentioned economic reason. These findings contribute to migration and reintegration studies by 
shedding light on what factors affect the sense of belonging of Ethiopian female return migrants from Arabian Gulf countries.

\subsection{Theoretical contributions}

This dissertation makes three theoretical contributions to the debate on the reintegration of return migrants into their home country. The first contribution is that it emphasizes the large role of the cultural context in the home country in shaping the reintegration process of returnees. In a collective society such as Ethiopia there is a high level of attachment between family members, which plays a significant role in the migration decision as well as the reintegration of return migrants. Interdependency and trust between family members creates an environment in which migrants send their entire salary to family members in the home country. Unfortunately, this can play a counterproductive role in the reintegration process, as many family members in the home country spend the remittances sent by migrants without saving some for their return and reintegration. Despite the fact that the returnees were dependent on their family for their financial and materials needs upon their return, and felt betrayed by their family for not saving some of their

remittances for their reintegration, many of them tried to cope by emphasizing the benefits and blessings their migration had brought to their family. Some of the returnees in this study said that receiving the blessing of their parents for helping their family, known as 'mirkat', although at their own expense, was satisfying. These findings highlight how values, norms, and traditions in the home country influence the migration as well as the reintegration of returnees. A structural approach to the study of the reintegration of return migrants emphasizes the role of context in the reintegration process; however, the focus is on the need to adjust to cultural values, norms, and traditions for better reintegration. Hence, examining how and why home country cultural values and traditions affect the reintegration process is something that complements the structural approach to study of the reintegration of return migrants.

The second contribution is that, in contrast to other research which emphasizes the importance of length of stay and motivation to return as determining factors for the successful reintegration of returnees (Cassarino, 2004; Van Houte \& Davids, 2008), this study found that the personal characteristics and traits of the migrants, migration setting, and cultural context play a significant role in the successful reintegration of Ethiopian return migrants from Arabian Gulf countries. The preparedness theory proposed by Cassarino (2004) assumes that the successful reintegration of 
returnees in their home country depends on the migrants' preparation to return, which requires time, resource mobilization, and willingness to return. Paradoxically, these factors were not found to be applicable to domestic workers who work under the domination of a specific employer within the kafala labor system. As shown in Chapter 2 of this dissertation, women who stayed longer in host countries did not necessarily mobilize more resources than women who stayed for shorter periods of time. A longer period of time in the host country was not always a positive predictor of resource accumulation and the successful reintegration of return migrants. These things were found to be dependent on the migration setting of the migrant in the destination country. In terms of reintegration, surprisingly, returning voluntarily or involuntarily yielded similar results in terms of the economic reintegration process (measured by the ability of returnees to generate income through employment or entrepreneurial activities and sustain their livelihood). Having a poor educational profile, with no possibility of improving it in the host country - which remains the same for those returning willingly and unwillingly - and continuously helping family members in the home country are two important factors that made involuntarily and voluntarily returning similar for this group of migrants. Of course, collecting all mobilized resources may not be possible in cases of expulsion (De Regt \& Tafesse, 2016). The sharp contrast between this finding and the findings of other research on female domestic workers in the Arabian Gulf relates to the fact that most migrants send their entire wage to their family in the home country before their return. The sudden return of migrants affects the household consumption of returnees' families negatively. However, in this study, sudden return had little impact on the reintegration of the returnees themselves, as family members were not saving money for the migrants from the remittances they were sending. In contrast, the influence of personality traits and personal characteristics (such as marital status and age) was significant, factors that are not considered in the theory of preparedness.

The third contribution of this dissertation to the reintegration debate is that it shows that reintegration is a social process and not solely dependent on the individual efforts of the returnees. Reintegration needs reciprocal action between the returnees and the home society. As indicated in Chapters 4 and 5, the desire of a returnee to reintegrate into the society is not enough - the society must also accept the returnee, which means it is a mutual process. For example, stereotypes and the stigmatization of women returnees from the Arabian Gulf were found to emerge from norms and attitudes associated with the patriarchal social structure in Ethiopia. The returnees were 
alienated and were unable to establish marital relationships because their migration experience was assumed to violate the chastity norm for women or because they were perceived to have been sexually exploited while in the destination countries. Some returnees planned to re-migrate because they were unable to fulfil the societal expectation of womanhood in Ethiopia, which revolves around getting married and having children. In Chapter 5, the importance of considering reintegration as a social process was discussed in detail. It was indicated that returnees' sense of belonging in the community was affected by socio-cultural norms and values that affect relationships between the returnees and the community. In the existing literature, reintegration is perceived as an individual process, but this study argues that it is a social process that necessitates the involvement of returnees in social, economic, and cultural activities and acceptance by the society. In other words, returnees' efforts to fit into or adapt to the home environment may not be enough to bring about successful reintegration, particularly in the social and cultural dimensions of the reintegration process. The home society also needs to make and accept some changes in order for returnees to successfully reintegrate into the socio-cultural environment of the home country. This is a major contribution to the return and reintegration debate, which often focuses on individual efforts by returnees for successful reintegration.

\subsection{Limitations of the study and suggestion for future research}

The results of this dissertation showed the link between migration experiences and the reintegration of female returnees from Arabian Gulf countries. The findings are not only applicable to Ethiopian women returnees from the Arabian Gulf, but also to African and Asian women who migrate under the same migration scheme (kafala) and come from a patriarchal society with a collective culture, like Ethiopia. The insights developed in each chapter of the dissertation contribute to the debate on the reintegration of return migrants. The study findings also highlight the practical reintegration challenges of women domestic workers returning from the Arabian Gulf, due to reasons related to the migration scheme, experiences in the destination country, and sociocultural values in the home society. These practical implications can inform policies and programs on the reintegration of female return migrants from these destinations. While there are valuable findings pointed out in this study that enhance our understanding of the reintegration of low-skilled women domestic workers, there are also some limitations to the study that necessitate caution 
when generalizing the findings and making comparisons with other contexts, as well as areas that call for future research.

A limitation of this study, which is also common to other studies on the reintegration of return migrants, is the lack of a standard measure of successful reintegration of migrants (Koser \& Kuschminder, 2015). This makes comparison with other findings difficult. Remigration intention and remigration indicate the poor reintegration of return migrants (Ghosh, 2000), and are also used as an indicator in this study. In addition, what constitutes the economic or socio-cultural dimensions of reintegration, and the magnitude of each dimension, is debatable. For example, some studies measure economic reintegration by the investment made by returnees and the assets acquired (Setrana \& Tonah, 2014; Thomas, 2008), while others measure it by the ability of returnees to sustain their livelihood (Perruchoud \& Redpath-Cross, 2011). In this dissertation I argued that sustaining's one's livelihood is the basic form of economic reintegration. The ability of migrants to generate income to sustain their livelihood, either through small-scale business or employment, was used as an indicator to evaluate the economic reintegration of the returnees. However, such operationalization may oversimplify economic reintegration, as it is based on the temporary income gained from different sources. In general, inconsistency in the definitions used by scholars, as well as the operationalization of terms, poses a limitation on the generalizability of the findings of this study.

Another limitation that may pose difficulty in generalizing the findings of this study relates to the selection of participants and the data sources used. The participants selected for this research are returnees residing in Addis Ababa at the time of data collection. Negative gender attitudes and masculine dominance is expected to be more pronounced in rural areas, than cities. Considering this, it is recommended that future research on the reintegration of returnees attempts to strengthen the findings by incorporating the experience of women returnees from different rural areas. This will bring new insights about the socio-economic reintegration of returnees that would be useful in relation to both urban and rural returnees.

The findings of this study highlight that there is a difference in the reintegration process between men and women. However, this issue is not well examined here, as it was beyond the scope of the study. Chapter 4 shows that female return migrants from the Arabian Gulf countries are stigmatized because of negative perceptions held by society about their experiences and behavior 
abroad, while their male counterparts are not exposed to such stigma. Moreover, some studies show that in Ethiopia young girls grow up shouldering complex responsibilities for supporting the family on a day-to-day basis (Abebe, 2012). This might relate to the fact that many of the women returnees in this research sacrificed a lot for their family, with little benefit accruing to themselves. Most tried to make sense of their suffering in the host country by focusing on the blessings (financial) they brought to their family. Other studies also show that there is a gap in our understanding of the impact of migration on the reintegration process of male and female returnees in Ethiopia (Bilgili, Kuschminder, \& Siegel, 2017). Therefore, to better understand the gender dynamics in the reintegration process, comparative research on men and women returnees is suggested as a future research agenda.

Finally, in this study, it was indicated that the reintegration assistance provided to returnees by the Ethiopian government, international humanitarian organizations and local NGOs in the wake of the mass deportation and return crisis of 2013/14 was helpful merely in enabling the returnees to sustain their livelihood. Lack of capital to work with the skills acquired, lack of follow-up programs to sustain the small businesses started, and the existence of infrastructural problems were observed. Some scholars suggest that to bring sustainable and successful reintegration, wellplanned reintegration assistance programs should be developed for return migrants (Arowolo, 2000). However, little is known about the role of assistance programs in the reintegration of return migrants, except for some studies that highlight it from the perspective of forced return cases (see, for example, Van Houte \& Davids, 2008), and hence it is also suggested as a future research agenda.

\subsection{Practical policy implications}

The return crisis of 2013/14 forced Ethiopian society to deal with the sudden influx of a massive number of traumatized female returnees. This made the reintegration of returnees an urgent public issue. Well-established reintegration programs for return migrants do not exist in Ethiopia (Kuschminder \& Richard-Guay, 2018). The Ethiopian government, together with the International Organization for Migration (IOM) and local NGOs provided ad hoc humanitarian support, vocational skills training (such as food preparation, catering, and hairdressing), short-term business skill training, financial and credit facilities, and small shops to start small businesses to help returnees reintegrate into life in their home country. Based on the findings in this study, the 
assistance helped only a few returnees, but did not help the majority of the returnees to generate an income and sustain their livelihood. Based on the findings, the following recommendations are made to bring about the successful economic and socio-cultural reintegration of female returnees in the long term. It contains insights into how to manage mass return cases by highlighting focus areas that the government and other stakeholders need to consider for successful and sustainable socio-economic reintegration.

\subsubsection{Need for pre-departure training programs}

As indicated in Chapter 3 of this dissertation, many of the migrants have the objective of helping their family and establishing a small business for themselves upon return. However, this last objective is seldom met, as the migrants do not accumulate savings from their migration experience. Many of the remittances they send are spent by family members. At the time of the return crisis, government assistance programs mainly focused on providing vocational skill training, which was unable to help many of the returnees to be self-sufficient in economic terms. Successful economic reintegration mainly depends on the extent migrants were able to save from the remittances they sent to their family members. Hence, training programs should be organized before the migrants depart for the Arabian Gulf countries, include money management skills and how to establish their own savings account while working abroad (instead of sending all their earnings to family members). This and other awareness programs that strengthen this idea will help in the reintegration of the returnees.

\subsubsection{Improving the working conditions of migrants in destination countries}

As highlighted in this dissertation, many of the reintegration problems emanate from the precarious nature of the migration experience. The kafala labor system mainly protects the employer and not the employee. Preventing Breaches of contract and financial, physical, sexual, and psychological exploitation and abuse by sponsors should be prevented by establishing mutual agreements with receiving countries and putting in place a strong legal framework that protects migrants. The Ethiopian government is taking steps to improve the working conditions and legal protection of migrants in Arabian Gulf countries. Improving the working conditions of migrants in host countries is a major step in bringing about the successful reintegration of returnees in the home country. Reducing vulnerability and taking legal action in cases of breaches of contract will enable 
migrants to accumulate the resources required for their economic and social reintegration upon return.

\subsubsection{Holistic reintegration assistance in the home country}

During the return crisis to manage the mass deportation of Ethiopians from the Arabian Gulf, reintegration assistance by stakeholders focused mainly on enabling returnees to generate income to sustain their livelihood. Except for one local NGO (Agar Ethiopia), the majority provided vocational skill training. However, the findings of this study suggest that returnees encounter multifaceted problems, of which generating income is but one, albeit a major, problem. Reintegration assistance programs for vulnerable migrants, such as domestic workers (in both voluntary and involuntary return cases) should be based on identifying the different needs of migrants, such as whether they were exposed to traumatic incidents and whether they have been able to recover from the experiences. This dissertation highlights the magnitude of the traumatic incidents experienced by migrants in host countries. The existence of mental health challenges among Ethiopian female returnees is also evidenced in other studies (Anbesse, Hanlon, Alem, Packer, \& Whitley, 2009; Zeleke, Minaye, \& Kygana, 2015). However, psychological and healthrelated problems are not given enough emphasis in the reintegration programs of Ethiopian female domestic workers. Therefore, rehabilitation programs to help returnees heal from their traumatic past and process trauma should be a significant part of the resettlement process. This is a vital practical implication to come out of the research. To this end, it is suggested that trauma rehabilitation centers be established and self-help groups organized where migrants and other stakeholders (i.e., family members) can share their experiences among returnees who went through more or less similar experiences. As discussed in the previous section, the reintegration of return migrants is a social process; hence, awareness programs to minimize negative perceptions and stigma within the community are vital. Such programs improve returnees' sense of belonging in the community and their socio-economic reintegration.

\subsection{Concluding remarks}

This dissertation looked at the socio-economic reintegration of Ethiopian women return migrants from Arabian Gulf countries. It examined the lived experiences of women who migrate to these countries and then return to their home country. How female returnees make sense of migrationrelated trauma, how migration settings impact on the migration as well as the reintegration process, 
and the understated role of home country cultural values in the reintegration process were new insights developed in this dissertation. This research also pinpoints the limited or non-existent support programs for returnees when they return to Ethiopia. It points out the practical policy implications of the findings for reintegration support programs, such as the need to support psychological and mental health, which is often neglected, but requires attention, given the immensely traumatic incidents that some returnees go through while in the destination countries.

Reintegration is a very challenging experience, even though the returnees are coming to their home country. Many of the returnees in this study were unable to sustain their livelihood upon return and ended up financially dependent on their family. Social reintegration such as a sense of belonging in the society and developing a good social relationship with family members, as well as entering a marital relationship or maintaining the existing one, was difficult for most of the returnees who participated in this study. These factors relate to migration experiences with the kafala labor system and the socio-cultural attitudes and norms that exist in the home country, which are often neglected in the discussion of the reintegration of return migrants. Particularly, the intangible social costs that women returnees from the Arabian Gulf bear (in terms of health and social relationships) and the stigma and discrimination they experience upon return are often neglected in the social science and migration debate. Often the focus is on the economic resources needed to enable returnees to reintegrate in the home society. Other societal and cultural factors are not considered in managing return crises, and reintegration programs usually focus on providing vocational and skill training that might help returnees to sustain their livelihood.

In general, while there are some studies that evidence the positive impact of women's migration to the Arabian Gulf and other countries (psychological and economic), caution needs to be exercised in generalizing such positive impact. Beyond short-term economic gains that mainly benefit the migrant's family, rather than the migrant herself, there are long-term intangible losses and reintegration in the home country can be difficult. This research calls for additional research to investigate the long-term needs of returnees and the impact of migration on the returnees, their families, and society at large. 


\section{References}

Abebe, T. (2012). Interdependent rights and agency: The role of children in collective livelihood strategies in rural Ethiopia. Reconceptualizing Children's Rights in International Development, 71-92.

Abu-Habib, L. (1998). The use and abuse of female domestic workers from Sri Lanka in Lebanon. Gender \& Development, 6(1), 52-56.

Afsar, R. (2011). Contextualizing gender and migration in South Asia: Critical insights. Gender, Technology and Development, 15(3), 389-410.

Anbesse, B., Hanlon, C., Alem, A., Packer, S., \& Whitley, R. (2009). Migration and mental health: A study of low-income Ethiopian women working in Middle Eastern countries. International Journal of Social Psychiatry, 55(6), 557-568.

Arowolo, O. O. (2000). Return migration and the problem of reintegration. International Migration, 38(5), 59-82.

Bélanger, D., \& Rahman, M. (2013). Migrating against all the odds: International labour migration of Bangladeshi women. Current Sociology, 61(3), 356-373.

Bhugra, D. (2004). Migration, distress and cultural identity. British Medical Bulletin, 69(1), 129-141.

Bilgili, Ö., Kuschminder, K., \& Siegel, M. (2017). Return migrants' perceptions of living conditions in Ethiopia: A gendered analysis. Migration Studies, 6(3), 345-366.

Cassarino, J.-P. (2004). Theorising return migration: The conceptual approach to return migrants revisited. International Journal on Multicultural Societies, 6(2), 253-279.

Dannecker, P. (2005). Transnational migration and the transformation of gender relations: The case of Bangladeshi labour migrants. Current Sociology, 53(4), 655-674.

De Regt, M., \& Tafesse, M. (2016). Deported before experiencing the good sides of migration: Ethiopians returning from Saudi Arabia. African and Black Diaspora: An International Journal, 9(2), 228 242.

Fernandez, B. (2010). Cheap and disposable? The impact of the global economic crisis on the migration of Ethiopian women domestic workers to the Gulf. Gender \& Development, 18(2), 249-262. doi:10.1080/13552074.2010.491335

Ghosh, B. (2000). Return migration: Journey of hope or despair? United Nations Publications.

Jones, N., Presler-Marshall, E., Tefera, B., Emirie, G., Gebre, B., \& Gezahegne, K. (2014). Rethinking girls on the move: The intersection of poverty, exploitation, and violence experienced by Ethiopian adolescents involved in the Middle East 'maid trade'. A report submitted to Overseas Development Institute and funded by Oak Foundation.

Jureidini, R., \& Moukarbel, N. (2006). Female Sri Lankan domestic workers in Lebanon: A case of 'contract slavery'? Journal of Ethnic and Migration Studies, 30(4), 581-607. doi:10.1080/13691830410001699478

Kebede, E. (2002). Ethiopia: An assessment of the international labour migration situation: The case of female labour migrants. Geneva: ILO.

Koser, K., \& Kuschminder, K. (2015). Comparative research on the assisted voluntary return and reintegration of migrants. Geneva: International Organization for Migration.

Kuschminder , K., \& Richard-Guay, A. (2018). Reintegration background report (9220309939).

Mulugeta, M., \& Makonnen, T. (2017). Illicit cross-border migration in Ethiopia: Causes, patterns and policy responses. Ethiopian Journal of the Social Sciences and Humanities, 13(2), 53-80.

Pande, A. (2013). 'The paper that you have in your hand is my freedom': Migrant domestic work and the sponsorship (kafala) system in Lebanon. International Migration Review, 47(2), 414-441.

Perruchoud, R., \& Redpath-Cross, J. (eds). (2011). International migration law: Glossary on migration. Geneva: International Organization for Migration.

Setrana, M. B., \& Tonah, S. (2014). Return migrants and the challenge of reintegration: The case of returnees to Kumasi Ghana. İrìnkèrindò, 7(Jun), 116-142.

Thomas, K. J. (2008). Return migration in Africa and the relationship between educational attainment and labor market success: Evidence from Uganda. International Migration Review, 42(3), 652-674. 
Van Houte, M., \& Davids, T. (2008). Development and return migration: from policy panacea to migrant perspective sustainability. Third World Quarterly, 29(7), 1411-1429.

Zeleke, W., Minaye, A., \& Kygana, G. (2015). Mental health and somatic distress among Ethiopian migrant returnees from the Middle-East. International Journal of Mental health and Psychiatry, 1, 2. 


\section{Annex 1 \\ Individual interviews \\ Women returnees from the Arabian Gulf Countries \\ January-March 2015}

Date of the Interview

Place of interview

Duration of the interview

\section{About the study}

This study tries to understand the relationship between migration experience in Arab country and the reintegration process in to home country, every discussion is very confidential and anonymity of participants is highly respected.

1. Let us start our conversation by telling me about your life before migration. (45 minutes)

- How was your upbringing?

- How was your family life as a child?

- How was your school life?

- Did you have permanent income?

- How was your health condition?

2. Women migrants have different reasons for going to the Arabian Countries. What was your motivation or reason to migrate to the Arab country?

- Who helped you to go there? (Agents, Brokers, relatives/friends)

3. The journey to the Arab country is easier for some and difficult for others. How was your migration journey starting from Ethiopia till you settled to your employer's house in the Arab country? 
4. Let us now discuss to your working conditions in the host country you lived. (1 hour on average 10 minutes for each question)

- For how many employers did you work for?

- Did you get a chance to work by yourself in the host country? (without having a sponsor)

- What were your main work activities?

- Women migrants may have good and bad working conditions in the home of their employer. How were your working conditions? (Work load, sleeping conditions, food, and relationship with employer?)

- Were you paid your salary as stated in the contract?

- Did you encounter any health problems during your migration experience?

- If yes, how did you solve them?

- How was your contact with your family while you were on your contract employment?

5. Different stories are told about migration experience in the Arabian Counties? Some say it is good and others say it is bad. How would you describe your migration experience? First let us start with the good experiences you had in the host country.

6. Some returnees tell that they have very bad working experiences. Knowing this can help to improve the condition for future women migrants to the Middle East counties. Did you have any bad working experiences in the host country?

7. Some returnees regret going to the Arab countries and others like it very much and want to go back. When you think about your migration experience, how do you feel about it?

- Do you think it improved you social status or not?

8. Now let us talk to the time after you came back to Ethiopia. ( 1 hour: on average 6 minutes to one question) 
- What were you main positive and negative experiences? Let us start with the good things that happened when you come back first.

- Some women encounter difficulties after coming back to their countries. What were the major difficulties you encountered after return?

- What do you do for a living now?

- Is your income enough for you and your family needs?

- How is your health now?

- How are things going in your family life right now? I would like to know this because sometimes people say migration and family life are difficult to go together. Let us discuss how your migration experience and your family life went with you.

- Do you want to go back to the Arab countries in the future? If yes, Why?

- Thinking of your return experience do you think women returnees need some kind of support from government or NGO's to successfully re-integrate into their home country? What then do they need exactly?

- Did you get a chance to get any kind of support from an organization? Do you think it helped you in settling well after your migration? How could you think even be improved?

I finished my questions and thank you very much for your time and sharing you experience with me. Your migration and return experience help to improve the reintegration of women returnees. I will contact you to let you know the results. Is there anything else you want to add? 


\title{
Annex 2 \\ Individual interviews \\ Women returnees from the Arabian Gulf countries \\ January 2016-March 2017
}

Date of the Interview

Place of interview

Duration of the interview

\begin{abstract}
About the study
This interview was prepared to gather information about social reintegration process of women return migrants from the Middle East. The objective is to understand women returnees' social reintegration process. The results of the study will facilitate smooth social reintegration of women return migrants. All the discussions to be made will be kept confidentially. Any information that can lead to the revelation of an individual identity will not occur.
\end{abstract}

1. Let us start our discussion by telling me how many times you traveled to the Middle East?

2. Do you remember the periods you spent in the Middle East and in Ethiopia?

3. What was the reason for going back first time, a second time etc.?

- I understand financial struggles may be the cause. What other day to day affairs could be the reason?

The following questions are about your living experiences in the Middle East.

1. Could you please tell me about your migration experience in the Middle East?

- What do you like about living in the Middle East? 
- What makes it difficult to live in the Middle East?

- Could you give me an example of major obstacle you encountered?

- How did you felt about it?

- How did you cope with it?

2. Can you give me an example of social or cultural activities you like and participated in while you were in the Middle East

- How did you decided to participate?

- How did you felt about it?

Now let us discuss about your social life in Ethiopia (in the first, second, third visits)

1. Could you please tell me about your experiences after your return?

- What do you like about living here in Ethiopia?

- What social factors makes it difficult to live in Ethiopia?

2. What sort of activities you would like to get involved here?

- Where you able to participate?

3. Do you feel differently treated compared to non-migrated women?

- Can you give an example?

- How did you felt about it?

- How did you coped with it?

\section{Questions regarding experiences in both countries}

1. Could you tell me what you think about feeling at home?

- What comes into your mind 
- Where do you feel most at home, In Ethiopia or in the Middle East? Why?

- If you are provided the possibility to choose where to live for the rest of your life, in Ethiopia or the Middle East, which one would you prefer? Why? 


\title{
Annex 3 \\ Focus group discussion themes
}

\begin{abstract}
About the study
The objective of this group discussion is to understand how pre-migration and migration experiences affect women return migrant's reintegration process in to their home country. The study helps to indicate problems in return and reintegration of women returnees from the Middle East. The results of the study will improve the social and economic life of women returnees. All the information to be collected on this questionnaire is only for study purpose and it is highly confidential. Any information that can lead to the revelation of an individual identity will not
\end{abstract} occur.

\section{Migration experience (1 hour)}

1. There are different reasons for women's motivation to migrate. What do you think motivates women to migrate to the Arab countries?

2. In most Arabian counties there is sponsorship employment system. What do you think about the sponsorship system? What advantage do you think it has?

3. In your opinion what disadvantage do you think it has?

4. There are both positive and negative consequences of women migration to the Arabian countries. What are in your opinion the positive consequences of migration to the Arabian country?

5. And what are in your opinion the negative consequences of migrating to the Arabian country on employment contract?

\section{Return and reintegration (1 hour)}

1. Now let us discuss about what happens after women return to their home country. For some women return and reintegration may not be easy as they expected it. For some it may be as expected or even better. Do you think women returnees encounter problem to reintegrate? What kind of problems?

2. How do you think the difficulties women encounter in reintegration should be solved? 
3. Do you think women migrant returning from the Arabian states need support to reintegrate? What kind?

Additional questions for those who received government of NGO support service for reintegration

4. Do you think the support provided by different organizations help returnees to successfully reintegrate with the home country?

5. Do you think other support services should be included? What kind? 


\title{
Annex 4 \\ Interview questions
}

\section{Government and NGO officials working in women's reintegration in Ethiopia}

\begin{abstract}
About the study
The objective of this study is to understand how women migration experiences in the Middle East counties may affect their socio-economic reintegration in return migration. The study result will add to the efforts made by government and NGO's in successful reintegration of women return migrants. All the interview discussions are very confidential. The anonymity of study participants is strictly respected.
\end{abstract}

\section{Expected duration (1 hour)}

1. How long have you been working with women returnees?

2. What are the main problems observed in unskilled women return and reintegration?

3. Can you briefly describe what kind of support programs are provided to unskilled women returnees? Can I have the paper documents for the program?

4. Based on the experiences you have working with women returnees, what do you think should be improved so that the women could successfully re-integrate into their home society?

5. When do you conclude you did a good job?

6. Thank you for your time. I finished my interview but if there is anything else you want to add in relation with women migration to the Arabian Country or their return and reintegration let me give you a chance. I will keep in touch to let you know the findings of the study. 


\section{Annex 5}

\section{Profile of respondents}

(for chapter two and three)

\begin{tabular}{|c|c|c|c|c|c|c|c|c|c|c|}
\hline Code & $\begin{array}{l}\text { Migration } \\
\text { experience }\end{array}$ & $\begin{array}{l}\text { Support } \\
\text { from } \\
\text { NGO or } \\
\text { govern- } \\
\text { ment }\end{array}$ & $\begin{array}{l}\text { Marital } \\
\text { status } \\
\text { before }\end{array}$ & $\begin{array}{l}\text { Marital } \\
\text { status } \\
\text { after }\end{array}$ & Children & $\begin{array}{l}\text { School } \\
\text { level }\end{array}$ & $\begin{array}{l}\text { Age at } \\
\text { departure }\end{array}$ & $\begin{array}{l}\text { Length of } \\
\text { year } \\
\text { stayed } \\
\text { abroad }\end{array}$ & Return type & Religion \\
\hline $\mathrm{p} 1$ & BOTH & YES & S & M & NO & $\begin{array}{l}\text { High } \\
\text { school }\end{array}$ & 20 & $\begin{array}{l}2 \text { years } \\
\text { and } 3 \\
\text { months }\end{array}$ & Voluntary & Orthodox \\
\hline $\mathrm{p} 2$ & $\mathrm{~K}$ & YES & S & $S$ & No & $\begin{array}{l}\text { High } \\
\text { school }\end{array}$ & 20 & 10 years & Involuntary & Orthodox \\
\hline p3 & NK & YES & S & M & YES & $\begin{array}{l}\text { High } \\
\text { school }\end{array}$ & 18 & 12 years & Voluntary & Orthodox \\
\hline $\mathrm{p} 4$ & ВОТН & YES & S & S & NO & $\begin{array}{l}\text { High } \\
\text { school }\end{array}$ & 20 & 11 years & Voluntary & Orthodox \\
\hline $\mathrm{p} 5$ & ВОтН & YES & S & S & NO & Diploma & 23 & $\begin{array}{l}1 \text { year and } \\
3 \text { months }\end{array}$ & Voluntary & Orthodox \\
\hline p6 & ВОTH & YES & S & S & NO & $\begin{array}{l}\text { High } \\
\text { school }\end{array}$ & 21 & 9 years & Voluntary & Orthodox \\
\hline p7 & $\mathrm{K}$ & YES & S & $S$ & NO & $\begin{array}{l}\text { High } \\
\text { school }\end{array}$ & 23 & 3 years & Involuntary & Orthodox \\
\hline $\mathrm{p} 8$ & $\mathrm{~K}$ & YES & S & $S$ & NO & $\begin{array}{l}\text { High } \\
\text { school }\end{array}$ & 16 & 6 months & Voluntary & Protestant \\
\hline p9 & $\mathrm{K}$ & YES & S & $S$ & NO & $\begin{array}{l}\text { High } \\
\text { school }\end{array}$ & 19 & 1 year & Involuntary & Orthodox \\
\hline p10 & $\mathrm{K}$ & YES & S & S & NO & $\begin{array}{l}\text { High } \\
\text { school }\end{array}$ & 24 & $\begin{array}{l}1 \text { year and } \\
2 \text { months }\end{array}$ & Involuntary & Orthodox \\
\hline p11 & $\mathrm{K}$ & YES & S & S & NO & $\begin{array}{l}\text { Element } \\
\text { ary }\end{array}$ & 20 & $\begin{array}{l}1 \text { year and } \\
2 \text { months }\end{array}$ & Involuntary & Muslim \\
\hline
\end{tabular}




\begin{tabular}{|c|c|c|c|c|c|c|c|c|c|c|}
\hline p12 & вОтН & NO & $\mathrm{S}$ & M & YES & $\begin{array}{l}\text { Element } \\
\text { ary }\end{array}$ & 21 & $\begin{array}{l}8 \text { years } \\
\text { and } 2 \\
\text { months }\end{array}$ & Voluntary & Orthodox \\
\hline p13 & K & NO & $\mathrm{S}$ & $\mathrm{S}$ & NO & $\begin{array}{l}\text { High } \\
\text { school }\end{array}$ & 20 & 8 years & $\begin{array}{l}\text { Voluntar } \\
\text { y }\end{array}$ & $\begin{array}{l}\text { Orthoc } \\
\text { ox }\end{array}$ \\
\hline p14 & ВОTH & NO & $\mathrm{S}$ & $\mathrm{S}$ & YES & $\begin{array}{l}\text { High } \\
\text { school }\end{array}$ & 25 & 11 years & Voluntary & Orthodox \\
\hline p15 & ВОТН & NO & $\mathrm{S}$ & $\mathrm{S}$ & NO & $\begin{array}{l}\text { High } \\
\text { school }\end{array}$ & 19 & 7 years & Involuntary & Orthodox \\
\hline p16 & ВОТн & NO & M & D & YES & $\begin{array}{l}\text { Element } \\
\text { ary }\end{array}$ & 27 & 2 years & Voluntary & Orthodox \\
\hline p17 & $\mathrm{K}$ & NO & $\mathrm{S}$ & $\mathrm{S}$ & NO & $\begin{array}{l}\text { Element } \\
\text { ary }\end{array}$ & 22 & $\begin{array}{l}1 \text { year and } \\
6 \text { months }\end{array}$ & Involuntary & Orthodox \\
\hline p18 & ВОТн & NO & $\mathrm{S}$ & $\mathrm{S}$ & NO & $\begin{array}{l}\text { High } \\
\text { school }\end{array}$ & 29 & 5 years & Voluntary & Orthodox \\
\hline p19 & NK & YES & M & D & YES & $\begin{array}{l}\text { Element } \\
\text { ary }\end{array}$ & 20 & 16 years & Voluntary & Muslim \\
\hline $\mathrm{p} 20$ & ВОТН & YES & $\mathrm{S}$ & D & YES & $\begin{array}{l}\text { High } \\
\text { school }\end{array}$ & 27 & 7 years & Voluntary & Orthodox \\
\hline p21 & NK & NO & $\mathrm{S}$ & $\mathrm{S}$ & NO & None & 14 & 10 years & Voluntary & Orthodox \\
\hline p22 & вОТН & NO & $\mathrm{S}$ & $\mathrm{S}$ & NO & $\begin{array}{l}\text { High } \\
\text { school }\end{array}$ & 24 & 3 years & Involuntary & Orthodox \\
\hline
\end{tabular}




\begin{tabular}{|c|c|c|c|c|c|c|c|c|c|c|}
\hline p23 & ВОТН & NO & $\mathrm{S}$ & $\mathrm{S}$ & NO & $\begin{array}{l}\text { High } \\
\text { school }\end{array}$ & 25 & 6 years & Voluntary & Orthodox \\
\hline p24 & ВОТН & NO & $\mathrm{S}$ & S & YES & $\begin{array}{l}\text { Element } \\
\text { ary }\end{array}$ & 27 & 3 years & Involuntary & Orthodox \\
\hline p25 & ВОТН & NO & M & $\mathrm{S}$ & YES & $\begin{array}{l}\text { High } \\
\text { school }\end{array}$ & 25 & 2 years & Involuntary & Orthodox \\
\hline $\mathrm{p} 26$ & NK & NO & $\mathrm{S}$ & D & NO & $\begin{array}{l}\text { High } \\
\text { school }\end{array}$ & 18 & 10 years & Voluntary & Muslim \\
\hline p27 & NK & NO & $\mathrm{S}$ & $\mathrm{S}$ & NO & $\begin{array}{l}\text { High } \\
\text { school }\end{array}$ & 19 & 9 years & Voluntary & Muslim \\
\hline $\mathrm{p} 28$ & NK & YES & $\mathrm{S}$ & $\mathrm{S}$ & NO & $\begin{array}{l}\text { High } \\
\text { school }\end{array}$ & - & 10 years & Involuntary & Orthodox \\
\hline p29 & ВОТН & YES & $\mathrm{S}$ & $\mathrm{S}$ & NO & $\begin{array}{l}\text { High } \\
\text { school }\end{array}$ & - & 15 years & Involuntary & Orthodox \\
\hline $\mathrm{p} 30$ & ВОТН & NO & $\mathrm{S}$ & D & YES & $\begin{array}{l}\text { High } \\
\text { school }\end{array}$ & 16 & 22 years & Voluntary & Muslim \\
\hline $\mathrm{p} 31$ & ВОТН & NO & D & D & YES & $\begin{array}{l}\text { High } \\
\text { school }\end{array}$ & - & 21 years & Voluntary & Orthodox \\
\hline p32 & вОТН & YES & $\mathrm{S}$ & $\mathrm{S}$ & NO & $\begin{array}{l}\text { High } \\
\text { school }\end{array}$ & - & 11 years & Involuntary & Orthodox \\
\hline p33 & вОТн & NO & $\mathrm{S}$ & $\mathrm{S}$ & NO & $\begin{array}{l}\text { High } \\
\text { school }\end{array}$ & 19 & 5 years & Involuntary & Orthodox \\
\hline
\end{tabular}




\begin{tabular}{|c|c|c|c|c|c|c|c|c|c|c|}
\hline p34 & BOTH & YES & $\mathrm{S}$ & $\mathrm{S}$ & NO & $\begin{array}{l}\text { High } \\
\text { school }\end{array}$ & 20 & 10 years & Voluntary & Muslim \\
\hline p35 & NK & YES & $\mathrm{S}$ & $\mathrm{S}$ & NO & $\begin{array}{l}\text { High } \\
\text { school }\end{array}$ & 17 & 8 years & Voluntary & Orthodox \\
\hline p36 & $\mathrm{K}$ & YES & $\mathrm{S}$ & M & YES & None & 20 & 6 years & Voluntary & Muslim \\
\hline p37 & $\mathrm{K}$ & YES & $\mathrm{S}$ & $\mathrm{S}$ & YES & $\begin{array}{l}\text { High } \\
\text { school }\end{array}$ & - & 5 years & Voluntary & Orthodox \\
\hline $\mathrm{p} 38$ & $\mathrm{~K}$ & YES & $\mathrm{S}$ & S & NO & $\begin{array}{l}\text { Element } \\
\text { ary }\end{array}$ & - & 7 years & Voluntary & Muslim \\
\hline p39 & $\mathrm{K}$ & YES & $\mathrm{S}$ & $\mathrm{S}$ & NO & $\begin{array}{l}\text { Element } \\
\text { ary }\end{array}$ & - & 2 years & Involuntary & Muslim \\
\hline $\mathrm{p} 40$ & K & YES & $\mathrm{S}$ & M & YES & $\begin{array}{l}\text { Element } \\
\text { ary }\end{array}$ & - & 6 years & Voluntary & Orthodox \\
\hline p41 & ВОТН & YES & $\mathrm{S}$ & $\mathrm{S}$ & yes & $\begin{array}{l}\text { Element } \\
\text { ary }\end{array}$ & - & 3 years & Involuntary & Orthodox \\
\hline p42 & ВОTH & YES & $\mathrm{S}$ & $\mathrm{S}$ & NO & $\begin{array}{l}\text { High } \\
\text { school }\end{array}$ & - & 3 years & Voluntary & Orthodox \\
\hline $\mathrm{p} 43$ & ВОТН & YES & $\mathrm{S}$ & $\mathrm{S}$ & NO & $\begin{array}{l}\text { High } \\
\text { school }\end{array}$ & 17 & $\begin{array}{l}5 \text { years } \\
\text { and } 3 \\
\text { months }\end{array}$ & Involuntary & Orthodox \\
\hline p44 & $\mathrm{K}$ & YES & $\mathrm{S}$ & $\mathrm{S}$ & NO & $\begin{array}{l}\text { High } \\
\text { school }\end{array}$ & 18 & $\begin{array}{l}3 \text { years } \\
\text { and } 6 \\
\text { months }\end{array}$ & Involuntary & Muslim \\
\hline
\end{tabular}




\begin{tabular}{|c|c|c|c|c|c|c|c|c|c|c|}
\hline p45 & K & YES & $\mathrm{S}$ & M & YES & $\begin{array}{l}\text { High } \\
\text { school }\end{array}$ & - & 2 years & Voluntary & Orthodox \\
\hline p46 & BOTH & YES & S & M & YES & $\begin{array}{l}\text { High } \\
\text { school }\end{array}$ & & 5 years & Voluntary & Protestant \\
\hline p47 & BOTH & YES & M & D & YES & $\begin{array}{l}\text { High } \\
\text { school }\end{array}$ & & 3 years & Voluntary & Orthodox \\
\hline $\mathrm{p} 48$ & BOTH & YES & $\mathrm{S}$ & $\mathrm{S}$ & NO & Diploma & & $\begin{array}{l}9 \text { years } \\
\text { and } 6 \\
\text { months }\end{array}$ & Involuntary & Orthodox \\
\hline
\end{tabular}

Note

1. Migration experience through kafala represents contract work throughout the migration experience. Both refers to those who started with a contract job and ran away from the sponsors. None refers to those who travelled through a pilgrimage and overstayed their visa period or those who have a legal resident permit, often by paying some money to citizens to act as sponsors.

2. Educational background was classified as grade 1-8 elementary (E), 9-12 high school $(\mathrm{H}), 12+2$ diploma (D).

3. 'Voluntary return' was considered throughout the study as based on the existence of free will by the returnee to return (Perruchoud \& Redpath-Cross, 2011), except in cases of contract breach or violation of human rights.

4. (-) represent answers not provided by the respondents.

5. $\mathrm{p}=$ participant; $\mathrm{K}=$ stayed under the kafala system; $\mathrm{NK}=$ migration and stay without kafala system, such as on a tourist visa; $\mathrm{M}=$ married; $\mathrm{S}=$ single; $\mathrm{D}=$ divorced

6. Orthodox refers to follower of Ethiopian Orthodox religion, which is the major religion in Ethiopia. 


\section{Annex 6}

\section{Generic intersectionality template}

\section{(for chapter 4)}

\begin{tabular}{|c|c|c|}
\hline Social categories & $\begin{array}{l}\text { Discrete consideration } \\
\left(1^{\text {st }} \text { step }\right)\end{array}$ & $\begin{array}{l}\text { Intersectional consideration } \\
\left(2^{\text {nd }} \text { step }\right)\end{array}$ \\
\hline Gender & How does gender inform this individual account? & $\begin{array}{l}\text { How does gender interact/intersect with other social } \\
\text { categories in this individual account? } \\
\text { Or which dimensions of the experience are interacting with } \\
\text { gender? }\end{array}$ \\
\hline Class & How does class inform this individual account? & $\begin{array}{l}\text { How does class interact/intersect with other social } \\
\text { categories in this individual account? } \\
\text { Or which dimensions of the experience are interacting with } \\
\text { class? }\end{array}$ \\
\hline Race & How does race inform this individual account? & $\begin{array}{l}\text { How does race interact/intersect with other social categories } \\
\text { in this individual account? } \\
\text { Or which dimensions of the experience are interacting with } \\
\text { race? }\end{array}$ \\
\hline Ethnicity & How does ethnicity inform this individual account? & $\begin{array}{l}\text { How does ethnicity interact/intersect with other social } \\
\text { categories in this individual account? }\end{array}$ \\
\hline Religion & How does religion inform this individual account? & $\begin{array}{l}\text { How does religion interact/intersect with other social } \\
\text { categories in this individual account? }\end{array}$ \\
\hline Sexual orientation & $\begin{array}{l}\text { How does sexual orientation inform this individual } \\
\text { account? }\end{array}$ & $\begin{array}{l}\text { How does sexual orientation interact/intersect with other } \\
\text { social categories in this individual account? }\end{array}$ \\
\hline Age & How does age inform this individual account? & $\begin{array}{l}\text { How does age interact/intersect with other social categories } \\
\text { in this individual account? }\end{array}$ \\
\hline Handicap & $\begin{array}{l}\text { How does being handicapped inform this individual } \\
\text { account? }\end{array}$ & $\begin{array}{l}\text { How does being handicapped interact/intersect with other } \\
\text { social categories in this individual account? }\end{array}$ \\
\hline $\begin{array}{l}\text { Other relevant } \\
\text { categories } \\
\text { (immigration status, } \\
\text { family status, language } \\
\text { etc.) }\end{array}$ & $\begin{array}{l}\text { How do other relevant categories inform this } \\
\text { individual account? }\end{array}$ & $\begin{array}{l}\text { How do other relevant categories interact/intersect with } \\
\text { other social categories in this individual account? }\end{array}$ \\
\hline
\end{tabular}

